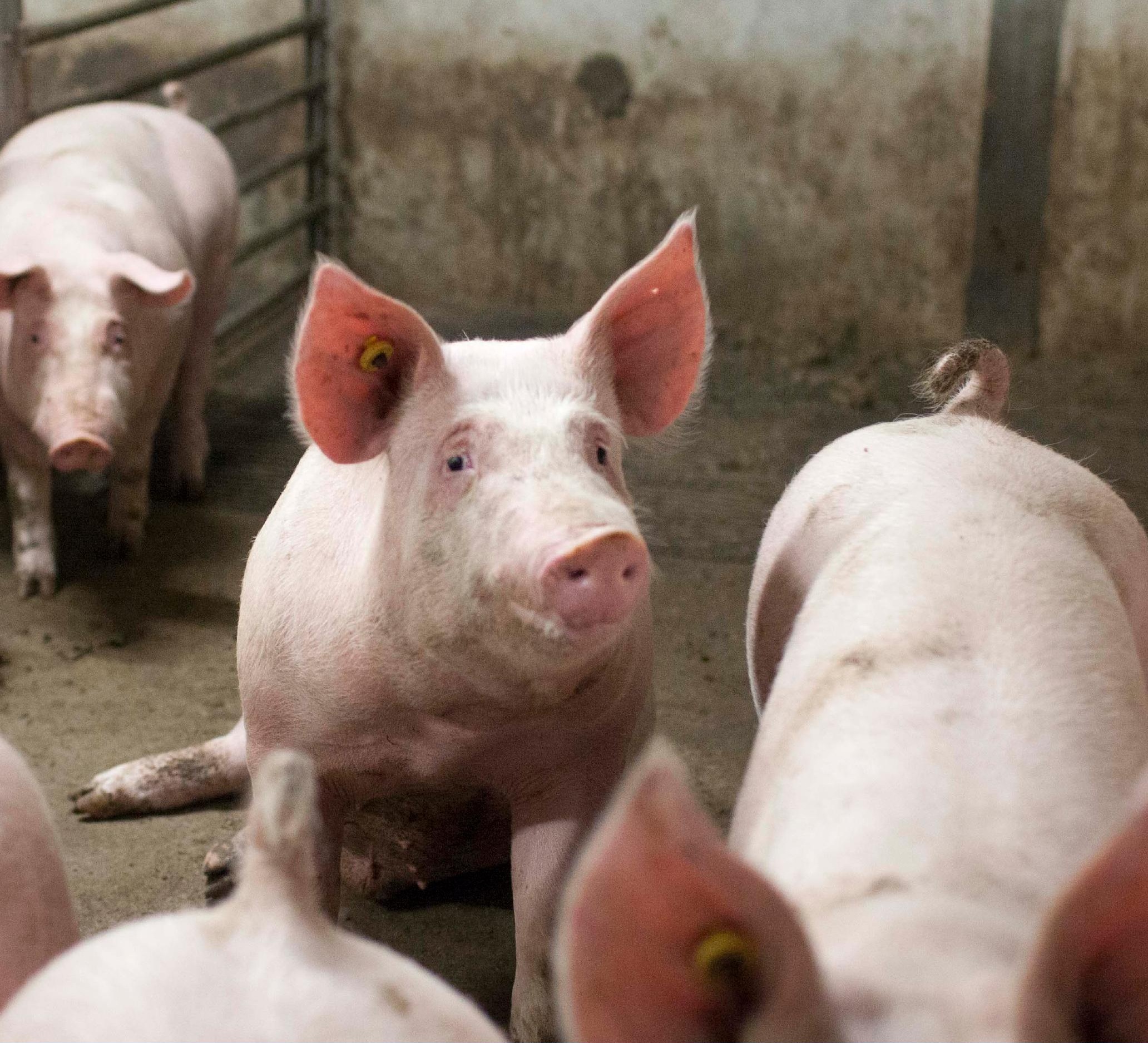

Amino acid and energy requirements of growing-finishing pigs kept under low and high sanitary conditions

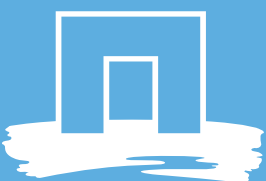





\title{
Amino acid and energy requirements of growing-finishing pigs kept under low and high sanitary conditions
}

\author{
C.M.C. van der Peet-Schwering ${ }^{1}$, R.G.J.A. Verheijen ${ }^{2}$, G.P. Binnendijk ${ }^{1}$, A.J.M. Jansman ${ }^{1}$ \\ ${ }^{1}$ Wageningen Livestock Research; ${ }^{2}$ Varkens Innovatiecentrum Sterksel
}

This research was conducted by Wageningen Livestock Research as part of the Public Private Partnership "Breed\&Feed4Food" (TKI-AF-14215) and "Feed4Foodure" (TKI-AF16123), and funded by Vereniging Diervoederonderzoek Nederland (VDN) and the Ministry of Agriculture, Nature and Food Quality (LNV).

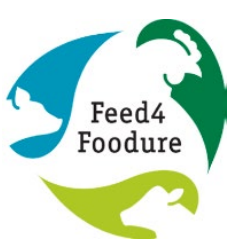


C.M.C. van der Peet-Schwering, R.G.J.A. Verheijen, G.P. Binnendijk, A.J.M. Jansman, 2020. Amino acid and energy requirements of growing-finishing pigs kept under low and high sanitary conditions. Wageningen Livestock Research, Report 1248.

This report can be downloaded for free at https://doi.org/10.18174/520612 or at www.wur.nl/livestock-research (under Wageningen Livestock Research publications).

(C) 2020 Wageningen Livestock Research

P.O. Box 338, 6700 AH Wageningen, The Netherlands, T +31 (0)317 483953 ,

E info.livestockresearch@wur.nl, www.wur.nl/livestock-research. Wageningen Livestock Research is part of Wageningen University \& Research.

All rights reserved. No part of this publication may be reproduced and/or made public, whether by print, photocopy, microfilm or any other means, without the prior permission of the publisher or author.

Wageningen Livestock Research is NEN-EN-ISO 9001:2015 certified.

All our research commissions are in line with the Terms and Conditions of the Animal Sciences Group. These are filed with the District Court of Zwolle.

Public Wageningen Livestock Research Report 1248 


\section{Table of contents}

$\begin{array}{ll}\text { Foreword } & 5\end{array}$

$\begin{array}{ll}\text { Summary } & 7\end{array}$

1

$\begin{array}{ll}\text { Introduction } & 9\end{array}$

2

$\begin{array}{ll}\text { Material and methods } & 11\end{array}$

2.1 Animals 11

2.2 Experimental treatments 11

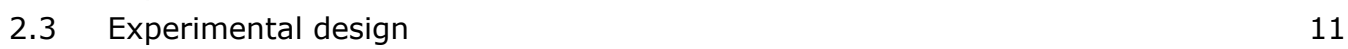

2.4 Housing and climate 12

2.5 Feeding and water supply 12

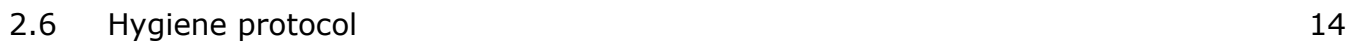

2.7 Measurements $\quad 14$

$\begin{array}{lll}2.8 & \text { Statistical analysis } & 16\end{array}$

3

$\begin{array}{ll}\text { Results } & 17\end{array}$

$\begin{array}{lll}3.1 & \text { Weaned piglets } & 17\end{array}$

3.1.1 Performance of the piglets $\quad 17$

3.1.2 Culling and veterinary treatments piglets 18

$\begin{array}{ll}3.2 & \text { Growing and finishing pigs }\end{array}$

3.2.1 Performance of the growing and finishing pigs 19

$\begin{array}{ll}3.2 .2 \text { Slaughter results } & 22\end{array}$

3.2.3 Health and faecal scores $\quad 22$

3.2.4 Skin and tail damage scores $\quad 24$

3.2.5 Nutrient composition and nutrient digestibility $\quad 25$

$\begin{array}{ll}3.2 .6 \text { Blood parameters } & 27\end{array}$

4 Discussion $\quad 30$

$5 \quad$ Conclusions $\quad 35$

References $\quad 37$

$\begin{array}{lll}\text { Appendix } 1 & \text { Composition of the experimental diets } & 40\end{array}$

Appendix 2 Analysed nutrient composition of the experimental diets $(\mathrm{g} / \mathrm{kg}) 46$

$\begin{array}{lll}\text { Appendix } 3 & \text { Performance of the GF pigs } & 47\end{array}$

$\begin{array}{llr}\text { Appendix } 4 & \text { Blood parameters } & 49\end{array}$ 



\section{Foreword}

Feed4Foodure is a public-private partnership between the Dutch Ministry of Agriculture, Nature and Food Quality, a consortium of various organizations within the animal production chain and Wageningen Livestock Research. Feed4Foodure aims to contribute to sustainable and healthy livestock farming in the Netherlands, simultaneously strengthening its competitive position on the global market.

In the Feed4Foodure program line "Improvement of the utilization of nitrogen in pigs" research is conducted to improve resource and protein efficiency in pigs. This report presents the results of a study performed by Wageningen Livestock Research on the effects of dietary energy source (starch vs fat) and increased levels of dietary energy and amino acids on the growth performance of growingfinishing pigs kept under low or high sanitary conditions.

The authors thank the industry partners of the Feed4Foodure consortium for their valuable input in the study.

Alfons Jansman, project leader 


\section{Summary}

The present study was performed to evaluate the effects of dietary energy source (starch vs fat) and of increased levels of dietary energy and essential amino acids (EAA), related to the assumed increased EAA and energy requirements in immune stimulated pigs, on the growth performance of growing-finishing (GF) pigs under low sanitary conditions (LSC), in which the immune system of the pigs was activated, or under high sanitary conditions (HSC) resulting in a lower state of activation of the immune system. The trial was conducted with 408 male pigs (Tempo boar x (York x Dutch Landrace) sow) during the weaner, grower and finisher phase. Piglets were weaned at an age of four weeks and followed till delivery to the slaughterhouse. In a $2 \times 2 \times 2$ factorial design, pigs were allocated to either high sanitary conditions (HSC) or low sanitary conditions (LSC). A contrast in sanitary conditions was generated by imposing to the pigs differences in strategy for vaccination against pathogens, cleaning and hygiene protocol, antibiotic treatment and deworming. During the growing and finishing period, pigs had ad libitum access to one of four experimental diets, a diet with starch as main energy source or a diet with fat and starch as main energy source, each diet having either basal energy and EAA concentrations ( $B$ diet) or increased concentrations in energy and EAA (I diet). The levels of supplementation of EAA and energy in the I diets compared to the $B$ diets were based on a model that calculated the effects of low sanitary conditions on the EAA and energy requirements of pigs. At an age of nine weeks, pigs were moved to the rooms for GF pigs. The HSC GF pigs were fed a starter diet during the first five weeks, followed by a grower diet for four weeks and then a finisher diet till delivery to the slaughterhouse. The LSC GF pigs were fed a starter diet during six weeks, followed by a grower diet for four weeks and then a finisher diet till delivery to the slaughterhouse. In all pens, 8 or 9 GF pigs were housed.

The main conclusions of the study are:

\section{Sanitary conditions:}

- $\quad$ From weaning till day 35 after weaning, HSC piglets showed a $4 \%$ higher ADFI and ADG than LSC piglets. Moreover, the number of culled piglets was lower in HSC piglets.

- During the GF phase (from start till slaughter), the performance of both the LSC and HSC pigs was very high (HSC pigs: ADG $1080 \mathrm{~g} / \mathrm{d}$, ADFI $2.36 \mathrm{~g} / \mathrm{d}$, FCR 2.19; LSC pigs: ADG $1033 \mathrm{~g} / \mathrm{d}$, ADFI $2.28 \mathrm{~kg} / \mathrm{d}$, FCR 2.21).

- Despite the contrast in cleaning-, vaccination- and hygiene protocol, only relatively small differences in degree of activation of the immune system between HSC and LSC pigs were observed.

- $\quad$ HSC GF pigs showed a numerically $4 \%$ higher ADFI $(0.08 \mathrm{~kg} / \mathrm{d})$ and ADG $(47 \mathrm{~g} / \mathrm{d})$ than LSC GF pigs, whereas FCR was similar in HSC and LSC GF pigs. The coefficient of variance (CV) in body weight was lower in HSC than LSC GF pigs at day 35 and 63.

- $\quad$ During the grower phase apparent faecal N digestibility was lower in LSC than HSC pigs (78.4 vs $79.5 \%$ ). During the starter and finisher phase, $\mathrm{N}$ digestibility was similar in HSC and LSC pigs. During the starter phase apparent faecal digestibility of energy was lower in LSC than HSC pigs ( 83.2 vs $84.1 \%$ ). During the grower and finisher phase, energy digestibility was similar in HSC and LSC pigs.

- $\quad$ The number of veterinary treated GF pigs tended to be lower in HSC than LSC pigs (4.4 vs $8.5 \%$ of the pigs). Moreover, in week $1,3,5$ and 7 the percentage of GF pigs with diarrhoea was numerically lower in HSC than LSC pigs (2.3 vs 10.4\%).

Increased dietary energy and amino acid content and interaction with sanitary conditions:

- The increased energy and amino acid content in the diet increased ADG (1075 vs $1039 \mathrm{~g} / \mathrm{d}$ ) and average daily energy intake ( 2.74 vs $2.58 \mathrm{EW} / \mathrm{d}$ ), whereas ADFI was not affected by energy and amino acid content of the diet.

- $\quad$ The increase in ADG from start till day 98 on the I diet compared to the B diet was $62 \mathrm{~g} / \mathrm{d}$ in LSC pigs, whereas it was $21 \mathrm{~g} / \mathrm{d}$ in HSC pigs. 
- $\quad$ On the B diet, LSC pigs grew $68 \mathrm{~g} / \mathrm{d}(6.4 \%)$ less than HSC pigs, whereas on the I diet, LSC pigs grew $26 \mathrm{~g} / \mathrm{d}(2.4 \%)$ less.

- The energy intake on the I diet compared to the B diet was $0.23 \mathrm{EW} / \mathrm{d}$ higher in LSC pigs and $0.12 \mathrm{EW} / \mathrm{d}$ in HSC pigs.

- $\quad$ On the B diet, LSC pigs ate $0.17 \mathrm{EW} / \mathrm{d}(6.4 \%)$ less than HSC pigs, whereas on the I diet, LSC pigs ate $0.06 \mathrm{EW} / \mathrm{d}(2.2 \%)$ less.

- $\quad$ Feed conversion ratio was better but energy conversion ratio (ECR) was worse in pigs fed the I diet. The effects on FCR and ECR were similar in LSC and HSC pigs.

- In both the starter, grower and finisher diets, the apparent faecal digestibility of dry matter, ash, organic matter, crude protein, fat (only grower and finisher diet) and energy were higher for the I diets than for the B diets.

\section{Dietary energy source:}

- $\quad$ ADG was higher (1078 vs $1036 \mathrm{~g} / \mathrm{d}$ ) and ADFI (2.35 vs $2.29 \mathrm{~kg} / \mathrm{d}$ ) and average daily energy intake (ADEI) (2.70 vs $2.62 \mathrm{EW} / \mathrm{d}$ ) tended to be higher in pigs fed the starch based diets than in pigs fed the fat based diets. Feed conversion ratio and energy conversion ratio (ECR) were not affected by dietary energy source.

- There was no significant interaction between dietary energy source and sanitary conditions for any of the performance parameters which means that the effect of dietary energy source on performance was similar in LSC and HSC pigs.

- Apparent faecal digestibility of dry matter, organic matter, ash, crude protein, starch and energy were higher for the starch diets than for the fat diets. The digestibility of fat was lower for the starch based diets.

Overall, it can be concluded that an increase in contents of dietary energy and essential amino acids (Lys, Met, Thr, Trp, Val and Ile) increases growth performance and energy intake more in LSC than in HSC pigs. Compared with studies in which only EAA were supplemented and not energy to increase performance of immune challenged pigs, it seems that dietary supplementation of both EAA and energy is more effective in increasing performance of LSC pigs than dietary supplementation of EAA alone. This suggests opportunities to at least partly compensate for the reduction in growth performance in pigs kept under low sanitary conditions and/or sub-optimal health condition by modification of the energy and EAA composition of the diet. Partly replacing dietary starch with fat does not seem an interesting approach to increase the performance of the LSC GF pigs. 


\section{Introduction}

Large variation in performance of growing-finishing (GF) pigs exists between commercial pig farms (Agrovision, 2017). The health status of pigs is one of the major factors contributing to the variation in pig performance (Van der Peet-Schwering et al., 2019). Variation in health status exists between farms but also amongst individual pigs within farms, as indicated by variation in serum concentrations of acute phase proteins that was correlated to the occurrence of disease or presence of lesions like tail or ear biting (Petersen et al., 2002; Piñeiro et al., 2009; Piñeiro et al., 2013). In commercial pig farms, pigs are continuously exposed to (non-) pathogenic agents, which activate the immune system. During immune system stimulation (ISS), nutrients are redistributed from anabolic and maintenance processes towards processes involved in immunity and disease resistance (Klasing and Johnstone, 1991; Spurlock, 1997). Pigs with an activated immune system show a:

- Decreased feed intake, body weight gain, and nitrogen (N) retention (Williams et al., 1997a,b; Daiwen et al., 2008; Le Floc'h et al., 2008; Van der Meer et al., 2016), reduced protein synthesis and increased protein degradation, prioritized synthesis of immune proteins (e.g. acute phase proteins, cytokines and immune cells), reduced absolute requirements for lysine in pigs and chickens (Williams et al., 1997a,b; Webel et al., 1998) and changed optimal dietary amino acid (AA) profile (Van der Meer et al., 2016).

- Increased utilization of glucose by peripheral tissues and increased rates of gluconeogenesis from lactate and glucogenic AA (Spitzer and Spitzer, 1983).

- $\quad$ Reduced utilization and tissue metabolism of fatty acids (Butcher and Miles, 2002).

- Changed allocation and prioritization of nutrients (AA, glucose and fatty acids) utilization (Kampman-van de Hoek, 2015; Van der Meer, 2017).

Van der Meer et al. (2016) performed a study to determine the effects of two dietary AA profiles (basal profile and supplemented profile with higher levels of methionine, threonine and tryptophan, considering increased AA requirements under conditions of low sanitary status and activation of the immune system) and sanitary status of pigs and their interactions on energy and protein metabolism. Results of this study showed that AA requirements are dependent on sanitary conditions. Supplementation of diets with particular essential AA may therefore improve growth performance, especially under poor hygienic conditions. It was concluded that dietary protein concentration as well as methionine, threonine, and tryptophan supplementation can modify immune status, which may influence resistance to subclinical and clinical diseases. Despite the supplementation of some essential amino acids (EAA), however, growth performance of the pigs under low sanitary conditions (LSC) was still lower compared to pigs kept under high sanitary conditions (HSC). It might be assumed that supplementation of EAA under LSC is only supporting body protein retention and body weight gain if dietary energy intake is not limiting growth performance. In the research from Van der Meer et al. (2016, 2017), LSC pigs showed a 4\% lower feed and energy intake compared to HSC pigs and had a $10 \%$ higher maintenance requirement for energy. Therefore, an increase in dietary EAA levels to compensate for higher AA requirements under LSC, might only be effective if also the increased requirement for energy is considered by increasing the dietary energy level.

Compared to changes in requirements of EAA, less attention has been given to the changes in requirements for energy and dietary source of energy as affected by health status. Van Heugten et al. (1996) investigated the effects of nutrient density and dietary energy source (starch vs fat) on performance and immune function in LPS challenged weaned piglets. Their results indicated that increasing nutrient density of the diet by isocaloric fat or starch supplementation did not alter the depression in growth performance after LPS challenge. Addition of fat to the diet improved feed efficiency and efficiency of energy conversion but depressed the humoral immune response. Butcher and Miles (2002) stated that under ISS conditions, animals might have a preference for glucose over fatty acids as energy source as immunological stress may impair triglyceride clearance from the blood, thus decreasing use of fats and fatty acids in systemic metabolism related to a lower activity of the enzyme lipoprotein lipase. 
To further understand and implement the results obtained by Van der Meer et al. (2016) and Van der Meer (2017) in the form of more detailed recommendations for adjustments in dietary AA and energy levels for pigs in low sanitary status or immune challenge conditions, more insight is needed in the effects of dietary energy source and dietary energy and EAA levels on the growth performance of GF pigs under LSC and HSC. Therefore, a study was performed to evaluate the effects of dietary energy source (starch vs fat) and of increased levels of dietary energy and AA (via additional supplementation of free AA and increase of dietary energy density) on the performance of GF pigs under LSC, in which the immune system of the pigs was activated, or under HSC resulting in a lower state of activation of the immune system. The contrast in dietary AA level and profile and energy level of the diets was based on model calculations as described in the desk study "Amino acid requirements in relation to health in growing and finishing pigs" (Van der Peet-Schwering et al., 2019). Results of the present study contributes to knowledge and information for the pig production sector and the feed industry to more precisely match dietary nutrient composition and feeding strategy with the actual nutrient requirements of pigs under a variety of sanitary and health conditions as encountered in practice. 


\section{Material and methods}

\section{$2.1 \quad$ Animals}

The trial was conducted at Swine Innovation Centre Sterksel with 408 male pigs (Tempo boar $\mathrm{x}$ (York $x$ Dutch Landrace) sow) during the weaner, grower and finisher phase. Piglets were assigned to the trial in two batches with three weeks in between. Piglets were weaned at an age of four weeks and followed till delivery to the slaughterhouse. The trial was conducted from November 2018 till June 2019.

\subsection{Experimental treatments}

In a $2 \times 2 \times 2$ factorial design, pigs were allocated to either high sanitary conditions (HSC) or low sanitary conditions (LSC). During the growing and finishing period, pigs had ad libitum access to one of four experimental diets, a diet with starch as main energy source or a diet with fat and starch as main energy source, each diet having either basal energy and EAA concentrations (B diet) according to current recommendations (Van der Peet-Schwering and Bikker, 2018) or increased concentrations in energy and EAA (I diet).

\subsection{Experimental design}

\section{Suckling piglets}

In the nursery room, half of the male piglets within a litter was vaccinated against Mycoplasma hyopneumonia and Circovirus one week before weaning (litter 1: the male piglets with the heaviest birth weight was vaccinated, the second heaviest was not vaccinated, the third heaviest was vaccinated etc.; litter 2: the male piglets with the heaviest birth weight was not vaccinated, the second heaviest was vaccinated, the third heaviest was not vaccinated, etc.).

\section{Weaned piglets}

At an age of four weeks, the piglets were weaned and allotted to the HSC or LSC treatment based on vaccination regime in the nursery room and body weight at weaning. The vaccinated male piglets were allotted to the HSC treatment and the non-vaccinated male piglets to the LSC treatment. Within sanitary conditions there were low weight, medium weight and heavy body weight blocks. Each block consisted of four pens with each 8 or 9 piglets per pen. HSC and LSC piglets were housed in separate rooms. Each room had separate manure pits and separate ventilation regulation. The HSC piglets were vaccinated against PIA at nine days post weaning, against PRRS at two weeks post weaning and against Influenza $A$ at two and five weeks post weaning. A strict hygiene protocol for personnel (see chapter 2.6) was used when entering the HSC rooms. The LSC piglets were only vaccinated against PIA at nine days after weaning. No hygiene protocol for personnel was used when entering the LSC rooms.

\section{Growing and finishing pigs}

At an age of nine weeks, the HSC piglets were moved to HSC growing and finishing (GF) rooms. LSC piglets were moved to LSC growing and finishing rooms. Pigs out of the same weaning pen stayed together. The four pens within every weight block were randomly assigned to one of the four dietary treatments. Each GF room had separate manure pits and separate ventilation regulation. The HSC rooms were intensively cleaned in four steps before the pigs were moved to the rooms: 1 ) cleaning the room (including ceiling, feeding hoppers and drinking trough) with water; 2) foaming with MS Topfoam LC ALK (MS Schippers, Bladel, The Netherlands); 3) high pressure washing; 4) disinfecting with MS Megades Oxy (MS Schippers). The HSC pigs received a preventive antibiotic 
injection (Florkem, $1 \mathrm{ml} / 20 \mathrm{~kg} \mathrm{pig}$ ) at day 1 and day 3 after moving to the GF room and were dewormed (flubenol $5 \%$ as topdressing) in week 1, 6 and 11. A strict hygiene protocol (see chapter 2.6) was used when entering the HSC rooms.

The LSC rooms were not cleaned after a previous batch of GF pigs left the room and no hygiene protocol was used when entering the rooms. Moreover, in week 5, 7, 9, 11 and 13 after moving to the GF room, fresh manure from other pigs at the Swine Innovation Centre (a mix of fresh manure of younger and older GF pigs and weaned piglets) were spread in the LSC pens to enhance the contrast in sanitary status between treatment. Each time 5 litres of fresh manure were spread per LSC pen. The LSC pigs did not receive a preventive antibiotic injection and were not dewormed.

In each batch, pigs were delivered to the slaughterhouse in two deliveries with three weeks in between.

\subsection{Housing and climate}

\section{Weaned piglets}

The HSC weaned piglets were housed in two rooms with each 8 pens (batch 1) and in one room with 16 pens (batch 2). Per batch, 12 pens were used for the experiment. In four pens in one room in batch 1 and in four pens in batch 2, gilts born in the same litters as the boars were housed. The gilts were vaccinated according to the HSC boars.

The LSC weaned piglets were housed in four rooms with each 8 pens (two rooms in batch 1 and two rooms in batch 2). Per batch, 12 pens were used for the experiment. In four pens in one room in each batch, gilts born in the same litters as the boars were housed. The gilts were vaccinated according to the LSC boars.

In all pens, 8 or 9 piglets were housed. In two rooms (one room with 8 pens and one room with 16 pens), the pens were $2.65 \times 1.78 \mathrm{~m}$. In the other rooms, the pens were $2.20 \times 2.20 \mathrm{~m}\left(0.5 \mathrm{~m}^{2}\right.$ space/piglet). In all rooms, pens had a plastic coated fully slatted floor. The climate in the rooms was controlled by computer and a ventilation regime, as advised by the Dutch "Klimaatplatform", was used. Fresh air was entering the room trough ceiling ventilation. From 7.00 till $20.00 \mathrm{~h}$ the light was on in the rooms (automatically by a timer).

\section{Growing and finishing pigs}

The HSC GF pigs were housed in two HSC rooms with each 12 pens (one room in batch 1 and one room in batch 2). The LSC GF pigs were housed in two LSC rooms with each 12 pens (one room in batch 1 and one room in batch 2). In all pens, 8 or 9 GF pigs were housed. In all rooms, the pens were $2.5 \times 5.0 \mathrm{~m}\left(1.4 \mathrm{~m}^{2}\right.$ space/pig) and had $40 \%$ concrete solid floor and $60 \%$ slats. The climate was controlled by computer and a ventilation regime, as advised by the Dutch "Klimaatplatform", was used. Fresh air entered the room trough canals underneath the slatted floor in the corridor between the pens. From the corridor the fresh air spread into the pens. From 7.00 till $20.00 \mathrm{~h}$ the light was on in the rooms (automatically by a timer).

\subsection{Feeding and water supply}

\section{Weaned piglets}

From weaning till day 8 after weaning, piglets were fed ad libitum a commercial pelleted weaner diet in a dry feed hopper with two feeding places. Besides, during the first week after weaning, the weaner diet was supplied two times a day in a round bowl per pen. From day 8 till day 35 after weaning, piglets were fed ad libitum a commercial pelleted piglet diet in a dry feed hopper with two feeding places. Drinking water was supplied ad libitum via a drinking bowl in the pen.

\section{Growing and finishing pigs}

Pigs were allotted to a diet with starch or with fat as main energy source, both having either a basal energy content and basal concentration of EAA or an increased energy content and increased concentrations of EAA. So, in total four dietary treatments were evaluated: starch-basal energy and EAA (starch-B), starch-increased energy and EAA (starch-I), fat-basal energy and EAA (fat-B) and fat- 
increased energy and EAA (fat-I). Each diet was fed to the pigs in both sanitary conditions, resulting in eight treatment groups. The HSC pigs were fed a starter diet during the first five weeks, then a grower diet for four weeks and then a finisher diet till delivery to the slaughterhouse. The LSC pigs were fed a starter diet during the first six weeks ( 1 week longer than the HSC pigs, because we expected that at six weeks the LSC pigs would have the same BW as the HSC pigs at five weeks), then a grower diet for four weeks and then a finisher diet till delivery to the slaughterhouse.

The levels of supplementation of EAA and energy in diets for the treatments "I" (dietary EAA and energy supplemented) were based on the use of a calculation model as described by van der PeetSchwering et al. (2019) in the report entitled "Amino acid requirements in relation to health status in growing and finishing pigs". In this report model calculations are made for five scenarios representing different conditions of health challenge of pigs considering gut and systemic challenges, both in acute and chronic form and a scenario called "low sanitary conditions". Using a factorial approach for calculating requirements for protein and energy deposition, the effects of "low sanitary conditions" on the EAA and energy requirements of pigs were estimated and translated to adjusted optimal dietary energy and EAA levels.

The scenario "low sanitary conditions" as used in the calculations included effects related to feed intake, ileal digestibility of $A A$, additional requirements for maintenance, reduction of post absorptive efficiency of $A A$, maximum protein deposition capacity and increase in maintenance requirement for energy as given in Table 1.

Table 1 Settings for factors considered in the model for calculating increases in amino acid (AA) and energy requirements in pigs under conditions of low sanitary status relative to control conditions.

\begin{tabular}{|c|c|c|c|c|c|c|}
\hline & $\begin{array}{l}\text { Feed intake } \\
\text { rel. to } \\
\text { reference } \\
\text { scenario }{ }^{2}\end{array}$ & $\begin{array}{c}\text { Ileal AA } \\
\text { digestibility } \\
\text { (SID) and } \\
\text { faecal energy } \\
\text { digestibility } \\
\text { rel. to } \\
\text { reference } \\
\text { scenario }^{2}\end{array}$ & $\begin{array}{c}\text { Extra } \\
\text { maintenance } \\
\text { and immune } \\
\text { proteins (g/d) }\end{array}$ & $\begin{array}{c}\text { Post } \\
\text { absorptive } \\
\text { AA }^{1} \\
\text { efficiency } \\
\text { relative to } \\
\text { ref. scenario }{ }^{2}\end{array}$ & $\begin{array}{l}\text { Max. PD } \\
\text { relative } \\
\text { to PDref } \\
(\%)^{2}\end{array}$ & $\begin{array}{c}\text { Increase in } \\
\text { maintenance } \\
\text { requirement } \\
\text { for energy }(\%)\end{array}$ \\
\hline Reference & 1.00 & 1.00 & 0 & 1.00 & 100 & 0 \\
\hline Low sanitary conditions & 0.96 & 0.96 & 2.5 & 0.96 & 100 & 8 \\
\hline
\end{tabular}

${ }^{1}$ Trp, Val, Leu and Ile, other essential AA unaffected.

${ }^{2}$ Values ranging from 0 to 1 (value for reference scenario) or between 0 and $100 \%$ (value for reference scenario).

The reference basal diets (B) were formulated to contain EAA relative to energy as proposed by Van der Peet-Schwering and Bikker (2018). The energy value (EW) of the basal diets was 1.12, 1.10 and 1.10 for the starter, grower and finisher diet, respectively. The levels of supplementation of EAA in the I diets (Lys, Met, Thr, Trp, Val and Ile) were calculated with the factorial model using a starter diet with $165 \mathrm{~g} / \mathrm{kg} \mathrm{CP}$ based on barley, corn and soya bean meal as a reference (Pluk and van Krimpen, 2018) for the starter diets and the respective grower and finisher " $B$ " diets in the present study for the grower and finisher diets, respectively.

The "I" diets relative to the "B" diets were increased with EAA (SID, g/kg) and energy (EW/kg) as shown in Table 2. The levels of EAA were increased by the inclusion of additional free AA. The energy level of these diets was increased by including additional soy oil and palm oil in the diets. 
Table 2 Absolute increase in concentration of essential amino acids ( $\mathrm{g} \mathrm{SID} / \mathrm{kg}$ ) and energy $(E W / \mathrm{kg})$ in the supplemented starter, grower and finisher diets relative to the basal diets.

\begin{tabular}{lccc} 
& Starter diet & Grower diet & Finisher diet \\
Lys & 0.88 & 0.85 & 0.80 \\
Met+Cys & 0.82 & 0.65 & 0.60 \\
\hline Thr & 0.73 & 0.60 & 0.61 \\
\hline Trp & 0.33 & 0.17 & 0.19 \\
\hline Val & 0.64 & 0.62 & 0.27 \\
\hline Ile & 0.27 & 0.00 & 0.00 \\
\hline Leu & - & - & - \\
\hline His & - & - & - \\
\hline EW & 0.08 & 0.08 & 0.08 \\
\hline
\end{tabular}

The contrast in energy source between the starch and fat based diets was achieved by contrasting the inclusion of maize starch at the expense of soy oil and palm oil and by increasing the inclusion of oat hulls and wheat straw. The difference in fat content between starch and fat based diets ranged from 55 to $58 \mathrm{~g} / \mathrm{kg}$ while the difference in starch content in the same diets ranged from 138 to $147 \mathrm{~g} / \mathrm{kg}$.

The ingredient and calculated nutrient composition of the starter, grower and finisher diets is shown in Appendix 1. All diets contained $\mathrm{TiO}_{2}$ as an indigestible marker for determining the faecal nutrient digestibility of the diets.

In all pens, feed was supplied ad libitum in a dry feed hopper with two feeding places. The feed was provided as pellets via a computerized automatic system, which registered the amount of feed (in $\mathrm{kg}$ ) supplied per pen per day. Drinking water was supplied ad libitum via a drinking bowl in the pen.

\subsection{Hygiene protocol}

Before entering an HSC room, the following hygiene protocol was used by the personnel involved:

- Hands were washed, a clean disposable overall, clean boots and gloves were put on and a hairnet was used. When entering a pen, plastic overshoes were put on and changed per pen.

- In the daily routine procedures (e.g. feeding and checking clinical health) and in performing specific measurements (e.g. weighing), first the compartments with HSC pigs were considered before performing the same activities in LSC compartments.

- When the weaned piglets were moved to the GF rooms, first the HSC piglets were moved and then the LSC piglets.

- $\quad$ Per pen clean materials (e.g. weighing scale, needles) were used. At weighing of the piglets and GF pigs, a piece of plastic was put in the weighing scale (to keep the weighing scale clean). The same piece of plastic was used for all pigs in a pen and changed by a clean one for every pen.

- $\quad$ Before delivery of pigs to the slaughterhouse, first the HSC pigs were weighed and placed in the truck for transport to the slaughterhouse and then the LSC pigs.

\subsection{Measurements}

Body weight, feed intake and slaughter data

The pigs were weighed individually at weaning, day 8 after weaning, day of moving to the GF rooms (is five weeks after weaning), day 35 and 63 in the GF room, one day prior to the first delivery to the slaughterhouse (day 98) and remaining pigs at the second delivery. In addition, in case of culling, the culled pig was weighed. Total feed intake per pen (feed supply - remainder of feed) was measured at every weighing of pigs and in case of culling of a pig. At every weighing of pigs, the remainders of the diet per pen were collected and weighed to determine the feed intake per pen. Feed intake included intake of weaner diet, piglet diet, starter diet, grower diet and finisher diet. At slaughter the following data were collected per pig: carcass weight, lean meat percentage, backfat thickness and muscle thickness. 


\section{Culling, veterinary treatments and faecal scores}

The number of culled pigs and the number of pigs treated with antibiotics were recorded including date and reason of culling and veterinary treatment. Feed intake was registered on the day of culling to correct for the estimated feed intake of the culled animal. Faecal consistency scores were performed in the GF pigs in week $1,3,5,7,9,11$ and 13. In each pen the number of GF pigs with normal faeces (score $=0$ ), soft faeces (score $=1$ ) and watery faeces (score $=2$ ) was scored visually by the same person across the treatment groups.

\section{Skin and tail damage scores}

Skin lesions on the forehand, middle hand and hindquarters and tail lesions were scored per GF pig at the day of moving to the GF room and at day 98 (one day prior to first delivery to the slaughterhouse). Skin lesions were recorded using the following scores: score $0=$ undamaged; score = a few small scratches; 2 = bigger scratches; 3 = scratches with blood; $4=$ small wounds; $5=$ big wounds. Tail damage was recorded using the following scores: score $0=$ no tail damage; score $1=$ bite marks; score 2 = wounds.

\section{Nutrient digestibility}

In week 5, 9 and 13 in eight (medium weight block and heavy weight block) of the twelve pens in each GF room faeces samples were collected. During three consecutive days in week 5, 9 and 13, twice a day fresh faeces samples were taken at three different places from the floor. At each first day of faeces collection, the floor was cleaned and "old" faeces were removed before taking the faeces samples. The six faeces samples per week of collection were pooled and stored at $-20^{\circ} \mathrm{C}$. Faecal samples were homogenized, sampled, freeze dried and ground through a $1 \mathrm{~mm}$ mesh sieve before chemical analysis.

Feed and faeces samples were analysed for dry matter, ash, nitrogen (N), crude fat, starch, energy and titanium. Feed samples were also analysed for sugar and AA composition and the pellet hardness and durability was measured. Dry matter was analysed by drying at $103^{\circ} \mathrm{C}$ (ISO 6496), ash by combustion to a constant weight at $550{ }^{\circ} \mathrm{C}$ (ISO, 5984), $\mathrm{N}$ by using the Dumas method (ISO 166341 ), crude fat after hydrolysis (ISO, 6492) and energy by using an adiabatic bomb calorimeter (ISO 9831). Titanium was determined by spectrophotometer after hydrolysis with $\mathrm{H}_{2} \mathrm{SO}_{4}$ and subsequent addition of peroxide (Myers et al., 2004). Starch was enzymatically determined (ISO 15914). Determination of sugars was based on the method described by Van Vuuren et al. (1993). Amino acid composition was analysed by acid hydrolysis at $110^{\circ} \mathrm{C}$ for $23 \mathrm{~h}$ and ion-exchange chromatography with post column derivatisation with ninhydrin (ISO13903; ISO, 2005a) and tryptophan by alkaline hydrolysis at $110^{\circ} \mathrm{C}$ for $20 \mathrm{~h}$ ion-exchange chromatography with fluorescence detection (MOD.0094 version G; ISO 13904; ISO, 2005c). Pellet durability was tested with durability testing equipment of Wemo Techniek. Pellet hardness was measured with a Dr Schleuniger hardness tester. Seven pellets per batch were tested of which the mean was calculated. The analysed nutrient composition of the diets is presented in Appendix 2. Apparent total tract digestibility (ATTD) of the diets for dry matter, organic matter, crude protein, crude fat, starch and energy was calculated using $\mathrm{TiO}_{2}$ as an indigestible marker.

\section{Blood sampling}

At day 1 in the GF room, two GF pigs with an average weight per pen were selected for blood sampling in week 5, 9 and 13 from the vena jugularis. Per sampling moment one 9-mL serum tube and one 9-mL EDTA tube per pig were filled. The blood samples collected in EDTA tubes were immediately stored on ice and transported to the lab for blood cell counts. Blood samples collected in serum tubes were allowed to clot for $1.5 \mathrm{~h}$ at room temperature. Serum was collected after centrifugation for 15 minutes at 2,000 g/min. The serum samples were stored on ice and transported to the lab together with the EDTA samples. The full blood samples (EDTA) were analysed on blood cell composition and the serum samples on acute phase proteins (haptoglobin and pigMAP) and on antibodies against PRRS, Mycoplasma hyopneumonia, PCV2 (Circovirus), Lawsonia intracellularis (PIA) and Influenza A using ELISA tests (Animal Health Service, The Netherlands). 


\subsection{Statistical analysis}

The data were statistically analysed by means of F-tests using ANOVA (GenStat, 2018) using pen as the experimental unit. Results were considered as significant at $P \leq 0.05$ and as a trend at $P \leq 0.10$.

Weaned piglets

Daily gain, daily feed intake and feed conversion ratio were analysed with the following model:

$Y=\mu+$ batch + block within batch + sanitary condition + residual error

The number of culled and veterinary treated piglets was analysed using the Chi-square test.

\section{Growing and finishing pigs}

Performance data, slaughter data, nutrient digestibility, percentage of pigs with diarrhoea and tail and skin lesions and blood parameters were analysed with a split-plot model. Sanitary condition was analysed on room level (residual error 1 ) and dietary treatments on pen level (residual error 2).

$Y=\mu+$ batch + sanitary condition + residual error $1+$ block within batch + dietary energy source + dietary energy and EAA content + sanitary condition $x$ dietary energy source + sanitary condition $x$ dietary energy and EAA content + dietary energy source $x$ dietary energy and EAA content + sanitary condition $x$ dietary energy source $x$ dietary energy and EAA content + residual error 2

The number of culled and veterinary treated piglets was analysed using the Chi-square test. 


\section{Results}

\subsection{Weaned piglets}

\subsubsection{Performance of the piglets}

The performance of the piglets from weaning till day 35 after weaning is presented in Table 3.

Table 3 Performance from weaning till day 35 after weaning of male piglets that were kept under low (LSC) or high (HSC) sanitary conditions ${ }^{1}$.

\begin{tabular}{lcccc} 
& LSC & HSC & SEM ${ }^{2}$ \\
Number of piglets & 204 & 204 & & \\
\hline Number of pens & 24 & 24 & & \\
\hline & & & & \\
\hline BW at weaning $(\mathrm{kg})$ & 8.0 & 8.0 & & \\
\hline BW at day $35(\mathrm{~kg})$ & 21.1 & 21.7 & & \\
\hline ADG $(\mathrm{g} / \mathrm{d})$ & 379 & 395 & 5.8 & 0.05 \\
\hline ADFI $(\mathrm{kg} / \mathrm{d})$ & 0.59 & 0.61 & 0.007 & 0.06 \\
\hline FCR & 1.58 & 1.55 & 0.017 & 0.24
\end{tabular}

${ }^{1}$ Contrast in sanitary conditions in the piglet phase only holds for the vaccination regime applied and hygiene measures taken by the personnel involved before access of the animal rooms and handling of the piglets.

2 SEM $=$ standard error of the mean

Table 3 shows that ADFI and ADG were higher in HSC piglets than in LSC piglets. Feed conversion ratio was not affected by sanitary conditions.

The performance of the piglets from weaning till day 8 after weaning and from day 8 till day 35 after weaning is presented in Table 4.

Table $4 \quad$ Performance from weaning till day 8 after weaning and from day 8 till day 35 after weaning of piglets that were kept under low (LSC) or high (HSC) sanitary conditions ${ }^{1}$.

\begin{tabular}{|c|c|c|c|c|}
\hline & LSC & HSC & SEM ${ }^{2}$ & P-value \\
\hline Number of piglets & 204 & 204 & & \\
\hline Number of pens & 24 & 24 & & \\
\hline \multicolumn{5}{|l|}{ Weaning till day 8: } \\
\hline BW at weaning $(\mathrm{kg})$ & 8.0 & 8.0 & & \\
\hline BW at day $8(\mathrm{~kg})$ & 9.3 & 9.3 & & \\
\hline FCR & 1.44 & 1.48 & 0.034 & 0.45 \\
\hline \multicolumn{5}{|l|}{ Day 8 till day 35: } \\
\hline BW at day $8(\mathrm{~kg})$ & 9.3 & 9.3 & & \\
\hline BW at day $35(\mathrm{~kg})$ & 21.1 & 21.7 & & \\
\hline
\end{tabular}

${ }^{1}$ Contrast in sanitary conditions in the piglet phase only holds for the vaccination regime applied and hygiene measures taken by the personnel involved before access of the animal rooms and handling of the piglets.

2 SEM $=$ standard error of the mean

Table 4 shows that from weaning till day 8 after weaning feed intake was higher in HSC piglets than in LSC piglets. Daily gain and feed conversion ratio were not affected by sanitary conditions.

From day 8 till day 35 after weaning, feed intake tended to be higher and daily gain was higher in HSC piglets. Feed conversion ratio was not affected by sanitary conditions. 


\subsubsection{Culling and veterinary treatments piglets}

The number of culled and veterinary treated piglets is presented in Table 5. Also the reason of culling and veterinary treatment is presented.

Table $5 \quad$ Number of culled and veterinary treated weaned piglets that were kept under low (LSC) or high (HSC) sanitary conditions.

\begin{tabular}{|c|c|c|c|}
\hline & LSC & HSC & P-value \\
\hline Number of piglets at weaning & 204 & 204 & \\
\hline Number of culled piglets & $4(2.0 \%)$ & $0(0.0 \%)$ & 0.04 \\
\hline \multicolumn{4}{|l|}{ Reason of culling: } \\
\hline - infection with Streptococcus suis & 1 & 0 & 1 \\
\hline - leg problems & 1 & 0 & 1 \\
\hline - dead (reason unknown) & 1 & 0 & 1 \\
\hline - miscellaneous & 1 & 0 & 1 \\
\hline Number of individually veterinary treated piglets & $9(4.4 \%)$ & $8(3.9 \%)$ & 0.80 \\
\hline \multicolumn{4}{|l|}{ Reason of veterinary treatment: } \\
\hline - infection with Streptococcus suis & 5 & 3 & 0.48 \\
\hline - lung problems & 2 & 2 & 0.99 \\
\hline - leg problems & 2 & 3 & 0.65 \\
\hline
\end{tabular}

Table 5 shows that the number of culled piglets was lower in HSC piglets. The number of individually veterinary treated piglets and the reasons for veterinary treatment were not affected by sanitary conditions. 


\subsection{Growing and finishing pigs}

\subsubsection{Performance of the growing and finishing pigs}

The performance of the GF pigs from the start till day 98 (first delivery to the slaughter house) and from start till slaughter is presented in Table 6 (per treatment) and Appendix 3 (per main effect).

Table 6 Performance ${ }^{1}$ from the start till the day of first delivery (day 98) and from the start till slaughter of male GF pigs that were kept under different sanitary conditions and were fed diets differing in energy source and in energy and amino acid content.

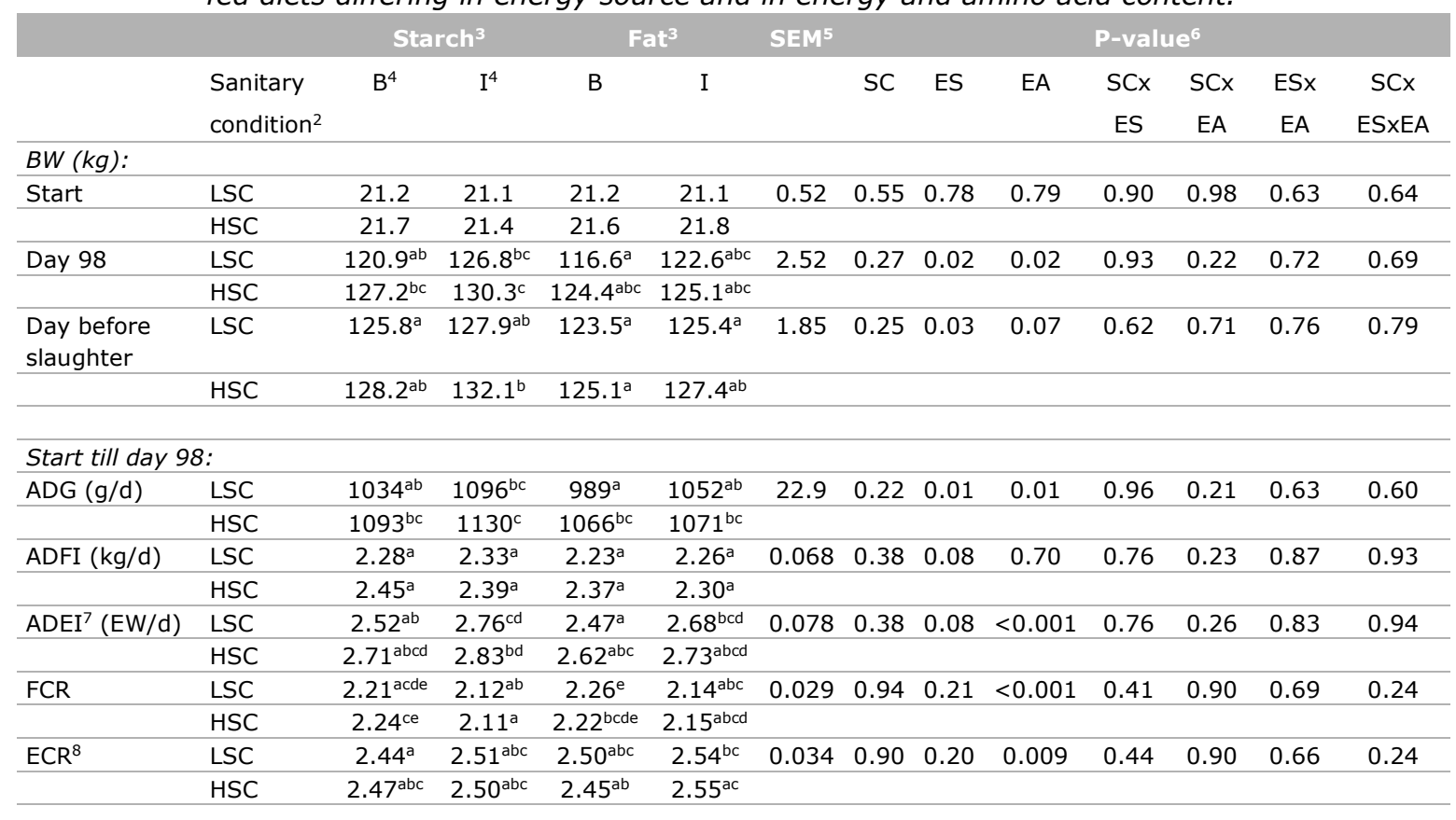

\begin{tabular}{|c|c|c|c|c|c|c|c|c|c|c|c|c|c|}
\hline \multicolumn{14}{|c|}{ Start till slaughter: } \\
\hline \multirow[t]{2}{*}{ No of days } & LSC & 101.7 & 99.3 & 104.3 & 100.6 & & & & & & & & \\
\hline & HSC & 98.3 & 99.2 & 98.1 & 99.6 & & & & & & & & \\
\hline \multirow[t]{2}{*}{ ADG $(g / d)$} & LSC & $1032^{\mathrm{ab}}$ & $1078^{\mathrm{bc}}$ & $984^{a}$ & $1039^{a b}$ & 20.5 & 0.14 & 0.01 & 0.030 & 0.96 & 0.35 & 0.73 & 0.53 \\
\hline & HSC & $1083^{\mathrm{bc}}$ & $1119^{c}$ & $1057^{\mathrm{bc}}$ & $1062^{\mathrm{bc}}$ & & & & & & & & \\
\hline \multirow[t]{2}{*}{ ADFI $(\mathrm{kg} / \mathrm{d})$} & LSC & $2.30^{\mathrm{a}}$ & $2.32^{\mathrm{a}}$ & $2.25^{\mathrm{a}}$ & $2.25^{\mathrm{a}}$ & 0.060 & 0.37 & 0.08 & 0.50 & 0.71 & 0.34 & 0.88 & 0.90 \\
\hline & HSC & $2.43^{a}$ & $2.37^{a}$ & $2.35^{a}$ & $2.29^{a}$ & & & & & & & & \\
\hline \multirow[t]{2}{*}{ FCR } & LSC & $2.22^{\text {acde }}$ & $2.15^{\mathrm{ab}}$ & $2.29^{\mathrm{e}}$ & $2.17^{\mathrm{abcd}}$ & 0.032 & 0.61 & 0.17 & $<0.001$ & 0.34 & 0.88 & 0.91 & 0.15 \\
\hline & HSC & $2.25^{\text {bde }}$ & $2.12^{\mathrm{a}}$ & $2.22^{\text {bcde }}$ & $2.16^{\mathrm{abc}}$ & & & & & & & & \\
\hline \multirow[t]{2}{*}{ ECR } & LSC & $2.46^{\mathrm{ab}}$ & $2.55^{\mathrm{abc}}$ & $2.54^{\mathrm{abc}}$ & $2.57^{\mathrm{ac}}$ & 0.036 & 0.60 & 0.17 & 0.007 & 0.36 & 0.92 & 0.87 & 0.15 \\
\hline & HSC & $2.48^{\mathrm{abc}}$ & $2.51^{\mathrm{abc}}$ & $2.46^{\mathrm{a}}$ & $2.56^{b c}$ & & & & & & & & \\
\hline
\end{tabular}

${ }^{1}$ Data are based on 6 pens ( 50 or 51 pigs) per dietary treatment per sanitary condition; ${ }^{2}$ LSC = low sanitary conditions; HSC $=$ high sanitary conditions; ${ }^{3}$ Starch or fat as dietary energy source; ${ }^{4} \mathrm{~B}=$ basal dietary energy and amino acid content; $\mathrm{I}=$ increased dietary energy and amino acid content; ${ }^{5} \mathrm{SEM}=$ pooled SEM. Means are presented as least squares means; ${ }^{6}$ $\mathrm{SC}=$ sanitary conditions; $\mathrm{ES}=$ dietary energy source; $\mathrm{EA}=$ energy and amino content; ${ }^{7} \mathrm{ADEI}=$ average daily energy intake; ${ }^{8} \mathrm{ECR}=$ energy conversion ratio.

Table 6 and Appendix 3 show that from start till day 98 and from start till slaughter, performance of the pigs was not significantly affected by sanitary conditions. From start till day 98 and from start till slaughter, ADG was higher and ADFI and average daily energy intake (ADEI) tended to be higher in pigs fed the starch diet than in pigs fed the fat diet. Feed conversion ratio and energy conversion ratio (ECR) were not affected by dietary energy source. From start till day 98 and from start till slaughter, ADG and ADEI were higher on the I diet than on the B diet, whereas ADFI was not affected by energy and amino acid content in the diet. Feed conversion ratio was lower but energy conversion ratio (ECR) was higher in pigs fed the I diet.

The performance of the GF pigs from the start till day 35, day 35-63, day 63-98 and day 63 till slaughter is presented in Table 7 (per treatment) and Appendix 3 (per main effect). 
Table 7 Performance ${ }^{1}$ from the start till day 35, day 35-63, day 63-98 and from day 63 till slaughter of male GF pigs that were kept under different sanitary conditions and were fed diets differing in energy source and in energy and amino acid content.

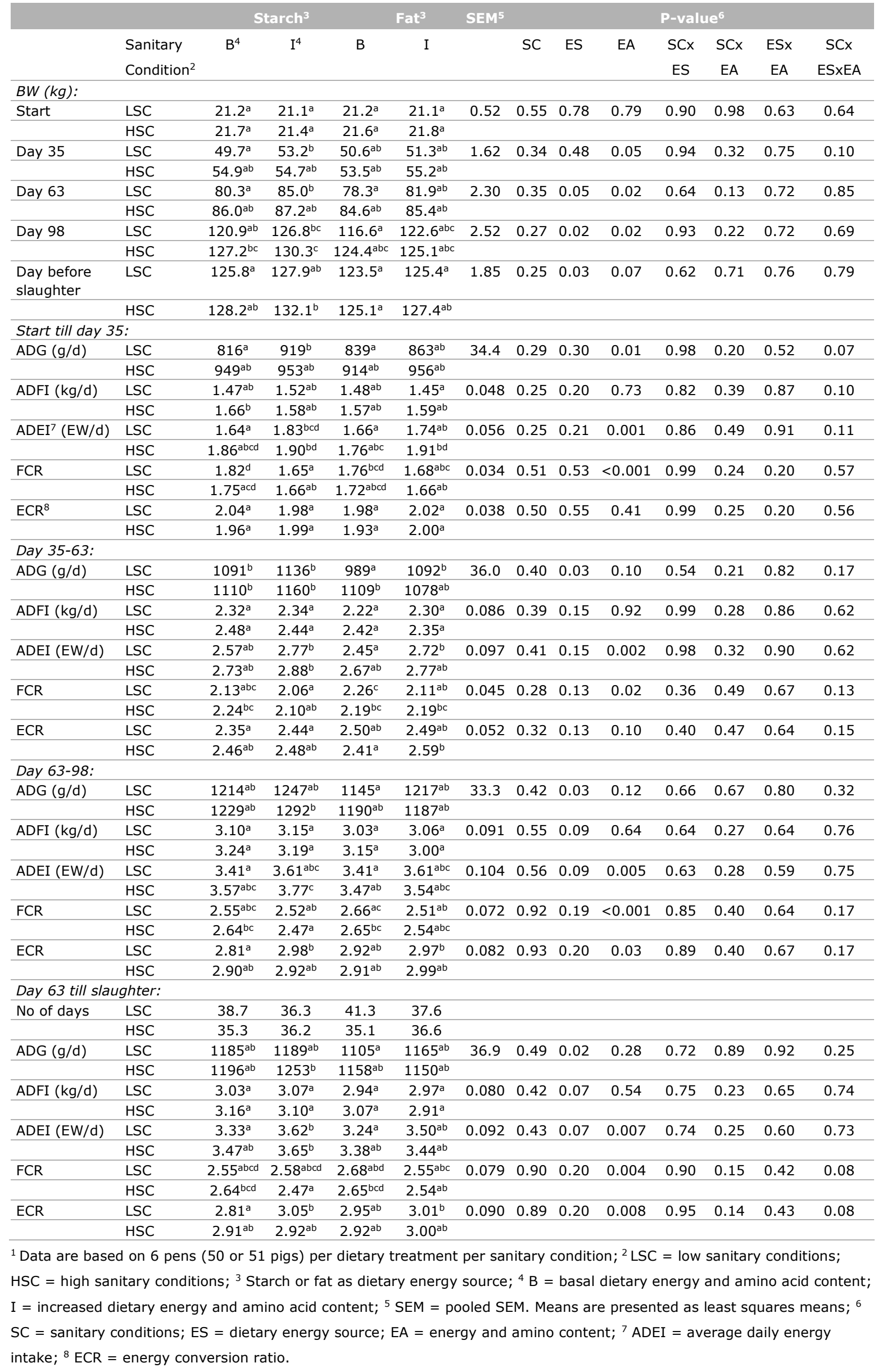


Table 7 shows that from start till day 35, performance of the pigs was not affected by sanitary conditions and energy source in the diet. Average daily gain and ADEI were higher on the I diet than on the B diet, whereas ADFI was not affected by energy and amino acid content in the diet. Feed conversion ratio was lower in pigs fed the I diet whereas ECR was not affected by energy and amino acid content in the diet.

From day 35-63, performance of the pigs was not affected by sanitary conditions. Average daily gain was higher in pigs fed the starch diet than in pigs fed the fat diet. Average daily feed intake, ADEI, FCR and ECR were not significantly affected by dietary energy source. Average daily gain tended to be higher and ADEI was higher on the I diet than on the B diet, whereas ADFI was not affected by energy and amino acid content in the diet. Feed conversion ratio was lower but ECR tended to be higher in pigs fed the I diet.

From day 63-98 and from day 63 till slaughter, performance of the pigs was not affected by sanitary conditions. Average daily gain, ADFI and ADEI from day 63-98 and from day 63 till slaughter were higher in pigs fed the starch diet than in pigs fed the fat diet. Feed conversion ratio and ECR were not affected by dietary energy source. Average daily gain and ADFI from day 63-98 and from day 63 till slaughter were not affected by energy and amino acid content in the diet. Average daily energy intake and ECR ratio were higher and FCR was lower in pigs fed the I diet.

The standard deviation (SD) and coefficient of variance (CV) in BW of the GF pigs within a pen at start, days 35, 63 and 98 and slaughter are presented in Table 8.

Table 8 Standard deviation (SD; $\mathrm{kg}$ ) and coefficient of variation (CV; \%) in BW within a pen at start, days 35, 63 and 98 and slaughter of male GF pigs that were kept under different sanitary conditions and were fed diets differing in energy source and in energy and amino acid content.

\begin{tabular}{|c|c|c|c|c|c|c|c|c|c|c|c|c|c|}
\hline & & \multicolumn{2}{|c|}{ Starch $^{2}$} & \multicolumn{2}{|c|}{ Fat $^{2}$} & SEM 4 & \multicolumn{7}{|c|}{ P-value ${ }^{5}$} \\
\hline & Condition $^{1}$ & & & & & & & & & ES & EA & EA & ESxEA \\
\hline SD BW start & HSC & 2.85 & 2.98 & 2.67 & 2.64 & & & & & & & & \\
\hline CV BW start & LSC & 13.3 & 15.1 & 16.1 & 14.9 & 0.83 & 0.66 & 0.81 & 0.75 & 0.18 & 0.93 & 0.48 & 0.56 \\
\hline SD BW day 35 & HSC & $6.19^{a b}$ & $6.02^{a b}$ & $4.95^{a}$ & $4.82^{a}$ & & & & & & & & \\
\hline \multirow[t]{2}{*}{ CV BW day 35} & LSC & $15.2^{c}$ & $13.2^{\mathrm{bc}}$ & $15.9^{c}$ & $14.7^{\mathrm{bc}}$ & 0.70 & 0.05 & 0.55 & 0.34 & 0.10 & 0.52 & 0.80 & 0.86 \\
\hline & HSC & $11.6^{\mathrm{ab}}$ & $11.2^{\mathrm{ab}}$ & $9.2^{\mathrm{a}}$ & $9.0^{\mathrm{a}}$ & & & & & & & & \\
\hline \multirow[t]{2}{*}{ SD BW day 63} & LSC & $9.40^{\mathrm{ab}}$ & $9.81^{\mathrm{ab}}$ & $12.54^{b}$ & $8.52^{a}$ & 0.598 & 0.14 & 0.83 & 0.47 & 0.20 & 0.17 & 0.81 & 0.03 \\
\hline & HSC & $9.90^{\mathrm{ab}}$ & $8.66^{a}$ & $6.81^{a}$ & $9.17^{a}$ & & & & & & & & \\
\hline SD BW day 98 & HSC & $10.06^{a}$ & $11.18^{\mathrm{ab}}$ & $10.00^{a}$ & $14.23^{\mathrm{ab}}$ & & & & & & & & \\
\hline \multirow[t]{2}{*}{ CV BW day 98} & LSC & $9.9 a^{b}$ & $9.7^{\mathrm{ab}}$ & $13.1^{b}$ & $9.1^{\mathrm{ab}}$ & 0.78 & 0.39 & 0.21 & 0.96 & 0.95 & 0.07 & 0.82 & 0.14 \\
\hline & HSC & $8.1^{\mathrm{a}}$ & $8.7^{a}$ & $8.2^{\mathrm{a}}$ & $11.5^{\mathrm{ab}}$ & & & & & & & & \\
\hline \multirow{2}{*}{$\begin{array}{l}\text { SD slaughter } \\
\text { weight }\end{array}$} & LSC & $7.74^{\mathrm{ab}}$ & $8.27^{a b}$ & $8.95^{\mathrm{ab}}$ & $6.91^{a}$ & 0.607 & 0.09 & 0.77 & 0.26 & 0.84 & 0.05 & 0.77 & 0.24 \\
\hline & HSC & $7.73^{\mathrm{ab}}$ & $9.69^{a b}$ & $6.51^{a}$ & $10.04^{b}$ & & & & & & & & \\
\hline \multirow{2}{*}{$\begin{array}{l}\text { CV BW slaughter } \\
\text { weight }\end{array}$} & LSC & $8.0^{\mathrm{a}}$ & $8.3^{a}$ & $9.5 a$ & $7.3^{a}$ & 0.64 & 0.11 & 0.93 & 0.41 & 0.83 & 0.07 & 0.90 & 0.23 \\
\hline & HSC & $7.9^{a}$ & $9.4^{\mathrm{a}}$ & $6.8^{\mathrm{a}}$ & $10.3^{a}$ & & & & & & & & \\
\hline
\end{tabular}

${ }^{1}$ LSC = low sanitary conditions; HSC = high sanitary conditions; ${ }^{2}$ Starch or fat as dietary energy source; ${ }^{3} \mathrm{~B}=$ basal dietary energy and amino acid content; I = increased dietary energy and amino acid content; ${ }^{4}$ SEM = pooled SEM. Means are presented as least squares means; ${ }^{5} \mathrm{SC}=$ sanitary conditions; $\mathrm{ES}=$ dietary energy source; $\mathrm{EA}=$ energy and amino content; ${ }^{6}$ Because of a system malfunction at the slaughterhouse, slaughterdata of 70 pigs are missing.

Table 8 shows that SD in BW is not affected by sanitary conditions. The CV in BW was lower in HSC than LSC pigs at day 35 and 63. The SD and CV in BW were not affected by dietary energy source and energy and amino acid content in the diet. The SD in BW increased from the start till day 98 , whereas the CV decreased from the start till day 98. 


\subsubsection{Slaughter results}

The slaughter results of the GF pigs are presented in table 9.

Table 9 Slaughter results of male GF pigs that were kept under different sanitary conditions and were fed diets differing in energy source and in energy and amino acid content.

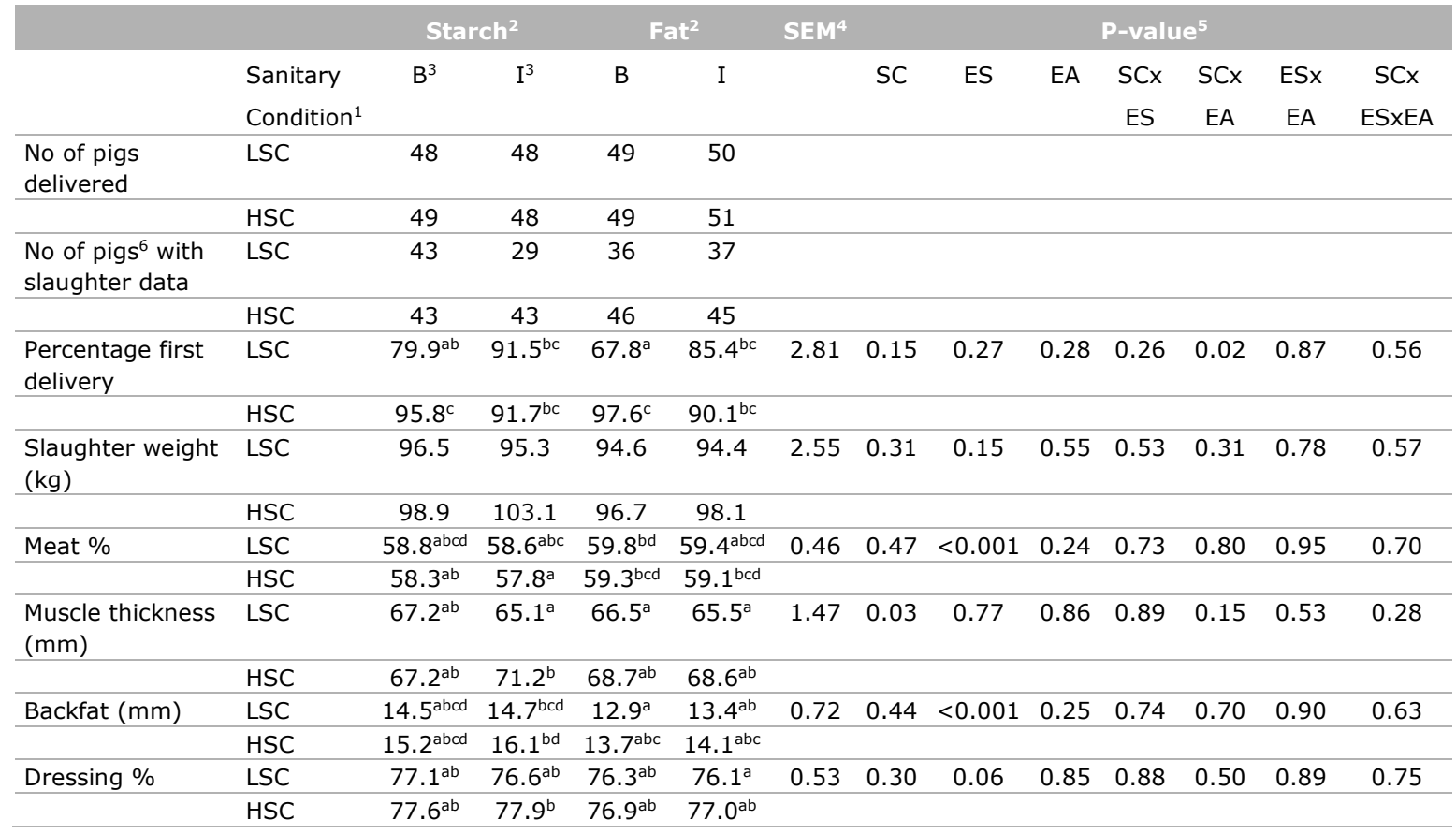

${ }^{1}$ LSC = low sanitary conditions; HSC $=$ high sanitary conditions; ${ }^{2}$ Starch or fat as dietary energy source; ${ }^{3} \mathrm{~B}=$ basal dietary energy and amino acid content; I = increased dietary energy and amino acid content; ${ }^{4}$ SEM = pooled SEM. Means are presented as least squares means; ${ }^{5} \mathrm{SC}=$ sanitary conditions; $\mathrm{ES}=$ dietary energy source; $\mathrm{EA}=$ energy and amino content; ${ }^{6}$ Because of a system malfunction at the slaughterhouse, slaughterdata of 70 pigs are missing.

Table 9 shows that sanitary conditions did not affect slaughter weight, meat\%, backfat thickness and dressing\%. Muscle thickness was lower in LSC pigs than in HSC pigs. Meat\% was lower and backfat thickness and dressing\% were higher in pigs fed the starch diet than in pigs fed the fat diet. Slaughter weight and muscle thickness were not affected by dietary energy source. Energy and amino acid content in the diet did not affect slaughter results.

\subsubsection{Health and faecal scores}

The number of culled and veterinary treated GF pigs is presented in Table 10. Also the reasons of culling and veterinary treatment are presented.

Table 10 shows that sanitary conditions and energy and amino acid content in the diet did not affect the number of culled pigs, whereas the number of culled pigs was higher on the starch diet than on the fat diet. The number of veterinary treated pigs tended to be higher in LSC pigs than in HSC pigs (17 vs 9 pigs). Especially, the number of pigs that was treated due to lung problems and diarrhoea was higher in LSC pigs. Energy source and energy and amino acid content in the diet did not affect the number of veterinary treated pigs. 
Table 10 Number of culled and veterinary treated male GF pigs that were kept under different sanitary conditions and were fed diets differing in energy source and in energy and amino acid content.

\begin{tabular}{|c|c|c|c|c|c|c|c|c|c|c|c|}
\hline & \multicolumn{4}{|c|}{$\mathrm{LSC}^{1}$} & \multicolumn{4}{|c|}{ HSC $^{1}$} & \multicolumn{3}{|c|}{ P-value ${ }^{4}$} \\
\hline & \multicolumn{2}{|c|}{ Starch $^{2}$} & \multicolumn{2}{|c|}{ Fat $^{2}$} & \multicolumn{2}{|c|}{ Starch } & \multicolumn{2}{|c|}{ Fat } & \multirow[b]{2}{*}{$\mathrm{SC}$} & \multirow[b]{2}{*}{ ES } & \multirow[b]{2}{*}{ EA } \\
\hline & $B^{3}$ & $\mathrm{I}^{3}$ & B & I & B & I & B & I & & & \\
\hline No of pigs & 50 & 50 & 49 & 50 & 51 & 51 & 51 & 51 & & & \\
\hline No of culled pigs & 2 & 2 & 0 & 0 & 2 & 3 & 2 & 0 & 0.38 & 0.03 & 0.75 \\
\hline \multicolumn{12}{|l|}{ Reason of culling: } \\
\hline - GIT disorder 6 & 1 & 1 & 0 & 0 & 1 & 0 & 0 & 0 & 5 & 5 & 5 \\
\hline - PIA & 0 & 0 & 0 & 0 & 0 & 0 & 1 & 0 & 5 & 5 & 5 \\
\hline - poor growth & 0 & 0 & 0 & 0 & 0 & 1 & 1 & 0 & 5 & 5 & 5 \\
\hline - dead (reason unknown) & 1 & 1 & 0 & 0 & 0 & 2 & 0 & 0 & 5 & 5 & 5 \\
\hline - miscellaneous & 0 & 0 & 0 & 0 & 1 & 0 & 0 & 0 & 5 & 5 & 5 \\
\hline $\begin{array}{l}\text { No of veterinary treated } \\
\text { pigs }\end{array}$ & 8 & 2 & 4 & 3 & 1 & 0 & 2 & 6 & 0.09 & 0.41 & 0.41 \\
\hline \multicolumn{12}{|l|}{ Reason of treatment: } \\
\hline - lung problems & 4 & 0 & 3 & 1 & 0 & 0 & 0 & 1 & 0.02 & 0.73 & 0.09 \\
\hline - leg problems & 0 & 1 & 0 & 0 & 0 & 0 & 0 & 2 & 5 & 5 & 5 \\
\hline - diarrhoea & 3 & 1 & 1 & 2 & 1 & 0 & 0 & 0 & 0.03 & 0.48 & 0.47 \\
\hline - PIA & 0 & 0 & 0 & 0 & 0 & 0 & 2 & 3 & 5 & 5 & 5 \\
\hline - poor body condition & 1 & 0 & 0 & 0 & 0 & 0 & 0 & 0 & 5 & 5 & 5 \\
\hline \multicolumn{12}{|c|}{$\begin{array}{l}{ }^{1} \text { LSC = low sanitary conditions; HSC }=\text { high sanitary conditions; }{ }^{2} \text { Starch or fat as dietary energy source; }{ }^{3} \mathrm{~B}=\text { basal dietary } \\
\text { energy and amino acid content; I = increased dietary energy and amino acid content; }{ }^{4} \mathrm{SC}=\text { sanitary conditions; ES }= \\
\text { dietary energy source; EA = energy and amino content; }{ }^{5} \text { Numbers too low to allow statistical analysis; }{ }^{6} \mathrm{GIT}= \\
\text { gastrointestinal tract. }\end{array}$} \\
\hline
\end{tabular}

The percentage of GF pigs with diarrhoea (score 1 and 2) within a pen in week 1, 3, 5, 7, 9, 11 and 13 after the start is presented in Table 11.

Table 11 Percentage of male GF pigs with diarrhoea (score 1 and 2) within a pen that were kept under different sanitary conditions and were fed diets differing in energy source and in energy and amino acid content.

\begin{tabular}{|c|c|c|c|c|c|c|c|c|c|c|c|c|}
\hline \multirow{3}{*}{ Week } & \multirow{3}{*}{$\begin{array}{l}\text { Sanitary } \\
\text { Condition }^{1}\end{array}$} & \multicolumn{2}{|c|}{ Starch $^{2}$} & \multicolumn{2}{|c|}{ Fat $^{2}$} & \multicolumn{7}{|c|}{ P-value ${ }^{4}$} \\
\hline & & $\mathrm{B}^{3}$ & $\mathrm{I}^{3}$ & B & I & $\mathrm{SC}$ & ES & EA & SCX ES & SCX EA & $E S x E A$ & SCx ESxEA \\
\hline & & & & & & & & & & & & \\
\hline \multirow[t]{2}{*}{1} & LSC & 7.6 & 15.3 & 10.5 & 5.6 & 0.36 & 0.08 & 0.71 & 0.92 & 0.76 & 0.11 & 0.12 \\
\hline & $\mathrm{HSC}$ & 3.7 & 3.9 & 0.0 & 0.0 & & & & & & & \\
\hline \multirow[t]{2}{*}{3} & LSC & 10.2 & 17.2 & 3.7 & 5.8 & 0.20 & 0.003 & 0.24 & 0.01 & 0.08 & 0.61 & 0.27 \\
\hline & $\mathrm{HSC}$ & 1.9 & 0.0 & 0.0 & 0.0 & & & & & & & \\
\hline \multirow[t]{2}{*}{5} & LSC & 13.9 & 23.5 & 10.3 & 7.9 & 0.50 & 0.004 & 0.12 & 0.04 & 0.70 & 0.01 & 0.60 \\
\hline & $\mathrm{HSC}$ & 1.9 & 8.1 & 3.9 & 2.1 & & & & & & & \\
\hline \multirow[t]{2}{*}{7} & LSC & 10.0 & 12.6 & 6.3 & 6.0 & 0.16 & 0.006 & 0.41 & 0.84 & 0.84 & 0.37 & 0.89 \\
\hline & $\mathrm{HSC}$ & 3.9 & 7.9 & 0.0 & 0.0 & & & & & & & \\
\hline \multirow[t]{2}{*}{9} & LSC & 6.0 & 2.4 & 2.1 & 0.0 & 0.39 & 0.53 & 0.02 & 0.18 & 0.53 & 0.96 & 0.59 \\
\hline & $\mathrm{HSC}$ & 5.8 & 1.9 & 7.9 & 2.1 & & & & & & & \\
\hline \multirow[t]{2}{*}{11} & LSC & 0.0 & 1.9 & 0.0 & 0.0 & 0.50 & 0.33 & 0.33 & 0.33 & 0.33 & 0.33 & 0.33 \\
\hline & $\mathrm{HSC}$ & 0.0 & 0.0 & 0.0 & 0.0 & & & & & & & \\
\hline \multirow[t]{2}{*}{13} & LSC & 2.1 & 4.2 & 0.0 & 0.0 & 0.70 & 0.25 & 0.99 & 0.03 & 0.25 & 0.25 & 0.99 \\
\hline & $\mathrm{HSC}$ & 0.0 & 0.0 & 2.1 & 0.0 & & & & & & & \\
\hline \multirow[t]{2}{*}{ All } & LSC & 7.1 & 11.0 & 4.7 & 3.6 & 0.40 & $<0.001$ & 0.45 & 0.02 & 0.20 & 0.02 & 0.29 \\
\hline & $\mathrm{HSC}$ & 2.4 & 3.1 & 2.0 & 0.6 & & & & & & & \\
\hline
\end{tabular}

${ }^{1}$ LSC = low sanitary conditions; HSC $=$ high sanitary conditions; ${ }^{2}$ Starch or fat as dietary energy source; ${ }^{3} \mathrm{~B}=$ basal dietary energy and amino acid content; I = increased dietary energy and amino acid content; ${ }^{4} \mathrm{SC}=$ sanitary conditions; $\mathrm{ES}=$ dietary energy source; $\mathrm{EA}=$ energy and amino content.

Table 11 shows that the mean percentage of pigs with diarrhoea during the overall GF period was lower in HSC than LSC pigs on the starch diet but was similar in HSC and LSC pigs on the fat diet. In LSC pigs, the mean percentage of pigs with diarrhoea during the overall GF period was lower on the fat diet than on the starch diet. In HSC pig, the mean percentage of pigs with diarrhoea was similar on the starch and fat diet. Energy and amino acid content in the diet did not affect the mean percentage of pigs with diarrhoea during the overall GF period. 


\subsubsection{Skin and tail damage scores}

The percentage of GF pigs with skin lesions (score 2-5) on the forehand, middle hand and hind quarters at the start of the GF phase and at day 98 (day of first delivery to the slaughterhouse) is presented in Table 12.

Table 12 Percentage of male GF pigs with skin lesions (score 2-5) on the forehand, middle hand and hind quarters at the start of the GF phase and at day 98 that were kept under different sanitary conditions and were fed diets differing in energy source and in energy and amino acid content.

\begin{tabular}{|c|c|c|c|c|c|c|c|c|c|c|c|c|}
\hline & & \multicolumn{2}{|c|}{ Starch ${ }^{2}$} & \multicolumn{2}{|c|}{ Fat $^{2}$} & \multicolumn{7}{|c|}{ P-value $^{4}$} \\
\hline & Condition $^{1}$ & & & & & & & & & & & \\
\hline \multicolumn{13}{|l|}{ Start: } \\
\hline \multirow[t]{2}{*}{ Forehand } & LSC & 23 & 11 & 42 & 40 & 0.32 & 0.06 & 0.54 & 0.09 & 0.32 & 0.63 & 0.06 \\
\hline & HSC & 9 & 26 & 21 & 17 & & & & & & & \\
\hline Middle hand & HSC & 2 & 0 & 0 & 0 & & & & & & & \\
\hline \multirow[t]{2}{*}{ Hind quarters } & LSC & 0 & 0 & 3 & 0 & 0.94 & 0.97 & 0.97 & 0.98 & 0.98 & 0.99 & 0.99 \\
\hline & HSC & 0 & 0 & 0 & 0 & & & & & & & \\
\hline
\end{tabular}

\begin{tabular}{|c|c|c|c|c|c|c|c|c|c|c|c|c|}
\hline \multicolumn{13}{|l|}{ Day 98: } \\
\hline \multirow[t]{2}{*}{ Forehand } & LSC & 6 & 2 & 19 & 13 & 0.52 & 0.01 & 0.61 & 0.56 & 0.42 & 0.92 & 0.57 \\
\hline & HSC & 4 & 6 & 11 & 11 & & & & & & & \\
\hline & HSC & 4 & 2 & 4 & 0 & & & & & & & \\
\hline \multirow[t]{2}{*}{ Hind quarters } & LSC & 4 & 2 & 4 & 7 & 0.46 & 0.41 & 0.71 & 0.85 & 0.86 & 0.40 & 0.77 \\
\hline & HSC & 1 & 1 & 1 & 3 & & & & & & & \\
\hline
\end{tabular}

${ }^{1}$ LSC = low sanitary conditions; HSC $=$ high sanitary conditions; ${ }^{2}$ Starch or fat as dietary energy source; ${ }^{3}$ B $=$ basal dietary energy and amino acid content; I = increased dietary energy and amino acid content; ${ }^{4} \mathrm{SC}=$ sanitary conditions; $\mathrm{ES}=$ dietary energy source; EA = energy and amino content.

Table 12 shows that both at the start of the GF phase and at day 98, the percentage of pigs with skin lesions on the forehand, middle hand and hind quarters was not affected by sanitary conditions or energy and amino acid content in the diet. The percentage of pigs with skin lesions on the forehand was higher in pigs fed the fat diet than in pigs fed the starch diet, both at the start and at day 98.

The percentage of GF pigs with tail lesions (score $0=$ no tail damage; score 1 = bite marks; score 2 = wounds) at the start of the GF phase and at day 98 (day of first delivery to the slaughterhouse) is presented in Table 13.

Table 13 shows that the percentage of pigs with tail lesions was not affected by sanitary conditions and energy and amino acid content in the diet. At the start of the GF phase, the percentage of pigs with tail lesions was higher in pigs fed the fat diet during the GF period than in pigs fed the starch diet. 
Table 13 Percentage of male GF pigs with tail lesions at the start of the GF phase and at day 98 that were kept under different sanitary conditions and were fed diets differing in energy source and in energy and amino acid content.

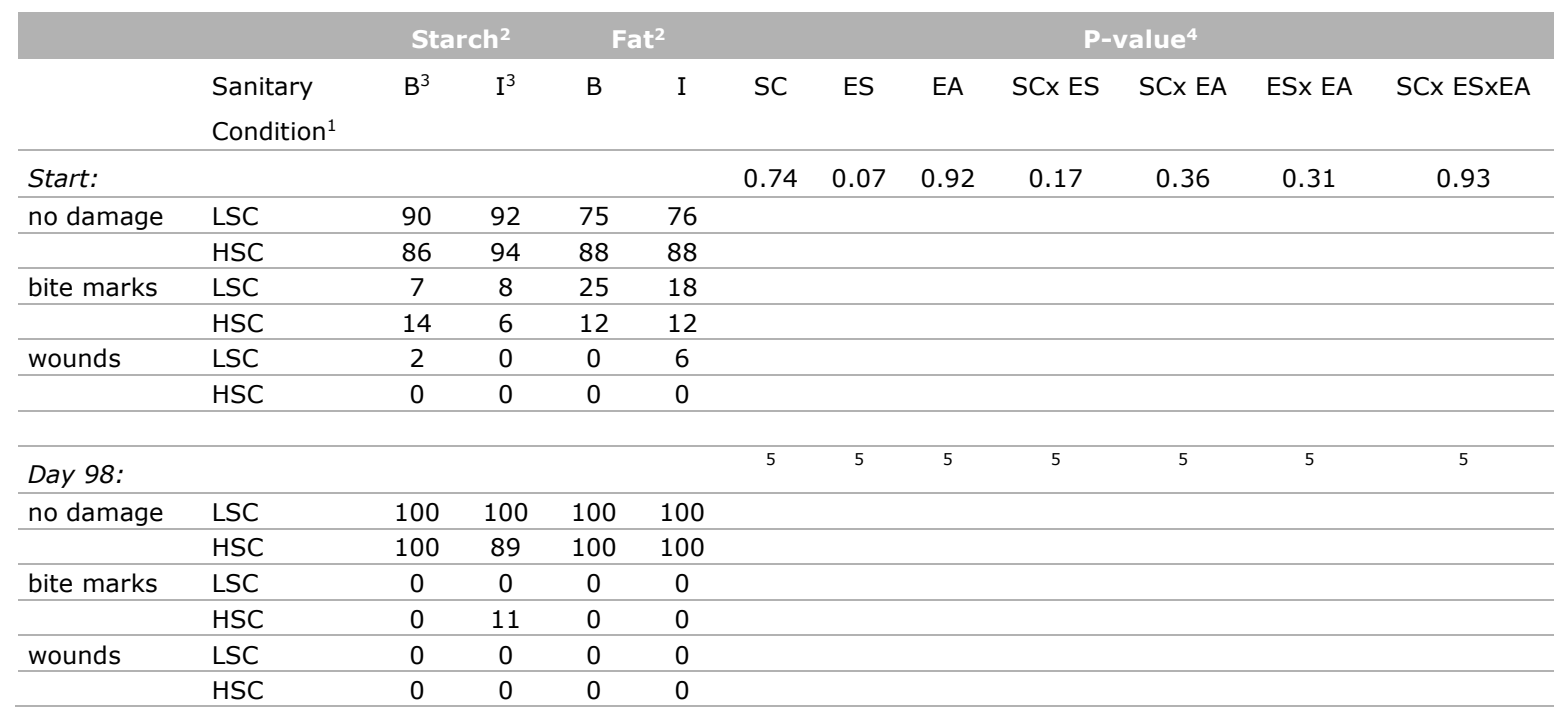

${ }^{1}$ LSC = low sanitary conditions; HSC $=$ high sanitary conditions; ${ }^{2}$ Starch or fat as dietary energy source; ${ }^{3} \mathrm{~B}=$ basal dietary energy and amino acid content; I = increased dietary energy and amino acid content; ${ }^{4} \mathrm{SC}=$ sanitary conditions; ES = dietary energy source; $\mathrm{EA}=$ energy and amino content; ${ }^{5}$ P-values could not be calculated because almost all measurements have tail lesion score $=0$ (no damage).

\subsubsection{Nutrient composition and nutrient digestibility}

The analysed nutrient composition (dry matter, ash, crude protein, crude fat, starch, sugar, titanium and GE) of the diets and the analysed contents of AA in the diets is presented in Appendix 2. Moreover, the pellet hardness and durability of the diets is presented in Appendix 2. In the I diets, the analysed ash contents were as expected. In the B diets, the analysed ash contents were between 12 and $20 \mathrm{~g} / \mathrm{kg}$ lower than the calculated contents. The analysed protein contents were as expected in the starch diets. In the fat diets (except the fat-I grower diet), the analysed protein contents were about $10 \mathrm{~g} / \mathrm{kg}$ higher than the calculated contents. The analysed fat contents were as expected in the starch diets, whereas in the fat diets the analysed fat contents were between 20 and $30 \mathrm{~g} / \mathrm{kg}$ lower than the calculated contents. In the starch starter diets and in the fat finisher diets, the analysed starch contents were between 15 and $30 \mathrm{~g} / \mathrm{kg}$ lower than the calculated contents. In all diets, the sugar contents were as expected. Pellet hardness and durability were similar in the starch and fat diets and in the $B$ and I diets.

In the grower diets and in the starch finisher diets, the differences in analysed lysine contents between the $B$ and I diets were smaller than expected. In the fat grower diets, the difference in analysed threonine contents between the B and I diets was smaller than the calculated difference. For the other EAA, the analysed contents were as expected.

Apparent faecal nutrient digestibility (dry matter, ash, organic matter, crude protein, crude fat, starch and energy) of the starter diets, grower diets and finisher diets in GF pigs that were kept under different sanitary conditions are presented in Table 14. 
Table 14 Apparent faecal nutrient digestibility (\%) ${ }^{1}$ in male GF pigs that were kept under different sanitary conditions and were fed diets differing in energy source and in energy and amino acid content.

\begin{tabular}{|c|c|c|c|c|c|c|c|c|c|c|c|c|c|}
\hline & & \multicolumn{2}{|c|}{ Starch $^{3}$} & \multicolumn{2}{|c|}{$\mathrm{Fat}^{3}$} & \multirow[t]{3}{*}{ SEM $^{5}$} & \multicolumn{7}{|c|}{ P-value $^{6}$} \\
\hline & \multirow{2}{*}{$\begin{array}{l}\text { Sanitary } \\
\text { Condition }^{2}\end{array}$} & $B^{4}$ & $\mathrm{I}^{4}$ & B & I & & SC & ES & EA & SCx & SCx & ESx EA & $\mathrm{SCx}$ \\
\hline & & & & & & & & & & ES & \multicolumn{2}{|l|}{ EA } & ESXEA \\
\hline \multicolumn{14}{|l|}{ Starter diet: } \\
\hline \multirow[t]{2}{*}{ Dry matter } & LSC & $82.9^{c}$ & $86.4^{d}$ & $72.6^{\mathrm{a}}$ & $77.8^{\mathrm{b}}$ & 0.46 & 0.04 & $<0.001$ & $<0.001$ & 0.44 & 0.58 & 0.07 & 0.69 \\
\hline & HSC & $83.9^{c}$ & $87.4^{d}$ & $73.3^{a}$ & $77.8^{\mathrm{b}}$ & & & & & & & & \\
\hline \multirow[t]{2}{*}{ Ash } & LSC & $29.6^{b}$ & $44.0^{d}$ & $26.1^{\mathrm{ab}}$ & $34.5^{c}$ & 1.19 & 0.30 & $<0.001$ & $<0.001$ & 0.99 & 0.30 & 0.002 & 0.65 \\
\hline & HSC & $28.7^{\mathrm{ab}}$ & $45.9^{d}$ & $26.0^{a}$ & $35.5^{c}$ & & & & & & & & \\
\hline \multirow[t]{2}{*}{ Organic matter } & LSC & $88.7^{c}$ & $89.5^{\mathrm{cd}}$ & $78.6^{a}$ & $82.1^{b}$ & 0.42 & 0.01 & $<0.001$ & $<0.001$ & 0.35 & 0.33 & 0.002 & 0.70 \\
\hline & HSC & $90.0^{d}$ & $90.4^{d}$ & $79.4^{\mathrm{a}}$ & $82.0^{\mathrm{b}}$ & & & & & & & & \\
\hline \multirow[t]{2}{*}{ Crude protein } & LSC & $77.9^{b}$ & $80.3^{d}$ & $74.2^{\mathrm{a}}$ & $77.9^{b}$ & 0.64 & 0.15 & $<0.001$ & $<0.001$ & 0.51 & 0.35 & 0.23 & 0.90 \\
\hline & HSC & $79.9^{\text {cd }}$ & $81.5^{d}$ & $75.7^{a}$ & $78.3^{b c}$ & & & & & & & & \\
\hline \multirow[t]{2}{*}{ Crude fat } & LSC & $80.3^{a}$ & $82.9^{b}$ & $86.1^{\mathrm{c}}$ & $87.0^{c}$ & 0.60 & 0.26 & $<0.001$ & 0.24 & 0.51 & 0.01 & 0.21 & 0.59 \\
\hline & $\mathrm{HSC}$ & $82.9^{b}$ & $82.5^{b}$ & $87.6^{c}$ & $86.6^{c}$ & & & & & & & & \\
\hline \multirow[t]{2}{*}{ Starch } & LSC & $99.7^{\text {de }}$ & $99.8^{\text {de }}$ & $99.4^{a}$ & $99.5^{\mathrm{abc}}$ & 0.04 & 0.33 & $<0.001$ & 0.04 & 0.52 & 0.62 & 0.006 & 0.06 \\
\hline & HSC & $99.9^{e}$ & $99.8^{e}$ & $99.5^{\mathrm{ab}}$ & $99.6^{\text {acd }}$ & & & & & & & & \\
\hline \multirow[t]{2}{*}{ Energy } & LSC & $86.7^{c}$ & $87.7^{\mathrm{cd}}$ & $77.4^{a}$ & $81.0^{\mathrm{b}}$ & 0.47 & 0.02 & $<0.001$ & $<0.001$ & 0.34 & 0.26 & 0.006 & 0.84 \\
\hline & HSC & $88.3^{d}$ & $88.6^{d}$ & $78.4^{\mathrm{a}}$ & $81.0^{\mathrm{b}}$ & & & & & & & & \\
\hline \multicolumn{14}{|l|}{ Grower diet: } \\
\hline \multirow[t]{2}{*}{ Dry matter } & LSC & $83.4^{c}$ & $87.4^{\mathrm{d}}$ & $71.9^{\mathrm{a}}$ & $75.5^{b}$ & 0.32 & 0.13 & $<0.001$ & $<0.001$ & 0.81 & 0.38 & 0.08 & 0.32 \\
\hline & HSC & $83.3^{c}$ & $88.3^{\mathrm{d}}$ & $72.5^{\mathrm{a}}$ & $76.0^{\mathrm{b}}$ & & & & & & & & \\
\hline \multirow[t]{2}{*}{ Ash } & LSC & $28.5^{\mathrm{ab}}$ & $45.1^{d}$ & $26.8^{a}$ & $32.6^{c}$ & 1.18 & 0.76 & $<0.001$ & $<0.001$ & 0.72 & 0.17 & $<0.001$ & 0.17 \\
\hline & $\mathrm{HSC}$ & $26.2^{\mathrm{a}}$ & $47.5^{d}$ & $26.2^{\mathrm{a}}$ & $32.0^{\mathrm{bc}}$ & & & & & & & & \\
\hline \multirow[t]{2}{*}{ Organic matter } & LSC & $89.5^{c}$ & $90.2^{\text {cd }}$ & $77.7^{\mathrm{a}}$ & $79.6^{b}$ & 0.30 & 0.20 & $<0.001$ & $<0.001$ & 0.70 & 0.55 & 0.12 & 0.42 \\
\hline & HSC & $89.7^{c}$ & $91.1^{d}$ & $78.4^{\mathrm{a}}$ & $80.2^{b}$ & & & & & & & & \\
\hline Crude protein & LSC & $80.1^{\mathrm{d}}$ & $82.7^{\mathrm{e}}$ & $74.8^{\mathrm{a}}$ & $76.0^{\mathrm{ab}}$ & 0.48 & 0.02 & $<0.001$ & $<0.001$ & 0.34 & 0.41 & 0.01 & 0.42 \\
\hline & HSC & $80.2^{\mathrm{d}}$ & $84.1^{\mathrm{e}}$ & $76.3^{b c}$ & $77.5^{c}$ & & & & & & & & \\
\hline Crude fat & LSC & $76.7^{\mathrm{a}}$ & $79.7^{b}$ & $85.5^{d}$ & $85.5^{d}$ & 0.50 & 0.03 & $<0.001$ & $<0.001$ & 0.07 & 0.83 & $<0.001$ & 0.24 \\
\hline & HSC & $78.5^{\mathrm{b}}$ & $82.6^{c}$ & $86.6^{d}$ & $85.8^{d}$ & & & & & & & & \\
\hline Starch & LSC & $99.8^{d}$ & $99.8^{d}$ & $99.5^{\mathrm{ab}}$ & $99.4^{a}$ & 0.03 & 0.16 & $<0.001$ & 0.77 & 0.07 & 0.09 & 0.59 & 0.20 \\
\hline & HSC & $99.8^{d}$ & $99.9^{d}$ & $99.6^{b c}$ & $99.7^{c}$ & & & & & & & & \\
\hline Energy & LSC & $87.6^{d}$ & $89.6^{\mathrm{e}}$ & $76.5^{\mathrm{a}}$ & $78.2^{\mathrm{bc}}$ & 0.31 & 0.14 & $<0.001$ & $<0.001$ & 0.67 & 0.48 & 0.54 & 0.32 \\
\hline & $\mathrm{HSC}$ & $87.8^{\mathrm{d}}$ & $89.6^{\mathrm{e}}$ & $77.4^{\mathrm{ab}}$ & $78.9^{c}$ & & & & & & & & \\
\hline Finisher diet: & & & & & & & & & & & & & \\
\hline Dry matter & LSC & $83.2^{c}$ & $87.7^{\mathrm{d}}$ & $72.5^{\mathrm{a}}$ & $76.5^{b}$ & 0.34 & 0.49 & $<0.001$ & $<0.001$ & 0.80 & 0.78 & 0.04 & 0.25 \\
\hline & $\mathrm{HSC}$ & $83.2^{c}$ & $88.2^{\mathrm{d}}$ & $73.0^{\mathrm{a}}$ & $76.5^{b}$ & & & & & & & & \\
\hline Ash & LSC & $24.2^{\mathrm{a}}$ & $41.7^{c}$ & $23.2^{\mathrm{a}}$ & $31.8^{\mathrm{b}}$ & 1.23 & 0.31 & $<0.001$ & $<0.001$ & 0.85 & 0.64 & $<0.001$ & 0.43 \\
\hline & HSC & $22.3^{\mathrm{a}}$ & $42.3^{c}$ & $22.5^{a}$ & $30.5^{b}$ & & & & & & & & \\
\hline Organic matter & LSC & $89.5^{c}$ & $90.8^{d}$ & $78.8^{\mathrm{a}}$ & $80.8^{\mathrm{b}}$ & 0.27 & 0.30 & $<0.001$ & $<0.001$ & 0.80 & 0.51 & 0.56 & 0.21 \\
\hline & HSC & $89.8^{c}$ & $91.3^{d}$ & $79.4^{\mathrm{a}}$ & $80.7^{b}$ & & & & & & & & \\
\hline Crude protein & LSC & $79.8^{\mathrm{cd}}$ & $83.5^{\mathrm{e}}$ & $76.4^{a}$ & $78.0^{\mathrm{ab}}$ & 0.59 & 0.24 & $<0.001$ & $<0.001$ & 0.97 & 0.68 & 0.02 & 0.93 \\
\hline & $\mathrm{HSC}$ & $81.2^{\mathrm{d}}$ & $84.6^{e}$ & $77.7^{\mathrm{ab}}$ & $79.0^{\mathrm{bc}}$ & & & & & & & & \\
\hline Crude fat & LSC & $78.3^{a}$ & $81.6^{\mathrm{bc}}$ & $87.1^{\text {de }}$ & $87.0^{\text {de }}$ & 0.79 & 0.48 & $<0.001$ & $<0.001$ & 0.40 & 0.49 & $<0.001$ & 0.78 \\
\hline & HSC & $80.0^{\mathrm{ab}}$ & $82.6^{\text {acd }}$ & $88.0^{e}$ & $87.6^{e}$ & & & & & & & & \\
\hline Starch & LSC & $99.9^{b}$ & $99.9^{b}$ & $99.7^{\mathrm{a}}$ & $99.6^{a}$ & 0.03 & 0.64 & $<0.001$ & 0.94 & 0.88 & 0.46 & 0.94 & 0.38 \\
\hline & HSC & $99.9^{b}$ & $99.9^{b}$ & $99.7^{\mathrm{a}}$ & $99.7^{\mathrm{a}}$ & & & & & & & & \\
\hline Energy & LSC & $87.8^{c}$ & $89.2^{\mathrm{d}}$ & $77.9^{\mathrm{a}}$ & $79.8^{\mathrm{b}}$ & 0.31 & 0.25 & $<0.001$ & $<0.001$ & 0.68 & 0.53 & 0.99 & 0.35 \\
\hline & HSC & $88.2^{c}$ & $89.8^{d}$ & $78.6^{a}$ & $79.7^{b}$ & & & & & & & & \\
\hline
\end{tabular}

Table 14 shows that the apparent faecal digestibility of dry matter, organic matter and energy in the starter diets and of crude protein and crude fat in the grower diet were higher in HSC pigs than in LSC pigs. The faecal digestibility of other nutrients was not affected by sanitary conditions. In both the starter, grower and finisher diets, the digestibility of dry matter, organic matter, ash, crude protein, starch and energy were higher on the starch diets than on the fat diets. The digestibility of fat was lower on the starch diet. In both the starter, grower and finisher diets, the digestibility of dry matter, ash, organic matter, crude protein and energy were higher on the I diets than on the B diets. The digestibility of starch was not affected by energy and amino acid content in the diet. Moreover, the digestibility of fat in the starter diet was not affected by energy and amino acid content in the diet. 
The digestibility of fat in the starch grower and finisher diets, however, was higher on the I diets than on the B diets, whereas the digestibility of fat in the fat grower and finisher diets was not affected by energy and amino acid content in the diet.

\subsubsection{Blood parameters}

The concentrations of the acute phase proteins haptoglobine and PigMap at day 1, 35, 56 and 84 are presented in Figure 1 and Appendix 4. Blood cell counts at day 1, 35, 56 and 84 are presented Appendix 4. The parameters haptoglobine and PigMAP, haemolysis index, MCH and numbers of leucocytes and monocytes were log transformed before statistical analysis.

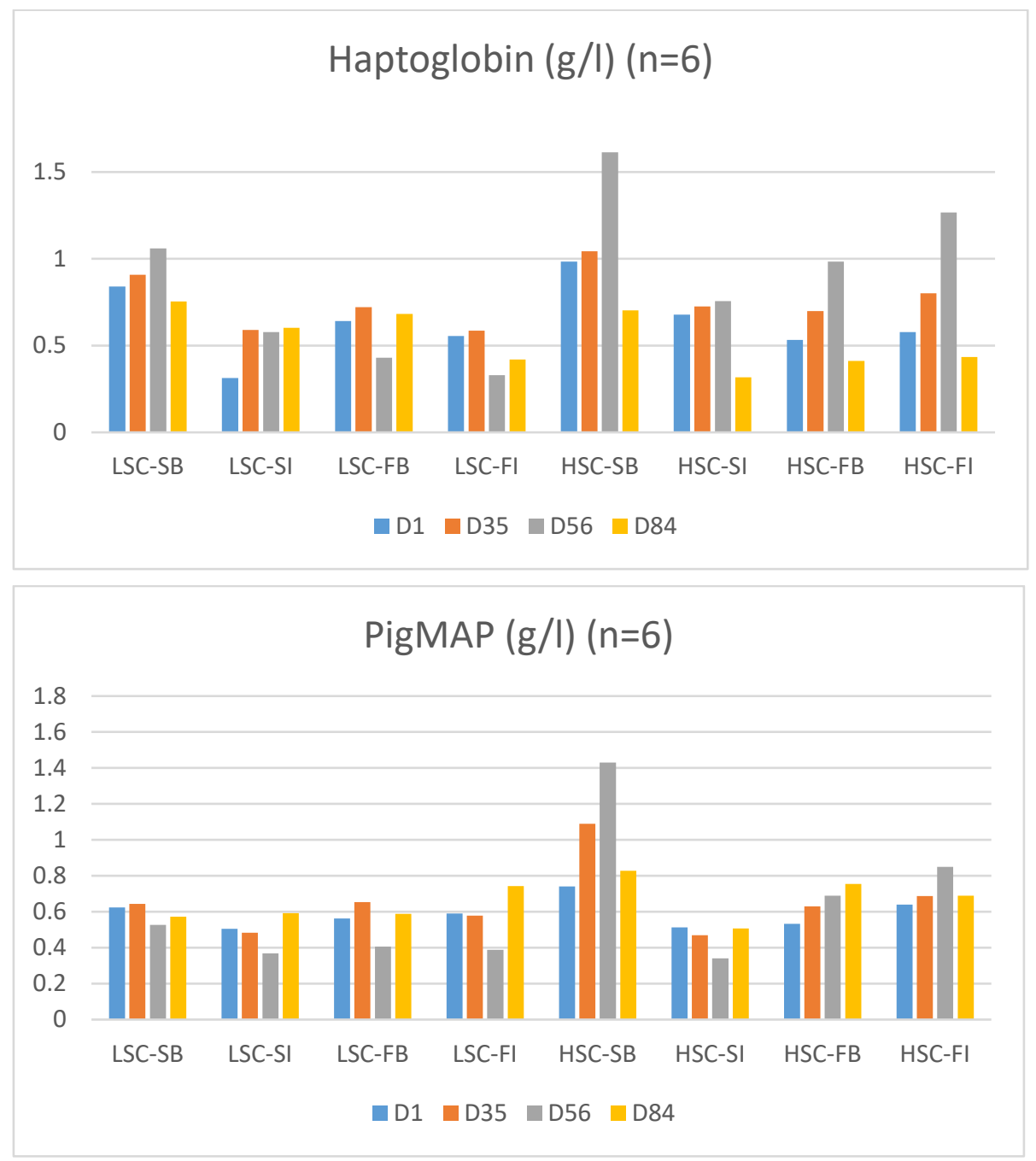

Figure 1 Haptoglobin and PigMAP concentration $(\mathrm{g} / \mathrm{L})$ at 1, 35, 56 and 84 days in male GF pigs that were kept under different sanitary conditions and were fed diets differing in energy source and in energy and amino acid content. LSC = low sanitary conditions; HSC = high sanitary conditions; $S=$ starch as dietary energy source; $F=$ fat as dietary energy source; $B=$ basal dietary energy and amino acid content; I = increased dietary energy and amino acid content.

Figure 1 and Appendix 4 show that the mean haptoglobin and PigMAP concentration only was higher in HSC than LSC pigs on day 56. Haptoglobin concentration was higher in pigs on the starch diet than in pigs on the fat diet on day 56. PigMAP on day 56 was higher in pigs fed the starch basal diet than in pigs fed the starch increased diet, whereas it was similar in pigs fed the fat basal or fat increased diet. Haptoglobin and PigMAP concentrations on day 35 and 84 were not affected by sanitary conditions, dietary energy source or energy and amino acid content in the diet.

Appendix 4 shows that the number of thrombocytes was lower in HSC than LSC pigs on day 56 and 84. The other blood cell count parameters were not affected by sanitary conditions. Haematocrit (day 35 ), haemolysis index (day 35), the number of erythrocytes (day 1, 35 and 56) and the number of 
leucocytes (day 35) were higher in pigs on the starch diet than on the fat diet. Mean corpuscular haemoglobin $(\mathrm{MCH})$ (day 56), mean corpuscular haemoglobin concentration (MCHC) and the number of thrombocytes (day 84) were lower in pigs on the starch diet than on the fat diet. The number of eosinophil granulocytes and of neutrophil granulocytes was higher in pigs on the I diet than on the $B$ diet. The other blood cell count parameters were not affected by energy and amino acid content in the diet.

The percentage of pigs with positive antibody levels against PRRS, Mycoplasma hyopneumonia, PCV2 (Circovirus), Lawsonia intracellularis (PIA) and Influenza A is presented in Table 15.

Table 15 shows that the percentage of pigs with positive antibody concentrations against circovirus (day 1, 35 and 56), Influenza A (day 35 and 56) and PRRS (day 1, 35 and 56) was higher in HSC than in LSC pigs. The percentage of pigs with positive antibody concentrations against Mycoplasma hyopneumonia and Lawsonia intracellularis (PIA) was not affected by sanitary conditions. On day 35, the percentage of pigs with positive antibody concentrations against Influenza $A$ tended to be higher in pigs on the starch diet than on the fat diet. Moreover, on day 35 the percentage of pigs with positive antibody concentrations against Lawsonia intracellularis was higher in pigs on the I diet than on the B diet. 


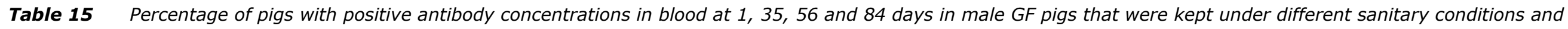
were fed diets differing in energy source and in energy and amino acid content.

\begin{tabular}{|c|c|c|c|c|c|c|c|c|c|c|c|c|c|c|c|c|c|}
\hline & \multicolumn{4}{|c|}{$\operatorname{LSC}^{1}$} & \multicolumn{4}{|c|}{$\mathrm{HSC}^{1}$} & \multicolumn{2}{|c|}{ SEM $^{4}$} & \multirow{3}{*}{ SC } & \multirow{3}{*}{ ES } & \multicolumn{5}{|c|}{ P-value ${ }^{5}$} \\
\hline & \multicolumn{2}{|c|}{ Starch $^{2}$} & \multicolumn{2}{|c|}{ Fat $^{2}$} & \multicolumn{2}{|c|}{ Starch } & \multicolumn{2}{|c|}{ Fat } & \multirow[t]{3}{*}{ SC } & \multirow{2}{*}{$\begin{array}{c}\text { ES / } \\
\text { EA }\end{array}$} & & & \multirow[t]{2}{*}{ EA } & \multirow[t]{2}{*}{$\mathrm{SC} \times \mathrm{ES}$} & \multirow[t]{2}{*}{$S C \times E A$} & \multirow[t]{2}{*}{$E S \times E A$} & \multirow[t]{2}{*}{$S C \times E S \times E A$} \\
\hline & $B^{3}$ & $\mathrm{I}^{3}$ & B & I & B & I & B & I & & & & & & & & & \\
\hline No of pigs & 6 & 6 & 6 & 6 & 6 & 6 & 6 & 6 & & & & & & & & & \\
\hline \multicolumn{18}{|c|}{ Circovir_Anti_IgG: } \\
\hline D1 & 0 & 0 & 0 & 0 & 67 & 83 & 83 & 67 & 3.6 & 6.8 & $<0.001$ & 0.99 & 0.99 & 0.99 & 0.99 & 0.39 & 0.39 \\
\hline D35 & 0 & 0 & 0 & 0 & 33 & 17 & 33 & 50 & 2.1 & 7.1 & $<0.001$ & 0.42 & 0.99 & 0.42 & 0.99 & 0.42 & 0.42 \\
\hline D56 & 0 & 0 & 0 & 0 & 33 & 0 & 17 & 17 & 2.9 & 6.1 & 0.02 & 0.99 & 0.34 & 0.99 & 0.34 & 0.34 & 0.34 \\
\hline D84 & 0 & 0 & 0 & 0 & 0 & 0 & 0 & 0 & & & & & & & & & \\
\hline \multicolumn{18}{|c|}{ M_Hyopneum_Antibody: } \\
\hline D1 & 0 & 0 & 0 & 17 & 0 & 0 & 0 & 0 & 4.4 & 2.9 & 0.54 & 0.33 & 0.33 & 0.33 & 0.33 & 0.33 & 0.33 \\
\hline D35 & 0 & 0 & 0 & 0 & 0 & 0 & 0 & 0 & & & & & & & & & \\
\hline D56 & 0 & 0 & 0 & 0 & 0 & 0 & 0 & 0 & & & & & & & & & \\
\hline D84 & 0 & 0 & 0 & 0 & 0 & 0 & 0 & 0 & & & & & & & & & \\
\hline \multicolumn{18}{|c|}{ Influenza_A_Antibody: } \\
\hline D1 & 33 & 50 & 0 & 50 & 17 & 17 & 33 & 17 & 5.3 & 7.6 & 0.17 & 0.70 & 0.25 & 0.25 & 0.06 & 0.70 & 0.25 \\
\hline D35 & 33 & 0 & 0 & 17 & 83 & 83 & 67 & 33 & 7.7 & 8.2 & 0.007 & 0.08 & 0.29 & 0.29 & 0.72 & 0.72 & 0.08 \\
\hline D56 & 17 & 0 & 0 & 17 & 33 & 67 & 33 & 17 & 7.4 & 8.6 & 0.05 & 0.31 & 0.73 & 0.31 & 0.73 & 0.73 & 0.10 \\
\hline D84 & 0 & 0 & 0 & 0 & 0 & 0 & 17 & 0 & 4.4 & 2.9 & 0.54 & 0.33 & 0.33 & 0.33 & 0.33 & 0.33 & 0.33 \\
\hline \multicolumn{18}{|c|}{ Ileitis / Lawsonia: } \\
\hline D1 & 0 & 0 & 0 & 0 & 0 & 0 & 17 & 17 & 5.1 & 4.3 & 0.31 & 0.18 & 0.99 & 0.18 & 0.99 & 0.99 & 0.99 \\
\hline D35 & 50 & 50 & 50 & 83 & 0 & 50 & 33 & 50 & 15.0 & 8.3 & 0.31 & 0.17 & 0.04 & 0.99 & 0.49 & 0.99 & 0.17 \\
\hline D56 & 83 & 67 & 83 & 83 & 67 & 83 & 83 & 67 & 6.7 & 9.8 & 0.69 & 0.77 & 0.77 & 0.77 & 0.77 & 0.77 & 0.38 \\
\hline D84 & 83 & 83 & 83 & 100 & 100 & 100 & 83 & 83 & 6.7 & 6.9 & 0.69 & 0.67 & 0.67 & 0.21 & 0.67 & 0.67 & 0.67 \\
\hline \multicolumn{18}{|c|}{ PRRS_Antibody: } \\
\hline D1 & 0 & 0 & 17 & 0 & 100 & 67 & 100 & 100 & 5.3 & 4.8 & $<0.001$ & 0.07 & 0.07 & 0.54 & 0.54 & 0.54 & 0.07 \\
\hline D35 & 0 & 17 & 0 & 0 & 100 & 83 & 100 & 100 & 5.5 & 4.2 & $<0.001$ & 0.99 & 0.99 & 0.17 & 0.17 & 0.99 & 0.17 \\
\hline D56 & 17 & 33 & 50 & 0 & 100 & 83 & 100 & 100 & 12.8 & 5.6 & 0.02 & 0.61 & 0.13 & 0.61 & 0.61 & 0.13 & 0.01 \\
\hline D84 & 50 & 50 & 50 & 50 & 83 & 83 & 100 & 100 & 20.7 & 4.3 & 0.23 & 0.18 & 0.99 & 0.18 & 0.99 & 0.99 & 0.99 \\
\hline
\end{tabular}

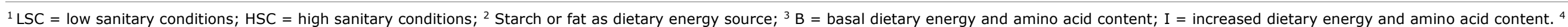
$\mathrm{SEM}=$ pooled SEM. Means are presented as least squares means; ${ }^{5} \mathrm{SC}$ = sanitary conditions; $\mathrm{ES}$ = dietary energy source; $\mathrm{EA}=$ energy and amino content. 


\section{Discussion}

The aim of the present study was to evaluate the effects of dietary energy source (starch vs fat) and of an increased energy and amino acid content in the diet, related to the assumed increased amino acid and energy requirements in immune stimulated pigs, on the growth performance of GF pigs. The diets were evaluated in pigs kept under a low or high sanitary status regime assumed to create a contrast in degree of immune system activation in the pigs.

\section{Effect of sanitary conditions on immune status}

A contrast in sanitary conditions was created by imposing the pigs to differences in vaccination, cleaning and hygiene protocol and deworming strategy. On day 1, 35 and 84, there were no differences in acute phase proteins haptoglobin and PigMAP concentrations in blood between HSC and LSC pigs. Only on day 56, haptoglobin and PigMAP concentrations were on average higher in HSC than in LSC pigs. Moreover, the blood cell count parameters were similar in HSC and LSC pigs throughout the study. The HSC pigs were vaccinated against several pathogens in their first 9 weeks of life. The percentage of pigs with positive antibody concentrations against circovirus, Influenza A and PRRS was higher in HSC than in LSC pigs. The higher percentage of HSC pigs with positive antibody concentrations against PPRS is due to the PRRS vaccination applied in HSC pigs, whereas the higher percentage of HSC pigs with positive antibody concentrations against Influenza A and circovirus might be due to the vaccination against Influenza $A$ and circovirus but might also be related to an infection of the HSC pigs with Influenza or circovirus during the study. It is known that vaccination against circovirus does only cause an antibody response in about half of a population of pigs (Koinig et al., 2015). In the LSC group, there were no piglets showing increased antibody concentrations against circovirus. The percentage of pigs with positive antibody concentrations against Mycoplasma hyopneumonia was zero in both HSC and LSC pigs, indicating that no infection with Mycoplasma occurred during the experiment. Both the HSC and LSC pigs were vaccinated against PIA. In both groups, the percentage of pigs with positive antibody concentrations against Lawsonia intracellularis (PIA) increased during the GF phase. All together, these results suggest that, despite the strict contrast in cleaning-, vaccination- and hygiene protocol, only relatively small differences in degree of activation of the immune system between HSC and LSC pigs were observed. These results are in line with the absence of major clinical signs of disease in the pigs included in the study. The number of veterinary treated pigs, however, tended to be lower in HSC than LSC pigs (4.4 vs $8.5 \%$ of the pigs), especially, the number of pigs that was treated for lung problems and diarrhoea. Moreover, in week 1 , 3,5 and 7 the percentage of pigs with diarrhoea was numerically lower in HSC than LSC pigs (2.3 vs $10.4 \%)$.

The small difference in immune system activation between the LSC and HSC pigs might also be the reason that the percentage of pigs with tail lesions at the start and at day 98 of the GF phase was not affected by sanitary conditions. Van der Meer et al. (2017) suggested a relationship between immune system activation and the occurrence of behavioral problems. They showed that the proportion of LSC pigs with tail damage $(0.80 \pm 0.03)$ indeed was higher than that of HSC pigs $(0.65 \pm 0.03)$ in the starter phase. In the grower phase, however, the proportion of pigs with tail damage in LSC pigs ( 0.81 $\pm 0.04)$ was lower than that in HSC pigs $(0.92 \pm 0.02)$. The percentage of pigs with tail lesions in the trial of Van der Meer et al. (2017), however, was much higher than in our study, possibly related to an interaction with the dietary protein level in the experimental diets in their study, as pigs on a low protein diet showed more lesions compared to a reference group on a protein adequate diet. Tail biting is a multi-factorial problem and the likelihood of its expression is influenced by several factors such as environmental enrichment, housing system, climate, stocking density, health, feeding management, breed and sex (Zonderland, 2010).

\section{Effect of sanitary conditions on growth performance}

From weaning till day 35 after weaning, HSC piglets showed a $4 \%$ higher ADFI $(0.02 \mathrm{~kg} / \mathrm{d})$ and ADG $(16 \mathrm{~g} / \mathrm{d})$ than LSC piglets. Moreover, the number of culled piglets was lower in HSC piglets. During the GF phase (from start till slaughter), the performance of both the LSC and HSC pigs was considered 
very high. HSC GF pigs showed a $4 \%$ higher ADFI $(0.08 \mathrm{~kg} / \mathrm{d} ; \mathrm{p}=0.14)$ and ADG $(47 \mathrm{~g} / \mathrm{d} ; \mathrm{p}=0.37)$ than LSC GF pigs, whereas over all diets FCR was similar in HSC and LSC pigs. The differences in ADFI and $A D G$, however, were not shown to be statistically different because, due to the experimental design, SC could only be tested at room level, and not on pen level, and the number of replicates (rooms) per SC was only two. During the starter, grower and finisher phase, HSC pigs showed a 10, 4 and $2 \%$ higher ADFI and ADG, respectively, than LSC pigs over all diets. A significant higher ADG of HSC pigs was found by Williams et al. (1997b), Van der Meer et al. (2016) and Van der Meer (2017). Immune system activation due to a sanitary challenge may increase the maintenance requirement for energy with 7 to $12 \%$ and may decrease digestibility of protein and energy (reviewed by Van der PeetSchwering et al., 2019) resulting in a lower ADG in LSC pigs. Moreover, LSC pigs might prioritize the use of nutrients for immune system functioning over use for deposition in body tissues (Le Floc'h et al., 2004). In addition, in several studies it was shown that immune system activation reduces feed intake of GF pigs (Williams et al., 1997b; Le Floc'h et al., 2009; Le Floc'h et al., 2014; Pastorelli et al., 2012b; van der Meer, 2017) resulting in a lower ADG. Pastorelli et al. (2012) carried out a metaanalysis on 122 published experiments to quantify the feed intake and body weight gain responses of growing pigs after a sanitary challenge. They concluded that poor housing conditions reduced ADG with $16.3 \%$ (compared to unchallenged pigs), of which $4.1 \%$ was due to a lower feed intake and $12.2 \%$ to a reduced feed efficiency, so worsened FCR. In our study, ADFI indeed was reduced with $4 \%$ in LSC pigs but FCR was not influenced by sanitary conditions. This suggests that maintenance requirement for energy of pigs in our study did not differ between LSC and HSC pigs, related to the relatively small difference in degree of immune system activation between both groups of pigs. Moreover, Van der Meer et al. (2016) stated that a poorer FCR in LSC pigs might partly be due to the observed lower apparent faecal $\mathrm{N}$ digestibility, considered as a proxy for the ileal digestibility of protein and AA of the diet. In our study, only during the grower phase faecal $\mathrm{N}$ digestibility was slightly lower in LSC pigs (78.4 vs $79.5 \%$; $p=0.02$ ). During the starter and finisher phase, faecal $N$ digestibility was similar in HSC and LSC pigs. So, the small difference in immune system activation and (intestinal) protein and AA digestibility between LSC and HSC pigs may be the reason that FCR was not affected by sanitary conditions in our study and that ADG and ADFI only were increased numerically with $4 \%$ in HSC pigs.

\section{Effect of increased dietary energy and amino acid levels on performance and behaviour}

In several studies it was shown that supplementation of some EAA (methionine+cystine, threonine and tryptophan) to the diet can reduce the difference in ADG and ADFI (Le Floc'h, 2006; Trevisi et al., 2009) or FCR (Van der Meer et al., 2016; Capozzalo et al., 2017) between LSC and HSC pigs. However, despite the dietary supplementation of specific EAA, growth performance of the LSC pigs was still lower than of HSC pigs in these studies. It can be assumed that supplementation of EAA is only supporting protein retention and body weight gain if dietary energy intake is not limiting. Therefore, in the present study we increased both the dietary EAA and energy levels in two of the four experimental diets. The increased energy and amino acid content in the diet increased ADG and average daily energy intake, whereas ADFI was not affected by energy and amino acid content in the diet. Feed conversion ratio was improved but energy conversion ratio (ECR) was worse in pigs fed the energy and EAA supplemented diets. There was no significant interaction between energy and amino acid content in the diet and sanitary conditions for any of the performance parameters. As can be seen in Figure 2 and Table 6, however, the increase in ADG from the start till day 98 of the GF phase on the I diet compared to the B diet was $62 \mathrm{~g} / \mathrm{d}$ in LSC pigs, whereas it was $21 \mathrm{~g} / \mathrm{d}$ in HSC pigs. This means that on the B diet, LSC pigs grew $68 \mathrm{~g} / \mathrm{d}(6.4 \%)$ less than HSC pigs, whereas on the I diet, LSC pigs grew $26 \mathrm{~g} / \mathrm{d}(2.4 \%)$ less. The energy intake on the I diet compared to the B diet was $0.23 \mathrm{EW} / \mathrm{d}$ higher in LSC pigs and $0.12 \mathrm{EW} / \mathrm{d}$ in HSC pigs. This means that on the $\mathrm{B}$ diet, LSC pigs ate $0.17 \mathrm{EW} / \mathrm{d}$ $(6.4 \%)$ less than HSC pigs, whereas on the I diet, LSC pigs ate $0.06 \mathrm{EW} / \mathrm{d}(2.2 \%)$ less. The effects on FCR and ECR were similar in LSC and HSC pigs. Thus, it can be concluded that an increase in dietary energy and amino acid content increased ADG and energy intake more in LSC than in HSC pigs. The ADG and energy intake of the LSC pigs on the I diet were still somewhat lower than of the HSC pigs on the I diet, but these differences were not statistically significant. In the studies of Le Floc'h et al. (2006) and Van der Meer et al. (2016) the differences in performance between HSC and LSC pigs that were fed EAA supplemented diets were greater than in our study. In these studies only EAA were supplemented whereas in our study both EAA and energy were supplemented. Therefore, it seems 
that dietary supplementation of both EAA and energy is more effective in increasing performance in LSC pigs than dietary supplementation of EAA alone.

The levels of supplementation of EAA and energy in the I diets compared to the $B$ diets were based on the use of a calculation model as described by van der Peet-Schwering et al. (2019). Model calculations were made for five scenarios among which a scenario called "low sanitary conditions". Using a factorial approach for calculating requirements for protein and energy deposition, with the model the effects of low sanitary conditions on the EAA and energy requirements of pigs were estimated and translated into adjusted optimal dietary energy and EAA levels. This information was used to formulate the EAA and energy enriched I diets. Regarding the original assumptions about the quantitative effects of sanitary conditions on feed intake, nutrient digestibility and additional amino acid requirements for immune proteins, used for calculating adjusted nutrient concentrations in the energy and amino acid supplemented diets, it can be concluded that effects on feed intake in the present study (-4\% in LSC pigs) were in line with the original assumption. For nutrient digestibility, faecal protein and energy digestibility for the basal diets was, on average over the three growth phases, respectively 1.3 and $0.8 \%$ lower in LSC pigs, which was less than assumed $(-4 \%$ for SID AA and apparent faecal energy digestibility). For acute phase proteins in blood the differences between HSC and LSC pigs were generally small, whereas the the levels of antibodies in blood were higher in higher HSC pigs compared to LSC pigs for Circo virus, influenza and PRRS, related to the vaccinations applied against these pathogens in HSC pigs. This suggests that the actual additional amino acid requirements for synthesis of immune proteins in LSC pigs were likely lower than assumed. The assumed effects of sanitary status on the post absorptive utilization of particular amino acids (Trp. Val, Leu and Ile) and the increased maintenance requirement for energy in pigs kept under low sanitary conditions cannot be compared directly as both parameters were not measured in the current study. They might only be reflected indirectly in the response of the pigs in terms of growth performance and feed conversion ratio. Overall, the former suggests that the "I diets" with increased amino acid and energy concentrations seem somewhat "over-supplemented" compared to additional nutrient requirements of LSC pigs assumed upon diet formulation. Further validation of the calculation model for adjusting dietary nutrient concentrations in relation to health status of pigs, however, is required using different environmental and/or challenge conditions.
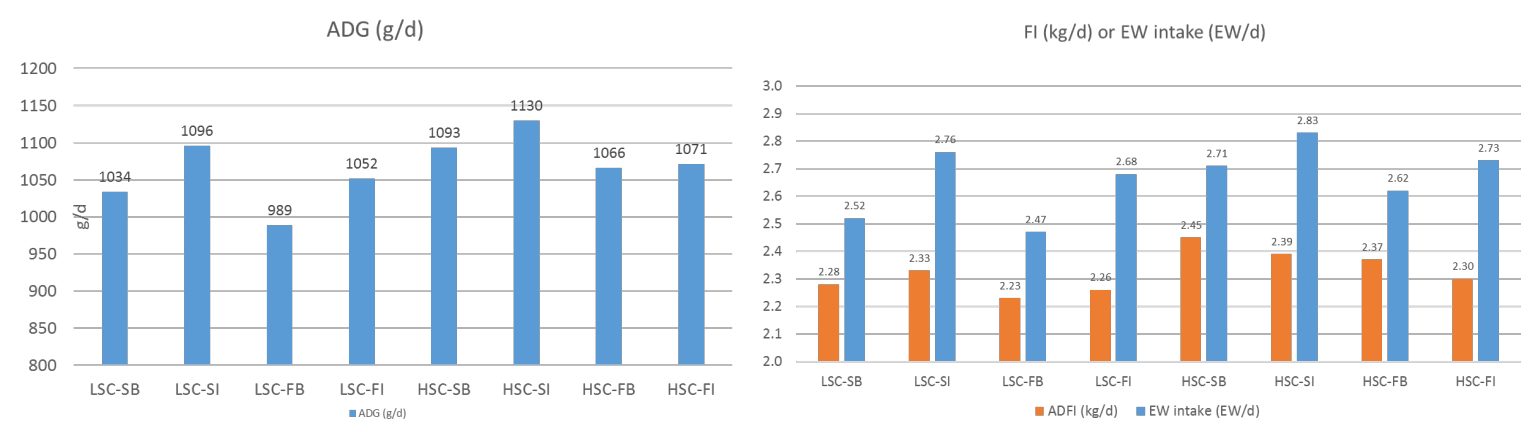

Figure 2 Average daily gain and average feed and EW intake from the start till the day of first delivery (day 98) in male GF pigs that were kept under different sanitary conditions and were fed diets differing in energy source and in energy and amino acid content. LSC = low sanitary conditions; HSC = high sanitary conditions; $S$ = starch as dietary energy source; $F=$ fat as dietary energy source; $B=$ basal dietary energy and amino acid content; I = increased dietary energy and amino acid content.

In both the starter, grower and finisher diets, the digestibility of dry matter, ash, organic matter, crude protein, fat (only grower and finisher diet) and energy were higher on the I diets than on the $B$ diets. This may partly be explained by differences in ingredient (and nutrient) composition between the basal and energy and EAA supplemented diets and to some extent to the increase in nutrient digestibility per se related to a more optimal functioning and digestive capacity of the gut in pigs fed these diets. This might partly explain the higher ADG in pigs on the I diet compared to the B diets (Van der Meer et al., 2016; Van der Peet-Schwering et al., 2019).

The percentage of pigs with tail lesions at the end of the finisher phase (day 98) was not affected by energy and amino acid content in the diet. Van der Meer et al. (2017) also showed that supplementation of methionine+cystine, threonine and tryptophan to the diet did not affect the percentage of pigs with tail lesions. Van der Peet-Schwering et al. (2017), however, showed that the 
percentage of pigs with tail lesions the day before delivery to the slaughterhouse was lower in pigs fed a diet supplemented with methionine, threonine and tryptophan. Also McIntyre and Edwards (2000) and Martinez-Trejo et al. (2009) showed less tail biting in pigs when extra tryptophan was added to the diet. Tryptophan is a precursor of serotonin, a neurotransmitter which is known to affect behaviour and emotional stage in humans and animals (Rieder et al., 2002). In our study, however, tail lesions were absent in pigs fed the basal diets and therefore the effects of increasing dietary amino acid and energy content on tail biting could not be determined.

\section{Effect of dietary energy source on growth performance}

In literature, less attention has been given to the dietary source of energy in relation to health status of the pigs. Butcher and Miles (2002) stated that under ISS conditions, animals might have a preference for glucose over fatty acids as energy source as immunological stress may impair triglyceride clearance from the blood, thus decreasing the use of fat in metabolism, because of a reduced activity of the enzyme lipoprotein lipase. Van Heugten et al. (1996) investigated the effects of dietary nutrient density and energy source (starch vs fat) on performance and immune function in LPS challenged weaned piglets. Their results indicated that increasing nutrient density of the diet by isocaloric fat or starch supplementation did not alter the performance depression after LPS challenge. Addition of fat to the diet improved feed efficiency and efficiency of energy conversion but may depress the humoral immune response (Van Heugten et al., 1996). In our study, from start till slaughter, ADG was higher and ADFI and average daily energy intake (ADEI) tended to be higher in pigs fed the starch diet than in pigs fed the fat diet. Feed conversion ratio and energy conversion ratio (ECR) were not affected by dietary energy source. There was no significant interaction between dietary energy source and sanitary conditions for any of the performance parameters which means that the effect of dietary energy source on performance was similar in LSC and HSC pigs. These results are comparable with the results of Van Heugten et al. (1996). The lower ADG, ADFI and ADEI in pigs fed the fat diet may be related to the higher NSP content in the fat diet than in the starch diet.

To obtain the same energy content in the starch and fat diet, starch was replaced by a combination of fat and NSP rich ingredients (maize starch was replaced with soy oil, palm oil, oat hulls and wheat straw pellets). In several studies (Van der Peet-Schwering et al., 2006; Van der Peet-Schwering et al., 2017), it has been shown that a high NSP level in diets for GF pigs, reduces ADG and ADFI. The reduction in ADFI is probably also the reason that backfat thickness was lower and meatpercentage was higher in pigs fed the fat diet.

The apparent faecal digestibility of dry matter, organic matter, crude protein, starch and energy were lower in pigs on the fat diet than in pigs on the starch diet. Similar effects on digestibility were found by Bakker (1996) and Rijnen (2003). Bakker (1996) replaced maize starch with fat, cellulose or soybean hulls. When maize starch was replaced with only fat, the apparent faecal digestibility of dry matter, crude protein, starch and energy was not affected. When maize starch, however, was replaced with cellulose or soybean hulls or with the combination of fat and cellulose or fat and soybean hulls, the apparent faecal digestibility of dry matter, crude protein energy was lower. Rijnen (2003) replaced maize starch with fat (soybean oil) and soybean hulls in diets for growing pigs. In the diets with fat and soybean hulls, the apparent faecal digestibility of dry matter, organic matter and crude protein was lower whereas the apparent faecal digestibility of fat was higher. As mentioned above, in our study maize starch was replaced with fat (soy oil and palm oil), oat hulls and wheat straw pellets. It may therefore be concluded that the decrease in apparent faecal digestibility in the fat diet is due to the higher NSP content in the fat diets and not to the higher fat content per se.

In LSC pigs, the mean percentage of pigs with diarrhoea during the overall GF period was lower on the fat diet than on the starch diet. In HSC pig, the mean percentage of pigs with diarrhoea was similar on the starch and fat diet. The higher NSP content in the fat diet may play a role. The inclusion of dietary fibre (especially fermentable NSP) in the diet influences the composition and activity of microbiota in the GIT (Williams et al., 2001), which may provide some protection against intestinal disorders (Jha and Berrocoso, 2012). Molist et al. (2009) showed that diets with a higher amount of insoluble NSP or a combination of insoluble and soluble NSP promote a beneficial shift in the microbial colonization, with a higher butyric acid production in the large intestine and lower enterobacteria counts in the digesta. Similarly, Gerritsen et al. (2012) reported that the inclusion of insoluble NSP in the diet 
decreases the number of E. coli in the ileum and colon digesta. Moreover, Mateos et al. (2006) showed that the inclusion of up to $4 \%$ oat hulls into a low-fibre diet reduced diarrhoea in weaned piglets from 21 to $41 \mathrm{~d}$ after weaning. So, the high level of NSP in the fat diet may have reduced the number of pigs with diarrhoea. 


\section{$5 \quad$ Conclusions}

The aim of the present study was to evaluate the effects of dietary energy source and of increasing dietary concentration of energy and EAA on the growth performance of growing-finishing kept under low (LSC) and high sanitary conditions (HSC). The main conclusions are:

Sanitary conditions:

- $\quad$ From weaning till day 35 after weaning, HSC piglets showed a 4\% higher ADFI and ADG than LSC piglets. Moreover, the number of culled piglets was lower in HSC piglets.

- During the GF phase (from start till slaughter), the performance of both the LSC and HSC pigs was very high (HSC pigs: ADG $1080 \mathrm{~g} / \mathrm{d}$, ADFI $2.36 \mathrm{~g} / \mathrm{d}$, FCR 2.19; LSC pigs: ADG $1033 \mathrm{~g} / \mathrm{d}$, ADFI $2.28 \mathrm{~kg} / \mathrm{d}$, FCR 2.21).

- Despite the contrast in cleaning-, vaccination- and hygiene protocol, only relatively small differences in degree of activation of the immune system between HSC and LSC pigs were observed.

- $\quad$ HSC GF pigs showed a numerically $4 \%$ higher ADFI $(0.08 \mathrm{~kg} / \mathrm{d})$ and ADG $(47 \mathrm{~g} / \mathrm{d})$ than LSC GF pigs, whereas FCR was similar in HSC and LSC GF pigs. The coefficient of variance (CV) in body weight was lower in HSC than LSC GF pigs at day 35 and 63.

- $\quad$ During the grower phase apparent faecal N digestibility was lower in LSC than HSC pigs (78.4 vs $79.5 \%$ ). During the starter and finisher phase, $\mathrm{N}$ digestibility was similar in HSC and LSC pigs. During the starter phase apparent faecal digestibility of energy was lower in LSC than HSC pigs ( 83.2 vs $84.1 \%$ ). During the grower and finisher phase, energy digestibility was similar in HSC and LSC pigs.

- $\quad$ The number of veterinary treated GF pigs tended to be lower in HSC than LSC pigs (4.4 vs $8.5 \%$ of the pigs). Moreover, in week 1, 3, 5 and 7 the percentage of GF pigs with diarrhoea was numerically lower in HSC than LSC pigs (2.3 vs $10.4 \%$ ).

Increased dietary energy and amino acid content and interaction with sanitary conditions:

- $\quad$ The increased energy and amino acid content in the diet increased ADG (1075 vs $1039 \mathrm{~g} / \mathrm{d}$ ) and average daily energy intake ( 2.74 vs $2.58 \mathrm{EW} / \mathrm{d}$ ), whereas ADFI was not affected by energy and amino acid content of the diet.

- $\quad$ The increase in ADG from start till day 98 on the I diet compared to the B diet was $62 \mathrm{~g} / \mathrm{d}$ in LSC pigs, whereas it was $21 \mathrm{~g} / \mathrm{d}$ in HSC pigs.

- $\quad$ On the B diet, LSC pigs grew $68 \mathrm{~g} / \mathrm{d}(6.4 \%)$ less than HSC pigs, whereas on the I diet, LSC pigs grew $26 \mathrm{~g} / \mathrm{d}(2.4 \%)$ less.

- $\quad$ The energy intake on the I diet compared to the B diet was $0.23 \mathrm{EW} / \mathrm{d}$ higher in LSC pigs and $0.12 \mathrm{EW} / \mathrm{d}$ in HSC pigs.

- $\quad$ On the B diet, LSC pigs ate $0.17 \mathrm{EW} / \mathrm{d}(6.4 \%)$ less than HSC pigs, whereas on the I diet, LSC pigs ate $0.06 \mathrm{EW} / \mathrm{d}(2.2 \%)$ less.

- $\quad$ Feed conversion ratio was better but energy conversion ratio (ECR) was worse in pigs fed the I diet. The effects on FCR and ECR were similar in LSC and HSC pigs.

- In both the starter, grower and finisher diets, the apparent faecal digestibility of dry matter, ash, organic matter, crude protein, fat (only grower and finisher diet) and energy were higher for the I diets than for the $B$ diets.

Dietary energy source:

- $\quad$ ADG was higher (1078 vs $1036 \mathrm{~g} / \mathrm{d}$ ) and ADFI (2.35 vs $2.29 \mathrm{~kg} / \mathrm{d}$ ) and average daily energy intake (ADEI) (2.70 vs $2.62 \mathrm{EW} / \mathrm{d}$ ) tended to be higher in pigs fed the starch based diets than in pigs fed the fat based diets. Feed conversion ratio and energy conversion ratio (ECR) were not affected by dietary energy source.

- There was no significant interaction between dietary energy source and sanitary conditions for any of the performance parameters which means that the effect of dietary energy source on performance was similar in LSC and HSC pigs. 
- Apparent faecal digestibility of dry matter, organic matter, ash, crude protein, starch and energy were higher for the starch diets than for the fat diets. The digestibility of fat was lower for the starch based diets.

Overall, it can be concluded that an increase in contents of dietary energy and essential amino acids (Lys, Met, Thr, Trp, Val and Ile) increases growth performance and energy intake more in LSC than in HSC pigs. Compared with studies in which only EAA were supplemented to the diet without increasing dietary energy content, it seems that dietary supplementation of both EAA and energy is more effective in increasing performance of LSC pigs than dietary supplementation of EAA alone. This suggests opportunities to at least partly compensate for the reduction in growth performance in pigs kept under low sanitary conditions and/or sub-optimal health condition by modification of the energy and EAA composition of the diet. Partly replacing dietary starch with fat does not seem an interesting approach to increase the performance of the LSC GF pigs. 


\section{References}

AgroVision. 2017. Kengetallenspiegel 2016. Bedrijfsvergelijking AgroVision B.V.

Bakker. 1996. Interaction between carbohydrates and fat in pigs - Impact on energy evaluation of feeds. PhD Dissertation, Wageningen University, Wageningen, the Netherlands.

Butcher, G.D. and R.D. Miles. 2002. Interrelationship of nutrition and immunity. VM139. University of Florida, IFAS extension. Available online at www.edis.ifas.ufl.edu (accessed 21 April 2010).

Capozzalo, M.M., J.C. Kim, J.K. Htoo, C.F.M. de Lange, B.P. Mullan, C.F. Hansen, J.W. Resink and J.R. Pluske. 2017. Pigs experimentally infected with an enterotoxigenic strain of Escherichia coli have improved feed efficiency and indicators of inflammation with dietary supplementation of tryptophan and methionine in the immediate post-weaning period. Animal Production Science, 57, 935-947.

Centraal Veevoederbureau. 2008. Tabellenboek veevoeding. CVB-reeks nr. 46.

Daiwen, C. Z. Keying, and W. Chunyan. 2008. Influences of lipopolysaccharide-induced immune challenge on performance and whole-body protein turnover in weanling pigs. Livestock Science, 113, 291-295.

GenStat. 2018. GenStat for Windows 18th Edition. VSN International Ltd. Hemel Hempstead, UK.

Gerritsen, R., P. van der Aar, P. and F. Molist. 2012. Insoluble nonstarch polysaccharides in diets for weaned piglets. Journal of Animal Science, 90, 318-320.

Jha, R. and J.F.D. Berrocoso, 2012. Dietary fiber and protein fermentation in the intestine of swine and their interactive effects on gut health and on the environment: A review. Animal Feed Science and Technology 212, 18-26.

Kampman-van de Hoek, E. 2015. Impact of health status on amino acid requirements of growing pigs: Towards feeding strategies for farms differing in health status. PhD Dissertation, Wageningen University, Wageningen, the Netherlands.

Klasing, K.C. and B.J. Johnstone. 1991. Monokines in growth and development. Poultry Science, 70, 1781-1789.

Koinig, H.C., S.C. Talker, M. Stadler, A. Ladinig, R. Graage, M. Ritzmann, I. Hennig-Pauka, W. Gerner and A. Saalmüller. 2015. PCV2 vaccination induces IFN-Y/TNF-a co-producing T cells with a potential role in protection. Veterinary Research, 46, 20-33.

Le Floc'h, N. 2006. Gepubliceerd in Orffa "Invloed van de gezondheidsstatus en het verbod op AMGB op de aminozuurbehoefte van varkens".

Le Floc'h, N., D. Melchior and C. Obled. 2004. Modifications of protein and amino acid metabolism during inflammation and immune system activation. Livestock Production Science, 87, 37-45.

Le Floc'h, N., D. Melchior, and B. Sève. 2008. Dietary tryptophan helps to preserve tryptophan homeostasis in pigs suffering from lung inflammation. Journal of Animal Science, 86, 3473-3479.

Le Floc'h, N., L. LeBellego, J.J. Matte, D. Melchior, and B. Sève. 2009. The effect of sanitary status degradation and dietary tryptophan content on growth rate and tryptophan metabolism in weaning pigs. Journal of Animal Science, 87, 1686-1694.

Le Floc'h, N., C. Knudsen, T. Gidenne, L. Montagne, E. Merlot and O. Zemb. 2014. Impact of feed restriction on health, digestion and faecal microbiota of growing pigs housed in good or poor hygiene conditions. Animal, 8, 1632-1642.

Martinez-Trejo, G., M.E. Ortega-Cerrilla, L.F. Rodarte-Covarrubias, J.G. Herrera-Haro, J.L. FigueroaVelasco, F. Galindo-Maldonado, O. Sánchez-Martinez and A. Lara-Bueno. 2009. Aggressiveness and productive performance of piglets supplemented with tryptophan. Journal of Animal and Veterinary Advances, 8, 4, 608-611.

Mateos, G.G., F. Martin, M.A. Latorre, B. Vicente and R. Lazaro. 2006. Inclusion of oat hulls in diets for young pigs based on cooked maize or cooked rice. Animal, 82, 57-63.

McIntyre, J. and S.A. Edwards. 2000a. An investigation into the effect of tryptophan on tail chewing behaviour of growing pigs. In: Proceedings of the British Society of Animal Science, 34.

Molist, F., A. Gómez de Segura, J. Gasa, R.G. Hermes, E.G. Manzanilla, M. Anguita and J.F. Pérez. 2009. Effects of the insoluble and soluble dietary fibre on thephysicochemical properties of digesta and the microbial activity in early weaned piglets. Animal Feed Science and Technololgy, 149, 346353.

Myers, W.D., P.A. Ludden, V. Nayigihugu, and B.W. Hess. 2004. Technical Note: A procedure for the preparation and quantitative analysis of samples for titanium dioxide. Journal of Animal Science, $82,179-183$.

Oude Voshaar. 1994. Statistiek voor onderzoekers. Wageningen Pers, Wageningen. 
Pastorelli, H., J. van Milgen, P. Lovatto, and L. Montagne. 2012. Meta-analysis of feed intake and growth responses of growing pigs after a sanitary challenge. Animal, 6, 952-961.

Petersen, H.H., A.K. Ersboll, C.S. Jensen and J.P. Nielsen. 2002. Serum-haptoglobin concentration in Danish slaughter pigs of different health status. Preventive Veterinary Medicine, 54, 325-335.

Piñeiro, C., M. Piñeiro, J. Morales, M. Andrés, E. Lorenzo, M. del Pozo, M.A. Alava and F. Lampreave. 2009. Pig-MAP and haptoglobin concentration reference values in swine from commercial farms. The Veterinary Journal, 179, 78-84.

Piñeiro, M., J. Morales, E. Vizcaíno, J.A. Murillo, Th. Klauke, B.Petersen, C.Piñeiro. 2013. The use of acute phase proteins for monitoring animal health and welfare in the pig production chain: The validation of an immunochromatographic method for the detection of elevated levels of pig-MAP. Meat Science, 95, 712-718.

Pluk, P. and M. van Krimpen. 2018. Effect of reducing dietary crude protein in hog finisher barrows and gilts on technical performance. Report 1111, Wageningen Liverstock Research, Wageningen.

Riedel, W.J., T. Klaassen and J.A.J. Schmitt. 2002. Tryptophan, mood, and cognitive function. Brain Behavior and Immunity, 16, 581-589.

Rijnen, M.M.J.A. 2003. Energetic utilization of dietary fiber in pigs. PhD Dissertation, Wageningen University, Wageningen, the Netherlands.

Spitzer, J.A. and J.J. Spitzer. 1983. Effect of LPS on Carbohydrate and Lipid Metabolism. In: Nowotny A. (eds) Beneficial Effects of Endotoxins. Springer, Boston, MA, USA.

Spurlock, M.E. 1997. Regulation of metabolism and growth during immune challenge: an overview of cytokine function. Journal of Animal Science, 75, 1773-1783.

Trevisi, P., D. Melchior, M. Mazzoni, L. Casini, S. De Filippi, L. Minieri, G. Lalatta-Costerbosa and P. Bosi. 2009. A tryptophan-enriched diet improves feed intake and growth performance of susceptible weanling pigs orally challenged with Escherichia coli K88. Journal of Animal Science, $87,148-156$.

Van der Meer, Y., A. Lammers, A.J.M. Jansman, M.M.J.A. Rijnen, W.H. Hendriks, and W.J.J. Gerrits. 2016. Performance of pigs kept under different sanitary conditions affected by protein intake and amino acid supplementation., Journal of Animal Science, 94, 4704-4719.

Van der Meer, Y. 2017. Nutrition of pigs kept under low and high sanitary conditions. PhD Dissertation, Wageningen University, Wageningen, the Netherlands.

Van der Meer, Y., W.J.J. Gerrits, A.J.M. Jansman, B. Kemp and J.E. Bolhuis. 2017. A link between damaging behaviour in pigs, sanitary conditions, and dietary protein and amino acid supply. PLoS one, 12, e0174688.

Van der Peet-Schwering, C.M.C. and P. Bikker. 2018. Amino acid requirement of growing and finishing pigs. Report 1101, Wageningen Livestock Research, Wageningen.

Van der Peet-Schwering, C.M.C., N. Dirx, M. Kluivers-Poodt, G.P. Binnendijk, J.E. Bolhuis and G.F.V. van der Peet. 2017. Effect van voersamenstelling op bijtgedrag bij varkens. Report 1008, Wageningen Livestock Research, Wageningen.

Van der Peet-Schwering, C.M.C., S.J. Koopmans and A.J.M. Jansman. 2019. Amino acid requirements in relation to health status in growing and finishing pigs. Report 1168, Wageningen Liverstock Research, Wageningen.

Van der Peet-Schwering, C.M.C., J.P. Plagge and G.P. Binnendijk. 2006. Effect van verzadigend voer en ruwvoer op de slachtkwaliteit van biologische varkens. Rapport 05, Wageningen Liverstock Research, Wageningen.

Van Heugten, E., M.T. Coffey and J.W. Spears. 1996. Effects of immune challenge, dietary energy density and source of energy on performance and immunity in weanling pigs. Journal of Animal Science, 74, 2431-2440.

Van Vuuren, A.M., C J. van der Koelen, H. Valk and H. de Visser. 1993. Effects of partial replacement of ryegrass by low protein feeds on rumen fermentation and nitrogen loss by dairy cows. Journal of Dairy Science, 76, 2982-2993.

Webel, D.M. , R.W. Johnson and D.H. Baker. 1998. Lipopolysaccharide-induced reduction s in food intake do not decrease the efficiency of lysine and threonine utilization for protein accretion in chickens. Journal of Nutrition, 128, 1760-1766.

Williams, N.H., T.S. Stahly and D.R. Zimmerman. 1997a. Effect of chronic immune system activation on body nitrogen retention, partial efficiency of lysine uitlization, and lysine needs of pigs. Journal of Animal Science, 75, 2472-2480.

Williams, N.H., T.S. Stahly and D.R. Zimmerman. 1997b. Effect of level of chronic immune system activation on the growth and dietary lysine needs of pigs fed from 6 to $112 \mathrm{~kg}$. Journal of Animal Science, 75, 2481-2496.

Williams, B.A., M.W.A. Verstegen and S. Tamminga. 2001. Fermentation in the large intestine of single-stomached animals and its relationship to animalhealth. Nutrition Research Reviews, 14, 207-227. 
Zonderland, J.J. 2010. Talking tails - Quantifying the development of tail biting in pigs. PhD Dissertation, Wageningen University, Wageningen, The Netherlands. 


\section{Appendix 1 Composition of the experimental diets}

\section{Starter diets}

\section{Energy source \\ Energy and AA content}

Maize

Wheat

Barley

Soybean meal

Molasses, cane

Maize starch

Soy oil

Palm oil

Oat hulls pellets

Wheat straw pellets

Diamol

Limestone

Monocalcium phosphate

Salt

Sodiumbicarbonate

Premix

Titanium dioxide

L-Lysine $\mathrm{HCl}$

DL-Methionine

L-Threonine

L-Tryptophan

L-Isoleucine

L-Valine

\section{Calculated content}

Dry matter

Ash

Crude protein

Crude fat

C18:2

Crude fibre

Starch

Sugar

NSP

Digestible crude protein

Digestible crude fat

Digestible NSP

EW

NEv

$\mathrm{Ca}$

$P$

Digestible $P$

$\mathrm{Ca} / \mathrm{dP}$

$\mathrm{Na}$

$\begin{array}{rrrr}\begin{array}{r}\text { Starch } \\ \text { Basal }\end{array} & \begin{array}{r}\text { Starch } \\ \text { Increased }\end{array} & \begin{array}{r}\text { Fat } \\ \text { Basal }\end{array} & \begin{array}{r}\text { Fat } \\ \text { Increased } \\ \text { \% }\end{array} \\ \text { \% } & \text { \% } & \text { \% } \\ 35.00 & 34.65 & 37.17 & 37.03 \\ 8.50 & 8.40 & 9.03 & 9.00 \\ 1.20 & 1.19 & 1.27 & 1.27 \\ 22.51 & 22.51 & 21.66 & 21.66 \\ 2.00 & 2.00 & 2.00 & 2.00 \\ 20.00 & 23.16 & 0.00 & 4.00 \\ 1.00 & 2.05 & 4.51 & 5.45 \\ 0.00 & 0.00 & 2.00 & 1.83 \\ 0.00 & 0.00 & 6.08 & 4.92 \\ 0.00 & 0.00 & 6.08 & 4.93 \\ 4.84 & 0.43 & 5.50 & 2.50 \\ 1.49 & 1.60 & 1.46 & 1.58 \\ 1.22 & 1.34 & 1.21 & 1.33 \\ 0.30 & 0.26 & 0.31 & 0.27 \\ 0.27 & 0.33 & 0.04 & 0.14 \\ 0.50 & 0.50 & 0.50 & 0.50 \\ 0.25 & 0.25 & 0.25 & 0.25 \\ 0.42 & 0.53 & 0.43 & 0.54 \\ 0.19 & 0.28 & 0.19 & 0.28 \\ 0.20 & 0.27 & 0.20 & 0.27 \\ 0.05 & 0.09 & 0.05 & 0.09 \\ 0.00 & 0.03 & 0.00 & 0.03 \\ 0.06 & 0.13 & 0.06 & 0.13\end{array}$

883

107

157

33

14

18

447

38

103

132

26

34

1.12

9.84

8.50

5.51

3.13

2.71

2.00
880

65

160

43

19

18

470

38

104

134

36

34

1.20

10.54

9.11

5.78

3.36

2.71

2.00
890

118

159

90

35

62

300

38

187

131

77

44

1.12

9.84

8.51

5.53

3.13

2.71

1.50 at

$\%$

9.00

1.27

2.00

4.00

5.45

1.83

4.92

4.93

2.50

0.27

0.14

0.50

0.25

0.27

0.09

0.13

888

90

161

98

39

54

332

38

172

133

84

43

1.20

10.54

9.11

5.80

3.36

2.71

1.64 


\begin{tabular}{|c|c|c|c|c|c|}
\hline K & $g$ & 7.33 & 7.31 & 8.43 & 8.20 \\
\hline $\mathrm{Cl}$ & $\mathrm{g}$ & 3.27 & 3.26 & 3.50 & 3.50 \\
\hline EB & $\mathrm{kg}$ & 182 & 182 & 182 & 182 \\
\hline $\mathrm{Fe}$ & $\mathrm{mg}$ & 193 & 192 & 212 & 208 \\
\hline $\mathrm{Cu}$ & $\mathrm{mg}$ & 24 & 24 & 27 & 27 \\
\hline $\mathrm{Zn}$ & $\mathrm{mg}$ & 94 & 94 & 101 & 100 \\
\hline LYS & $\mathrm{g}$ & 11.1 & 11.9 & 11.1 & 12.0 \\
\hline MET & $\mathrm{g}$ & 4.2 & 5.0 & 4.2 & 5.0 \\
\hline CYS & g & 2.5 & 2.5 & 2.6 & 2.5 \\
\hline$M+C$ & $\mathrm{~g}$ & 6.7 & 7.5 & 6.7 & 7.6 \\
\hline THR & $\mathrm{g}$ & 7.5 & 8.2 & 7.5 & 8.2 \\
\hline TRP & $g$ & 2.2 & 2.6 & 2.3 & 2.6 \\
\hline ILE & $\mathrm{g}$ & 6.3 & 6.6 & 6.3 & 6.5 \\
\hline ARG & $\mathrm{g}$ & 10.0 & 9.9 & 9.9 & 9.9 \\
\hline PHE & $\mathrm{g}$ & 7.5 & 7.5 & 7.5 & 7.5 \\
\hline HIS & $\mathrm{g}$ & 4.0 & 4.0 & 4.0 & 4.0 \\
\hline LEU & $\mathrm{g}$ & 12.5 & 12.5 & 12.6 & 12.6 \\
\hline TYR & $\mathrm{g}$ & 5.4 & 5.3 & 5.4 & 5.3 \\
\hline VAL & $\mathrm{g}$ & 7.6 & 8.3 & 7.7 & 8.3 \\
\hline ALA & $\mathrm{g}$ & 7.3 & 7.3 & 7.4 & 7.4 \\
\hline ASP & $\mathrm{g}$ & 15.3 & 15.3 & 15.2 & 15.1 \\
\hline GLU & g & 27.7 & 27.6 & 27.9 & 27.8 \\
\hline GLY & $\mathrm{g}$ & 6.2 & 6.2 & 6.3 & 6.2 \\
\hline PRO & $\mathrm{g}$ & 9.2 & 9.2 & 9.3 & 9.3 \\
\hline SER & $\mathrm{g}$ & 7.4 & 7.4 & 7.4 & 7.4 \\
\hline Sum_AA & $g$ & 153.7 & 157.0 & 154.2 & 157.4 \\
\hline SID LYS & $\mathrm{g}$ & 10.19 & 11.07 & 10.19 & 11.07 \\
\hline SID MET & $\mathrm{g}$ & 4.00 & 4.82 & 3.97 & 4.80 \\
\hline SID CYS & $\mathrm{g}$ & 2.13 & 2.12 & 2.15 & 2.14 \\
\hline SID $M+C$ & $\mathrm{~g}$ & 6.12 & 6.94 & 6.12 & 6.94 \\
\hline SID THR & g & 6.73 & 7.46 & 6.73 & 7.46 \\
\hline SID TRP & $\mathrm{g}$ & 2.04 & 2.37 & 2.04 & 2.37 \\
\hline SID ILE & g & 5.65 & 5.92 & 5.60 & 5.87 \\
\hline SID ARG & $\mathrm{g}$ & 9.32 & 9.30 & 9.22 & 9.20 \\
\hline SID PHE & $\mathrm{g}$ & 6.76 & 6.75 & 6.74 & 6.72 \\
\hline SID HIS & $\mathrm{g}$ & 3.63 & 3.62 & 3.62 & 3.61 \\
\hline SID LEU & g & 11.10 & 11.06 & 11.14 & 11.11 \\
\hline SID TYR & $\mathrm{g}$ & 4.79 & 4.78 & 4.77 & 4.76 \\
\hline SID VAL & $\mathrm{g}$ & 6.83 & 7.47 & 6.83 & 7.47 \\
\hline SID ALA & g & 6.40 & 6.38 & 6.44 & 6.42 \\
\hline SID ASP & $g$ & 13.48 & 13.46 & 13.28 & 13.25 \\
\hline SID GLU & $\mathrm{g}$ & 25.59 & 25.51 & 25.64 & 25.57 \\
\hline SID GLY & $\mathrm{g}$ & 5.78 & 5.77 & 5.75 & 5.74 \\
\hline SID PRO & $\mathrm{g}$ & 8.53 & 8.49 & 8.59 & 8.57 \\
\hline SID SER & $\mathrm{g}$ & 6.73 & 6.71 & 6.70 & 6.69 \\
\hline
\end{tabular}




\section{Grower diets}

\section{Energy source \\ Energy and AA content}

Maize

Wheat

Barley

Soybean meal

Molasses, cane

Maize starch

Soy oil

Palm oil

Oat hulls pellets

Wheat straw pellets

Diamol

Limestone

Monocalcium phosphate

Salt

Sodiumbicarbonate

Premix

Titanium dioxide

L-Lysine $\mathrm{HCl}$

DL-Methionine

L-Threonine

L-Tryptophan

L-Isoleucine

L-Valine

\section{Calculated content}

\section{Dry matter}

Ash

Crude protein

Crude fat

C18:2

Crude fibre

Starch

Sugar

NSP

Digestible crude protein

Digestible crude fat

Digestible NSP

EW

NEv

$\mathrm{Ca}$

$\mathrm{P}$

Digestible $P$

$\mathrm{Ca} / \mathrm{dP}$

$\mathrm{Na}$

$\mathrm{K}$

$\mathrm{Cl}$

EB

$\mathrm{Fe}$

$\mathrm{Cu}$

$\mathrm{Zn}$

LYS

MET

$\begin{array}{rrrr}\begin{array}{r}\text { Starch } \\ \text { Basal }\end{array} & \begin{array}{r}\text { Starch } \\ \text { Increased }\end{array} & \begin{array}{r}\text { Fat } \\ \text { Basal }\end{array} & \begin{array}{r}\text { Fat } \\ \text { Increased } \\ \text { \% }\end{array} \\ \mathbf{\%} & \% & 31.25 \\ 30.00 & 30.30 & 30.08 & 9.80 \\ 9.41 & 9.50 & 9.44 & 9.38 \\ 9.00 & 9.09 & 9.02 & 21.21 \\ 22.55 & 22.55 & 21.21 & 2.00 \\ 2.00 & 2.00 & 2.00 & 2.19 \\ 17.50 & 20.21 & 0.00 & 4.85 \\ 0.50 & 1.41 & 4.12 & 2.00 \\ 0.00 & 0.00 & 2.00 & 5.23 \\ 0.00 & 0.00 & 6.41 & 5.22 \\ 0.00 & 0.00 & 6.41 & 2.50 \\ 5.13 & 0.49 & 5.50 & 1.32 \\ 1.25 & 1.35 & 1.22 & 1.03 \\ 0.92 & 1.03 & 0.93 & 0.32 \\ 0.34 & 0.31 & 0.36 & 0.09 \\ 0.20 & 0.25 & 0.00 & 0.50 \\ 0.50 & 0.50 & 0.50 & 0.25 \\ 0.25 & 0.25 & 0.25 & 0.36 \\ 0.22 & 0.32 & 0.26 & 0.18 \\ 0.11 & 0.17 & 0.12 & 0.17 \\ 0.10 & 0.16 & 0.11 & 0.04 \\ 0.02 & 0.04 & 0.02 & 0.02 \\ 0.00 & 0.00 & 0.02 & 0.09 \\ 0.00 & 0.07 & 0.02 & \end{array}$

884

105

156

28

11

21

443

40

113

131

21

40

1.10

9.67

7.14

5.00

2.64

2.71

2.00

7.59

3.23

190

170

15

75

9.7

3.4

$\begin{array}{rrr}880 & 891 & 888 \\ 61 & 114 & 85 \\ 159 & 154 & 158 \\ 37 & 86 & 93 \\ 16 & 32 & 36 \\ 21 & 67 & 59 \\ 469 & 301 & 330 \\ 40 & 39 & 39 \\ 115 & 199 & 185 \\ 133 & 127 & 130 \\ 30 & 72 & 80 \\ 40 & 49 & 49 \\ 1.18 & 1.10 & 1.18 \\ 10.37 & 9.67 & 10.37 \\ 7.66 & 7.15 & 7.66 \\ 5.25 & 4.96 & 5.23 \\ 2.83 & 2.64 & 2.83 \\ 2.71 & 2.71 & 2.71 \\ 2.00 & 1.61 & 1.70 \\ 7.61 & 8.56 & 8.40 \\ 3.24 & 3.50 & 3.50 \\ 190 & 190 & 190 \\ 170 & 188 & 185 \\ 15 & 18 & 17 \\ 76 & 82 & 81 \\ 10.5 & 9.7 & 10.5 \\ 4.1 & 3.5 & 4.1\end{array}$




$\begin{array}{llrrrr}\text { CYS } & \mathrm{g} & 2.6 & 2.6 & 2.6 & 2.6 \\ \text { M+C } & \mathrm{g} & 6.0 & 6.7 & 6.0 & 6.7 \\ \text { THR } & \mathrm{g} & 6.6 & 7.2 & 6.6 & 7.2 \\ \text { TRP } & \mathrm{g} & 2.0 & 2.2 & 2.0 & 2.2 \\ \text { ILE } & \mathrm{g} & 6.4 & 6.4 & 6.4 & 6.4 \\ \text { ARG } & \mathrm{g} & 10.1 & 10.1 & 9.8 & 9.9 \\ \text { PHE } & \mathrm{g} & 7.7 & 7.7 & 7.4 & 7.5 \\ \text { HIS } & \mathrm{g} & 4.0 & 4.0 & 3.9 & 4.0 \\ \text { LEU } & \mathrm{g} & 12.4 & 12.4 & 12.1 & 12.2 \\ \text { TYR } & \mathrm{g} & 5.4 & 5.4 & 5.3 & 5.3 \\ \text { VAL } & \mathrm{g} & 7.2 & 8.0 & 7.2 & 8.0 \\ \text { ALA } & \mathrm{g} & 7.3 & 7.3 & 7.1 & 7.2 \\ \text { ASP } & \mathrm{g} & 15.5 & 15.5 & 14.9 & 15.0 \\ \text { GLU } & \mathrm{g} & 28.7 & 28.8 & 28.0 & 28.3 \\ \text { GLY } & \mathrm{g} & 6.3 & 6.4 & 6.2 & 6.2 \\ \text { PRO } & \mathrm{g} & 9.6 & 9.7 & 9.4 & 9.6 \\ \text { SER } & \mathrm{g} & 7.5 & 7.5 & 7.3 & 7.4 \\ \text { SUm_AZ } & \mathrm{g} & 152.0 & 155.4 & 149.0 & 153.1 \\ & & & & & \\ \text { SID LYS } & \mathrm{g} & 8.80 & 9.65 & 8.80 & 9.65 \\ \text { SID MET } & \mathrm{g} & 3.19 & 3.85 & 3.23 & 3.89 \\ \text { SID CYS } & \mathrm{g} & 2.18 & 2.19 & 2.14 & 2.16 \\ \text { SID M+C } & \mathrm{g} & 5.37 & 6.05 & 5.37 & 6.05 \\ \text { SID THR } & \mathrm{g} & 5.90 & 6.50 & 5.90 & 6.50 \\ \text { SID TRP } & \mathrm{g} & 1.76 & 1.95 & 1.76 & 1.95 \\ \text { SID ILE } & \mathrm{g} & 5.73 & 5.73 & 5.73 & 5.73 \\ \text { SID ARG } & \mathrm{g} & 9.44 & 9.46 & 9.08 & 9.14 \\ \text { SID PHE } & \mathrm{g} & 6.88 & 6.90 & 6.65 & 6.71 \\ \text { SID HIS } & \mathrm{g} & 3.66 & 3.67 & 3.53 & 3.57 \\ \text { SID LEU } & \mathrm{g} & 10.97 & 11.00 & 10.64 & 10.76 \\ \text { SID TYR } & \mathrm{g} & 4.84 & 4.85 & 4.68 & 4.72 \\ \text { SID VAL } & \mathrm{g} & 6.39 & 7.14 & 6.39 & 7.14 \\ \text { SID ALA } & \mathrm{g} & 6.40 & 6.42 & 6.21 & 6.29 \\ \text { SID ASP } & \mathrm{g} & 13.59 & 13.62 & 13.03 & 13.10 \\ \text { SID GLU } & \mathrm{g} & 26.57 & 26.66 & 25.80 & 26.09 \\ \text { SID GLY } & \mathrm{g} & 5.92 & 5.93 & 5.73 & 5.77 \\ \text { SID PRO } & \mathrm{g} & 8.96 & 9.00 & 8.73 & 8.86 \\ \text { SID SER } & \mathrm{g} & 6.83 & 6.84 & 6.59 & 6.65 \\ & & & & & \end{array}$




\section{Finisher diets}

\section{Energy source \\ Energy and AA content}

Maize

Wheat

Barley

Soybean meal

Molasses, cane

Maize starch

Soy oil

Palm oil

Oat hulls pellets

Wheat straw pellets

Diamol

Limestone

Monocalcium phosphate

Salt

Sodiumbicarbonate

Premix

Titanium dioxide

L-Lysine $\mathrm{HCl}$

DL-Methionine

L-Threonine

L-Tryptophan

L-Isoleucine

L-Valine

\section{Calculated content}

Dry matter

Ash

Crude protein

Crude fat

C18:2

Crude fibre

Starch

Sugar

NSP

Digestible crude protein

Digestible crude fat

Digestible NSP

EW

NEv

$\mathrm{Ca}$

$\mathrm{P}$

Digestible $P$

$\mathrm{Ca} / \mathrm{dP}$

$\mathrm{Na}$

$\mathrm{K}$

$\mathrm{Cl}$

EB

$\mathrm{Fe}$

$\mathrm{Cu}$

$\mathrm{Zn}$

LYS

MET

$\begin{array}{rrrr}\begin{array}{r}\text { Starch } \\ \text { Basal }\end{array} & \begin{array}{r}\text { Starch } \\ \text { Increased }\end{array} & \begin{array}{r}\text { Fat } \\ \text { Basal }\end{array} & \begin{array}{r}\text { Fat } \\ \text { Increased } \\ \text { \% }\end{array} \\ \text { \% } & \text { \% } & 27.62 \\ 28.10 & 28.10 & 27.65 & 11.21 \\ 11.40 & 11.40 & 11.22 & 10.81 \\ 11.00 & 11.00 & 10.83 & 19.95 \\ 21.05 & 21.05 & 19.95 & 2.00 \\ 2.00 & 2.00 & 2.00 & 3.11 \\ 17.00 & 19.95 & 0.00 & 5.23 \\ 0.50 & 1.50 & 4.20 & 2.00 \\ 0.00 & 0.00 & 2.00 & 5.65 \\ 0.00 & 0.00 & 6.45 & 5.65 \\ 0.00 & 0.00 & 6.44 & 3.00 \\ 5.59 & 1.19 & 6.00 & 1.15 \\ 1.10 & 1.18 & 1.06 & 0.79 \\ 0.70 & 0.79 & 0.70 & 0.35 \\ 0.34 & 0.30 & 0.38 & 0.09 \\ 0.21 & 0.26 & 0.00 & 0.50 \\ 0.50 & 0.50 & 0.50 & 0.25 \\ 0.25 & 0.25 & 0.25 & 0.27 \\ 0.13 & 0.23 & 0.17 & 0.14 \\ 0.07 & 0.13 & 0.08 & 0.13 \\ 0.06 & 0.12 & 0.07 & 0.03 \\ 0.00 & 0.02 & 0.01 & 0.02 \\ 0.00 & 0.00 & 0.02 & 0.05 \\ 0.00 & 0.03 & 0.02 & \end{array}$

884

105

150.2

28

11

21

450

39

113

126

21

41

1.10

9.67

6.16

4.46

2.20

2.80

2.00

7.37

3.03

190

167

14

75

8.7

2.9
880
63

152.4

38

16

22

474

39

115

127

30

41

1.18

10.37

6.60

4.67

2.36

2.80

2.00

7.38

3.03

190

167

14

75

9.5

3.5

$\begin{array}{rr}891 & 889 \\ 115 & 86\end{array}$

$149.0 \quad 150.7$

$86 \quad 96$

$32 \quad 37$

$67 \quad 61$

$306 \quad 331$

$38 \quad 38$

$199 \quad 189$

$122 \quad 124$

$72 \quad 82$

$50 \quad 49$

$1.10 \quad 1.18$

$9.67 \quad 10.37$

$6.16 \quad 6.60$

$4.42 \quad 4.61$

$2.20 \quad 2.36$

$2.80 \quad 2.80$

$1.72 \quad 1.81$

$8.37 \quad 8.21$

$3.50 \quad 3.50$

$190 \quad 190$

$186 \quad 183$

$17 \quad 17$

$81 \quad 81$

$8.7 \quad 9.5$

$3.0 \quad 3.6$ 


\begin{tabular}{|c|c|c|c|c|c|}
\hline CYS & $g$ & 2.5 & 2.5 & 2.5 & 2.5 \\
\hline$M+C$ & $\mathrm{~g}$ & 5.5 & 6.1 & 5.5 & 6.1 \\
\hline THR & $\mathrm{g}$ & 6.0 & 6.7 & 6.0 & 6.6 \\
\hline TRP & $\mathrm{g}$ & 1.8 & 2.0 & 1.8 & 2.0 \\
\hline ILE & $\mathrm{g}$ & 6.2 & 6.2 & 6.2 & 6.2 \\
\hline ARG & $\mathrm{g}$ & 9.7 & 9.7 & 9.5 & 9.4 \\
\hline PHE & $g$ & 7.4 & 7.4 & 7.2 & 7.2 \\
\hline HIS & $\mathrm{g}$ & 3.9 & 3.9 & 3.8 & 3.8 \\
\hline LEU & $\mathrm{g}$ & 12.0 & 12.0 & 11.7 & 11.6 \\
\hline TYR & $g$ & 5.2 & 5.2 & 5.1 & 5.1 \\
\hline VAL & $\mathrm{g}$ & 7.0 & 7.3 & 7.0 & 7.3 \\
\hline ALA & $g$ & 7.0 & 7.0 & 6.9 & 6.8 \\
\hline ASP & $\mathrm{g}$ & 14.8 & 14.8 & 14.3 & 14.3 \\
\hline GLU & $\mathrm{g}$ & 28.3 & 28.3 & 27.6 & 27.5 \\
\hline GLY & $g$ & 6.2 & 6.2 & 6.0 & 6.0 \\
\hline PRO & $\mathrm{g}$ & 9.6 & 9.6 & 9.4 & 9.3 \\
\hline SER & $\mathrm{g}$ & 7.3 & 7.3 & 7.1 & 7.1 \\
\hline Sum_AZ & $\mathrm{g}$ & 146.0 & 148.5 & 143.2 & 145.4 \\
\hline SID LYS & $\mathrm{g}$ & 7.81 & 8.61 & 7.81 & 8.61 \\
\hline SID MET & $\mathrm{g}$ & 2.69 & 3.29 & 2.74 & 3.34 \\
\hline SID CYS & $\mathrm{g}$ & 2.15 & 2.15 & 2.10 & 2.09 \\
\hline SID $M+C$ & $\mathrm{~g}$ & 4.84 & 5.44 & 4.84 & 5.44 \\
\hline SID THR & $\mathrm{g}$ & 5.31 & 5.92 & 5.31 & 5.92 \\
\hline SID TRP & $g$ & 1.56 & 1.75 & 1.56 & 1.75 \\
\hline SID ILE & $\mathrm{g}$ & 5.52 & 5.52 & 5.52 & 5.52 \\
\hline SID ARG & $\mathrm{g}$ & 9.06 & 9.06 & 8.75 & 8.73 \\
\hline SID PHE & $\mathrm{g}$ & 6.66 & 6.66 & 6.45 & 6.44 \\
\hline SID HIS & $\mathrm{g}$ & 3.53 & 3.53 & 3.41 & 3.41 \\
\hline SID LEU & $\mathrm{g}$ & 10.58 & 10.58 & 10.26 & 10.24 \\
\hline SID TYR & $\mathrm{g}$ & 4.67 & 4.67 & 4.52 & 4.51 \\
\hline SID VAL & $\mathrm{g}$ & 6.19 & 6.46 & 6.19 & 6.46 \\
\hline SID ALA & $\mathrm{g}$ & 6.19 & 6.19 & 6.00 & 5.99 \\
\hline SID ASP & $\mathrm{g}$ & 12.97 & 12.97 & 12.49 & 12.47 \\
\hline SID GLU & $\mathrm{g}$ & 26.22 & 26.22 & 25.47 & 25.42 \\
\hline SID GLY & $\mathrm{g}$ & 5.74 & 5.74 & 5.57 & 5.56 \\
\hline SID PRO & $\mathrm{g}$ & 8.92 & 8.92 & 8.67 & 8.66 \\
\hline SID SER & $\mathrm{g}$ & 6.60 & 6.60 & 6.38 & 6.37 \\
\hline
\end{tabular}




\section{Appendix 2 Analysed nutrient composition of the experimental diets $(\mathrm{g} / \mathrm{kg})$}

\begin{tabular}{|c|c|c|c|c|c|c|c|c|c|c|c|c|}
\hline & \multicolumn{4}{|c|}{ Starter diet } & \multicolumn{4}{|c|}{ Grower diet } & \multicolumn{4}{|c|}{ Finisher diet } \\
\hline & \multicolumn{2}{|c|}{ Starch $^{1}$} & \multicolumn{2}{|c|}{ Fat $^{1}$} & \multicolumn{2}{|c|}{ Starch } & \multicolumn{2}{|c|}{ Fat } & \multicolumn{2}{|c|}{ Starch } & \multicolumn{2}{|c|}{ Fat } \\
\hline & $\mathrm{B}^{2}$ & $\mathrm{I}^{2}$ & B & I & B & I & B & I & B & I & B & I \\
\hline Dry matter & 884 & 887 & 893 & 893 & 886 & 886 & 899 & 895 & 890 & 889 & 900 & 903 \\
\hline Ash & 87 & 61 & 103 & 80 & 89 & 56 & 102 & 77 & 87 & 56 & 102 & 79 \\
\hline Nitrogen & 25.7 & 25.6 & 27.1 & 27.5 & 26.1 & 25.9 & 26.3 & 26.1 & 25.1 & 25.1 & 25.9 & 25.8 \\
\hline Crude protein & 160.5 & 160.2 & 169.2 & 171.8 & 162.9 & 161.6 & 164.6 & 163.1 & 156.7 & 156.8 & 161.6 & 161.2 \\
\hline Crude fat & 37 & 47 & 68 & 69 & 27 & 36 & 61 & 65 & 27 & 36 & 61 & 66 \\
\hline Starch & 428 & 440 & 314 & 341 & 429 & 465 & 314 & 338 & 440 & 463 & 330 & 347 \\
\hline Sugar & 41 & 40 & 42 & 42 & 43 & 42 & 44 & 44 & 43 & 43 & 44 & 44 \\
\hline Titanium & 1.88 & 1.79 & 2.07 & 1.81 & 1.94 & 1.76 & 2.05 & 1.90 & 2.01 & 1.79 & 2.10 & 1.94 \\
\hline $\mathrm{GE}(\mathrm{KJ} / \mathrm{g})$ & 15.47 & 16.29 & 16.33 & 16.86 & 15.25 & 16.17 & 16.31 & 16.72 & 15.38 & 16.13 & 16.30 & 16.91 \\
\hline LYS & 10.8 & 12.1 & 11.8 & 12.4 & 10.1 & 10.6 & 10.2 & 10.5 & 9.3 & 9.7 & 9.3 & 10.2 \\
\hline MET & 3.7 & 4.6 & 3.9 & 4.7 & 3.1 & 3.6 & 3.2 & 3.8 & 2.8 & 3.7 & 2.9 & 3.4 \\
\hline CYS & 2.5 & 2.4 & 2.5 & 2.6 & 2.6 & 2.5 & 2.5 & 2.6 & 2.5 & 2.8 & 2.6 & 2.8 \\
\hline THR & 7.1 & 7.9 & 7.8 & 8.0 & 6.3 & 6.8 & 6.4 & 7.0 & 5.8 & 6.3 & 5.8 & 6.6 \\
\hline TRP & 2.4 & 2.8 & 2.5 & 2.8 & 2.5 & 2.4 & 2.3 & 2.4 & 2.0 & 2.1 & 2.1 & 2.2 \\
\hline ILE & 6.5 & 6.9 & 7.1 & 7.0 & 6.8 & 6.7 & 7.0 & 6.6 & 6.7 & 6.6 & 6.9 & 6.9 \\
\hline ARG & 9.6 & 10.3 & 10.4 & 10.3 & 10.3 & 10.2 & 10.0 & 9.9 & 10.1 & 9.9 & 10.0 & 10.0 \\
\hline PHE & 7.6 & 7.7 & 8.2 & 8.2 & 8.0 & 7.8 & 8.1 & 7.7 & 7.6 & 7.4 & 7.8 & 8.0 \\
\hline HIS & 4.3 & 4.4 & 4.6 & 4.6 & 4.4 & 4.2 & 4.4 & 4.1 & 4.4 & 4.3 & 4.3 & 4.3 \\
\hline LEU & 12.3 & 12.8 & 13.6 & 13.1 & 12.5 & 12.4 & 12.5 & 12.1 & 12.0 & 11.9 & 12.1 & 12.3 \\
\hline TYR & 5.7 & 5.9 & 6.3 & 6.3 & 5.9 & 6.0 & 6.1 & 6.0 & 5.7 & 5.7 & 5.8 & 6.1 \\
\hline VAL & 7.6 & 8.5 & 8.3 & 8.6 & 7.4 & 7.9 & 7.6 & 7.9 & 7.3 & 7.4 & 7.5 & 7.8 \\
\hline ALA & 7.1 & 7.5 & 7.8 & 7.6 & 7.2 & 7.2 & 7.3 & 7.1 & 6.9 & 6.8 & 6.9 & 7.1 \\
\hline ASP & 14.2 & 15.0 & 15.7 & 15.0 & 15.1 & 14.9 & 14.9 & 14.3 & 14.6 & 14.3 & 14.4 & 14.6 \\
\hline GLU & 27.5 & 28.0 & 29.6 & 28.7 & 28.8 & 28.4 & 28.0 & 27.9 & 28.6 & 28.4 & 28.6 & 29.0 \\
\hline GLY & 6.1 & 6.2 & 6.6 & 6.4 & 6.3 & 6.2 & 6.3 & 6.1 & 6.2 & 6.1 & 6.2 & 6.3 \\
\hline PRO & 9.5 & 9.5 & 10.0 & 10.8 & 9.8 & 10.2 & 10.6 & 9.8 & 9.8 & 9.6 & 10.1 & 10.2 \\
\hline SER & 14.2 & 15.0 & 15.7 & 15.0 & 15.1 & 14.9 & 14.9 & 14.3 & 14.6 & 14.3 & 14.4 & 14.6 \\
\hline $\begin{array}{l}\text { Pellet hardness } \\
\left(\mathrm{kg} / \mathrm{cm}^{2}\right)\end{array}$ & 4.8 & 4.1 & 4.3 & 4.1 & 4.8 & 4.7 & 5.1 & 4.5 & 5.5 & 4.6 & 4.8 & 4.5 \\
\hline Durability (\%) & 93.5 & 90.8 & 93.1 & 92.3 & 94.8 & 95.0 & 95.9 & 93.1 & 94.1 & 94.4 & 94.8 & 92.9 \\
\hline
\end{tabular}

${ }^{1}$ Starch or fat as dietary energy source; ${ }^{2} \mathrm{~B}=$ basal dietary energy and amino acid content; I = increased dietary energy and amino acid content; 


\section{Appendix 3 Performance of the GF pigs}

Performance from the start till first delivery (day 98) and from the start till slaughter of male GF pigs that were kept under different sanitary conditions and were fed diets differing in energy source and in energy and amino acid content.

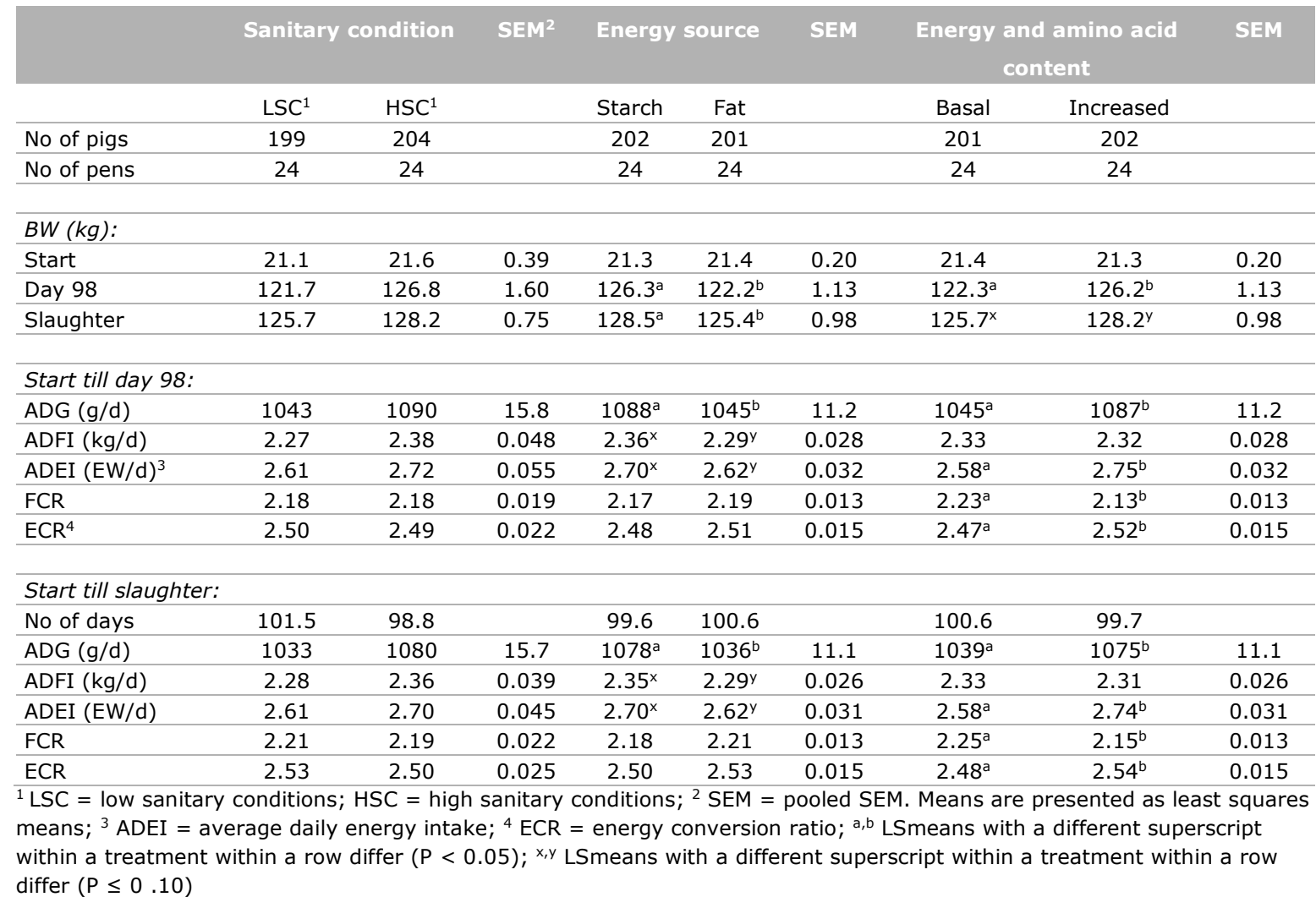


Performance from the start till day 35, day 35-63, day 63-98 and from day 63 till slaughter of male GF pigs that were kept under different sanitary conditions and were fed diets differing in energy source and in energy and amino acid content.

\begin{tabular}{|c|c|c|c|c|c|c|c|c|c|}
\hline & \multicolumn{2}{|c|}{ Sanitary condition } & \multirow[t]{2}{*}{ SEM ${ }^{2}$} & \multicolumn{2}{|c|}{ Energy source } & \multirow[t]{2}{*}{ SEM } & \multicolumn{2}{|c|}{$\begin{array}{l}\text { Energy and amino acid } \\
\text { content }\end{array}$} & \multirow[t]{2}{*}{ SEM } \\
\hline & LSC $^{1}$ & $\mathrm{HSC}^{1}$ & & Starch & Fat & & Basal & Increased & \\
\hline No of pens & 24 & 24 & & 24 & 24 & & 24 & 24 & \\
\hline Day 35 & 51.2 & 54.6 & 1.39 & 53.1 & 52.7 & 0.49 & $52.2^{\mathrm{a}}$ & $53.6^{\mathrm{b}}$ & 0.49 \\
\hline Day 63 & 81.4 & 85.8 & 1.92 & $84.6^{a}$ & $82.5^{b}$ & 0.73 & $82.3^{a}$ & $84.9^{b}$ & 0.73 \\
\hline Day 98 & 121.7 & 126.8 & 1.60 & $126.3^{a}$ & $122.2^{b}$ & 1.13 & $122.3^{a}$ & $126.2^{b}$ & 1.13 \\
\hline Slaughter & 125.7 & 128.2 & 1.38 & $128.5^{a}$ & $125.4^{b}$ & 0.98 & $125.7^{x}$ & $128.2^{y}$ & 0.98 \\
\hline FCR & 1.73 & 1.70 & 0.021 & 1.72 & 1.71 & 0.015 & $1.76^{\mathrm{a}}$ & $1.66^{b}$ & 0.015 \\
\hline $\mathrm{ECR}^{4}$ & 2.00 & 1.97 & 0.024 & 1.99 & 1.98 & 0.017 & 1.98 & 2.00 & 0.017 \\
\hline \multicolumn{10}{|l|}{ Day 35-63: } \\
\hline ADG $(g / d)$ & 1077 & 1114 & 19.2 & $1124^{a}$ & $1067^{b}$ & 17.6 & $1075^{x}$ & $1117^{y}$ & 17.6 \\
\hline ADFI $(\mathrm{kg} / \mathrm{d})$ & 2.30 & 2.42 & 0.063 & 2.39 & 2.32 & 0.034 & 2.36 & 2.36 & 0.034 \\
\hline ADEI $(E W / d)^{3}$ & 2.63 & 2.76 & 0.072 & 2.73 & 2.65 & 0.038 & $2.60^{\mathrm{a}}$ & $2.79^{b}$ & 0.038 \\
\hline FCR & 2.14 & 2.18 & 0.035 & 2.13 & 2.19 & 0.025 & $2.20^{\mathrm{a}}$ & $2.11^{\mathrm{b}}$ & 0.025 \\
\hline $\mathrm{ECR}^{4}$ & 2.44 & 2.48 & 0.041 & 2.43 & 2.50 & 0.029 & $2.43^{x}$ & $2.50^{y}$ & 0.029 \\
\hline \multicolumn{10}{|c|}{ Day 63 till slaughter: } \\
\hline No of days & 38.5 & 35.8 & & 36.6 & 37.6 & & 37.6 & 36.7 & \\
\hline ADG $(g / d)$ & 1161 & 1189 & 25.8 & $1206^{a}$ & $1144^{b}$ & 18.2 & 1161 & 1189 & 18.2 \\
\hline ADFI $(\mathrm{kg} / \mathrm{d})$ & 3.00 & 3.06 & 0.060 & $3.09^{x}$ & $2.97^{y}$ & 0.043 & 3.05 & 3.01 & 0.043 \\
\hline ADEI $(E W / d)$ & 3.42 & 3.49 & 0.069 & $3.52^{x}$ & $3.39^{y}$ & 0.049 & $3.36^{a}$ & $3.56^{b}$ & 0.049 \\
\hline FCR & 2.59 & 2.58 & 0.070 & 2.56 & 2.60 & 0.022 & $2.63^{a}$ & $2.54^{b}$ & 0.022 \\
\hline ECR & 2.95 & 2.93 & 0.080 & 2.92 & 2.97 & 0.024 & $2.89^{a}$ & $2.99^{b}$ & 0.024 \\
\hline
\end{tabular}




\section{Appendix 4 Blood parameters}

Blood parameters (acute phase proteins, blood cell composition) at 1, 35, 56 and 84 days in male GF pigs that were kept under different sanitary conditions and were fed diets differing in energy source and in energy and amino acid content.

\begin{tabular}{|c|c|c|c|c|c|c|c|c|c|c|c|c|c|c|c|c|c|}
\hline & \multicolumn{4}{|c|}{ LSC $^{1}$} & \multicolumn{4}{|c|}{$\mathrm{HSC}^{1}$} & \multicolumn{2}{|c|}{ SEM $^{4}$} & \multicolumn{7}{|c|}{ P-value ${ }^{5}$} \\
\hline & \multicolumn{2}{|c|}{ Starch $^{2}$} & \multicolumn{2}{|c|}{$\mathrm{Fat}^{2}$} & \multicolumn{2}{|c|}{ Starch } & \multicolumn{2}{|c|}{ Fat } & \multirow[t]{2}{*}{$\mathrm{SC}$} & \multirow[t]{3}{*}{ ES / EA } & \multirow[t]{2}{*}{ SC } & \multirow[t]{2}{*}{ ES } & \multirow[t]{2}{*}{ EA } & \multirow[t]{2}{*}{$\mathrm{SC} \times \mathrm{ES}$} & \multirow[t]{2}{*}{$S C \times E A$} & \multirow[t]{2}{*}{$E S \times E A$} & \multirow[t]{2}{*}{$S C \times E S \times E A$} \\
\hline & $B^{3}$ & $I^{3}$ & B & I & B & I & B & I & & & & & & & & & \\
\hline No of pigs & 6 & 6 & 6 & 6 & 6 & 6 & 6 & 6 & & & & & & & & & \\
\hline \multicolumn{18}{|c|}{ Haptoglobin $(\mathrm{g} / \mathrm{L})$ : } \\
\hline D1 & $0.840^{\mathrm{b}}$ & $0.313^{\mathrm{a}}$ & $0.642^{\mathrm{ab}}$ & $0.555^{\mathrm{ab}}$ & $0.983^{b}$ & $0.678^{\mathrm{b}}$ & $0.533^{\mathrm{ab}}$ & $0.577^{a b}$ & 0.0617 & 0.0798 & 0.34 & 0.46 & 0.05 & 0.24 & 0.18 & 0.12 & 0.41 \\
\hline D35 & $0.909^{a}$ & $0.590^{\mathrm{a}}$ & $0.722^{\mathrm{a}}$ & $0.586^{a}$ & $1.044^{\mathrm{a}}$ & $0.726^{a}$ & $0.699^{a}$ & $0.801^{\mathrm{a}}$ & 0.1175 & 0.0756 & 0.97 & 0.79 & 0.76 & 0.53 & 0.75 & 0.36 & 0.43 \\
\hline D56 & $1.060^{\mathrm{cd}}$ & $0.578^{\mathrm{abc}}$ & $0.430^{\mathrm{ab}}$ & $0.330^{\mathrm{a}}$ & $1.613^{\mathrm{d}}$ & $0.757^{\mathrm{bcd}}$ & $0.983^{\mathrm{cd}}$ & $1.267^{\mathrm{cd}}$ & 0.1187 & 0.1243 & 0.02 & 0.02 & 0.13 & 0.08 & 0.84 & 0.09 & 0.64 \\
\hline D84 & $0.754^{\mathrm{a}}$ & $0.603^{a}$ & $0.683^{\mathrm{a}}$ & $0.420^{\mathrm{a}}$ & $0.703^{a}$ & $0.318^{\mathrm{a}}$ & $0.412^{\mathrm{a}}$ & $0.435^{\mathrm{a}}$ & 0.1117 & 0.1221 & 0.44 & 0.71 & 0.30 & 0.54 & 0.60 & 0.71 & 0.35 \\
\hline \multicolumn{18}{|c|}{ PIGMAP $(\mathrm{g} / \mathrm{L})$ : } \\
\hline D1 & $0.623^{\mathrm{ab}}$ & $0.505^{\mathrm{a}}$ & $0.562^{\mathrm{ab}}$ & $0.590^{\mathrm{ab}}$ & $0.741^{\mathrm{b}}$ & $0.513^{\mathrm{a}}$ & $0.533^{\mathrm{ab}}$ & $0.640^{\mathrm{ab}}$ & 0.0361 & 0.0338 & 0.45 & 0.90 & 0.31 & 0.73 & 0.87 & 0.02 & 0.29 \\
\hline D35 & $0.644^{\mathrm{a}}$ & $0.483^{a}$ & $0.654^{\mathrm{a}}$ & $0.578^{\mathrm{a}}$ & $1.090^{\mathrm{b}}$ & $0.469^{a}$ & $0.630^{\mathrm{a}}$ & $0.687^{a}$ & 0.0501 & 0.0645 & 0.88 & 0.96 & 0.19 & 0.40 & 0.92 & 0.28 & 0.71 \\
\hline D56 & $0.527^{\mathrm{ab}}$ & $0.368^{\mathrm{a}}$ & $0.405^{\mathrm{a}}$ & $0.388^{\mathrm{a}}$ & $1.43^{\mathrm{c}}$ & $0.34^{\mathrm{a}}$ & $0.69^{\mathrm{ab}}$ & $0.85^{\mathrm{bc}}$ & 0.1259 & 0.1006 & 0.07 & 0.77 & 0.04 & 0.53 & 0.38 & 0.01 & 0.04 \\
\hline D84 & $0.572^{\mathrm{a}}$ & $0.593^{\mathrm{a}}$ & $0.588^{\mathrm{a}}$ & $0.743^{\mathrm{a}}$ & $0.827^{\mathrm{a}}$ & $0.507^{a}$ & $0.755^{\mathrm{a}}$ & $0.690^{a}$ & 0.1155 & 0.0858 & 0.49 & 0.93 & 0.62 & 0.62 & 0.57 & 0.57 & 0.36 \\
\hline \multicolumn{18}{|c|}{ Haemoglobin (mmol/L): } \\
\hline D1 & $6.67^{\mathrm{abc}}$ & $6.88^{\mathrm{c}}$ & $6.58^{\mathrm{abc}}$ & $6.47^{\mathrm{ab}}$ & $6.40^{\mathrm{a}}$ & $6.78^{\mathrm{bc}}$ & $6.67^{a b c}$ & $6.58^{\mathrm{abc}}$ & 0.117 & 0.058 & 0.81 & 0.20 & 0.23 & 0.09 & 0.55 & 0.02 & 0.69 \\
\hline D35 & $7.32^{\mathrm{ab}}$ & $7.58^{\mathrm{b}}$ & $7.37^{\mathrm{ab}}$ & $7.17^{\mathrm{a}}$ & $7.21^{\mathrm{ab}}$ & $7.43^{\mathrm{ab}}$ & $7.17^{\mathrm{a}}$ & $7.41^{\mathrm{ab}}$ & 0.078 & 0.056 & 0.67 & 0.20 & 0.11 & 0.36 & 0.22 & 0.17 & 0.14 \\
\hline D56 & $7.48^{\mathrm{a}}$ & $7.77^{\mathrm{a}}$ & $7.40^{\mathrm{a}}$ & $7.47^{\mathrm{a}}$ & $7.73^{\mathrm{a}}$ & $7.60^{\mathrm{a}}$ & $7.27^{\mathrm{a}}$ & $7.77^{\mathrm{a}}$ & 0.080 & 0.106 & 0.62 & 0.27 & 0.24 & 0.88 & 0.98 & 0.49 & 0.16 \\
\hline D84 & $7.75^{\mathrm{abc}}$ & $7.98^{\mathrm{c}}$ & $7.93^{\mathrm{bc}}$ & $7.87^{a b c}$ & $7.38^{\mathrm{a}}$ & $7.97^{\mathrm{bc}}$ & $7.53^{\mathrm{abc}}$ & $7.87^{a b c}$ & 0.085 & 0.088 & 0.47 & 0.58 & 0.18 & 0.45 & 0.03 & 0.07 & 0.38 \\
\hline D35 & $0.427^{\mathrm{ab}}$ & $0.448^{\mathrm{b}}$ & $0.427^{a b}$ & $0.415^{\mathrm{a}}$ & $0.429^{a b}$ & $0.434^{\mathrm{ab}}$ & $0.420^{\mathrm{a}}$ & $0.431^{\mathrm{ab}}$ & 0.0044 & 0.0038 & 0.89 & 0.05 & 0.25 & 0.34 & 0.74 & 0.23 & 0.09 \\
\hline D56 & $0.448^{a}$ & $0.463^{a}$ & $0.438^{a}$ & $0.438^{a}$ & $0.470^{a}$ & $0.457^{a}$ & $0.430^{a}$ & $0.465^{a}$ & 0.0055 & 0.0071 & 0.34 & 0.11 & 0.36 & 0.94 & 0.86 & 0.42 & 0.13 \\
\hline D84 & $0.447^{\mathrm{a}}$ & $0.460^{\mathrm{a}}$ & $0.452^{\mathrm{a}}$ & $0.428^{\mathrm{a}}$ & $0.433^{\mathrm{a}}$ & $0.458^{\mathrm{a}}$ & $0.430^{\mathrm{a}}$ & $0.453^{\mathrm{a}}$ & 0.0063 & 0.0059 & 0.76 & 0.30 & 0.26 & 0.58 & 0.09 & 0.26 & 0.30 \\
\hline \multicolumn{18}{|c|}{ Haemolysis index $(\mathrm{mmol} / \mathrm{L})$ : } \\
\hline D1 & $0.095^{\mathrm{b}}$ & $0.055^{\mathrm{ab}}$ & $0.068^{\mathrm{ab}}$ & $0.057^{a b}$ & $0.069^{\mathrm{ab}}$ & $0.060^{\mathrm{ab}}$ & $0.047^{a}$ & $0.075^{\mathrm{ab}}$ & 0.0058 & 0.0078 & 0.51 & 0.44 & 0.75 & 0.86 & 0.08 & 0.30 & 0.95 \\
\hline D35 & $0.082^{\mathrm{ab}}$ & $0.073^{\mathrm{ab}}$ & $0.062^{\mathrm{ab}}$ & $0.053^{\mathrm{ab}}$ & $0.056^{\mathrm{a}}$ & $0.074^{\mathrm{ab}}$ & $0.068^{b}$ & $0.068^{b}$ & 0.0065 & 0.0068 & 0.45 & 0.04 & 0.80 & 0.09 & 0.43 & 0.21 & 0.53 \\
\hline D56 & $0.048^{\mathrm{a}}$ & $0.095^{\mathrm{a}}$ & $0.050^{\mathrm{a}}$ & $0.052^{\mathrm{a}}$ & $0.097^{a}$ & $0.098^{\mathrm{a}}$ & $0.065^{\mathrm{a}}$ & $0.083^{\mathrm{a}}$ & 0.0057 & 0.0125 & 0.04 & 0.50 & 0.74 & 0.92 & 0.41 & 0.99 & 0.30 \\
\hline D84 & $0.129^{a}$ & $0.060^{\mathrm{a}}$ & $0.052^{\mathrm{a}}$ & $0.048^{\mathrm{a}}$ & $0.045^{\mathrm{a}}$ & $0.090^{\mathrm{a}}$ & $0.077^{\mathrm{a}}$ & $0.053^{\mathrm{a}}$ & 0.0185 & 0.0137 & 0.94 & 0.98 & 0.76 & 0.25 & 0.18 & 0.87 & 0.11 \\
\hline
\end{tabular}




\begin{tabular}{|c|c|c|c|c|c|c|c|c|c|c|c|c|c|c|c|c|c|}
\hline D1 & & & & & & & & & & & & & & & & & \\
\hline D1 & $1.08^{\mathrm{ab}}$ & $1.07^{\mathrm{ab}}$ & $1.10^{\mathrm{b}}$ & $1.10^{\mathrm{b}}$ & $1.05^{\mathrm{a}}$ & $1.10^{\mathrm{b}}$ & $1.08^{\mathrm{ab}}$ & $1.08^{\mathrm{ab}}$ & 0.0061 & 0.0083 & 0.39 & 0.18 & 0.40 & 0.39 & 0.17 & 0.31 & 0.24 \\
\hline D35 & $1.08^{\mathrm{a}}$ & $1.07^{\mathrm{a}}$ & $1.10^{\mathrm{ab}}$ & $1.11^{\mathrm{b}}$ & $1.07^{\mathrm{ab}}$ & $1.09^{\mathrm{ab}}$ & $1.09^{\mathrm{ab}}$ & $1.08^{\mathrm{ab}}$ & 0.0065 & 0.0071 & 0.80 & 0.15 & 0.45 & 0.15 & 0.64 & 0.50 & 0.35 \\
\hline D56 & $1.06^{\mathrm{a}}$ & $1.06^{\mathrm{a}}$ & $1.10^{\mathrm{ab}}$ & $1.11^{\mathrm{b}}$ & $1.06^{\mathrm{a}}$ & $1.08^{\mathrm{ab}}$ & $1.09^{\mathrm{ab}}$ & $1.07^{\mathrm{a}}$ & 0.0072 & 0.0071 & 0.43 & 0.02 & 0.75 & 0.06 & 0.80 & 0.68 & 0.11 \\
\hline D84 & $1.10^{\mathrm{a}}$ & $1.08^{\mathrm{a}}$ & $1.11^{\mathrm{a}}$ & $1.12^{\mathrm{a}}$ & $1.07^{\mathrm{a}}$ & $1.10^{\mathrm{a}}$ & $1.10^{\mathrm{a}}$ & $1.09^{\mathrm{a}}$ & 0.0108 & 0.0079 & 0.53 & 0.18 & 0.81 & 0.55 & 0.60 & 0.77 & 0.23 \\
\hline \multicolumn{18}{|c|}{ MCHC (mmol/L): } \\
\hline D1 & $16.97^{\text {abde }}$ & $16.62^{\mathrm{abc}}$ & $17.07^{\text {be }}$ & $16.72^{\mathrm{abcd}}$ & $16.52^{\mathrm{a}}$ & $17.00^{\text {cde }}$ & $16.62^{\mathrm{ab}}$ & $17.20^{\mathrm{e}}$ & 0.112 & 0.059 & 0.96 & 0.14 & 0.28 & 0.77 & $<0.001$ & 0.77 & 0.77 \\
\hline D35 & $17.15^{\mathrm{ab}}$ & $17.00^{\mathrm{ab}}$ & $17.31^{\mathrm{b}}$ & $17.25^{\mathrm{ab}}$ & $16.87^{a}$ & $17.15^{\mathrm{ab}}$ & $17.11^{\mathrm{ab}}$ & $17.27^{b}$ & 0.092 & 0.057 & 0.59 & 0.02 & 0.49 & 0.91 & 0.06 & 0.97 & 0.53 \\
\hline D56 & $16.73^{\mathrm{a}}$ & $16.77^{\mathrm{a}}$ & $16.98^{\mathrm{a}}$ & $17.05^{\mathrm{a}}$ & $16.55^{\mathrm{a}}$ & $16.65^{\mathrm{a}}$ & $16.90^{\mathrm{a}}$ & $16.72^{\mathrm{a}}$ & 0.133 & 0.069 & 0.39 & 0.02 & 0.97 & 0.77 & 0.64 & 0.53 & 0.43 \\
\hline D84 & $17.42^{\mathrm{ab}}$ & $17.52^{\mathrm{ab}}$ & $17.60^{\mathrm{b}}$ & $17.55^{\mathrm{ab}}$ & $17.13^{\mathrm{a}}$ & $17.47^{\mathrm{ab}}$ & $17.50^{\mathrm{ab}}$ & $17.35^{\mathrm{ab}}$ & 0.097 & 0.064 & 0.31 & 0.21 & 0.53 & 0.93 & 0.72 & 0.09 & 0.37 \\
\hline \multicolumn{18}{|c|}{$M C V(f L):$} \\
\hline D35 & $63.0^{\mathrm{a}}$ & $62.8^{a}$ & $63.7^{\mathrm{a}}$ & $64.5^{\mathrm{a}}$ & $63.3^{\mathrm{a}}$ & $63.6^{a}$ & $63.7^{a}$ & $62.5^{\mathrm{a}}$ & 0.53 & 0.45 & 0.78 & 0.50 & 0.96 & 0.23 & 0.61 & 0.84 & 0.34 \\
\hline D56 & $63.7^{\mathrm{a}}$ & $63.3^{\mathrm{a}}$ & $64.7^{\mathrm{a}}$ & $65.3^{\mathrm{a}}$ & $64.3^{\mathrm{a}}$ & $64.9^{\mathrm{a}}$ & $64.2^{\mathrm{a}}$ & $63.8^{\mathrm{a}}$ & 0.76 & 0.49 & 0.96 & 0.53 & 0.84 & 0.13 & 0.97 & 0.97 & 0.49 \\
\hline D84 & $63.2^{\mathrm{a}}$ & $61.8^{\mathrm{a}}$ & $63.0^{\mathrm{a}}$ & $63.3^{a}$ & $62.8^{\mathrm{a}}$ & $62.8^{\mathrm{a}}$ & $62.8^{\mathrm{a}}$ & $62.8^{\mathrm{a}}$ & 0.67 & 0.47 & 0.99 & 0.64 & 0.69 & 0.64 & 0.69 & 0.55 & 0.55 \\
\hline \multicolumn{18}{|c|}{$\begin{array}{l}\text { Erythrocytes } \\
\left(10^{12} / L\right):\end{array}$} \\
\hline D1 & $6.18^{\mathrm{ab}}$ & $6.47^{b}$ & $5.98^{a}$ & $5.90^{\mathrm{a}}$ & $6.12^{\mathrm{ab}}$ & $6.15^{\mathrm{ab}}$ & $6.20^{\mathrm{ab}}$ & $6.10^{\mathrm{ab}}$ & 0.094 & 0.063 & 0.95 & 0.05 & 0.71 & 0.03 & 0.46 & 0.17 & 0.52 \\
\hline D35 & $6.79^{a b c}$ & $7.13^{c}$ & $6.72^{\mathrm{ab}}$ & $6.46^{\mathrm{a}}$ & $6.76^{\mathrm{abc}}$ & $6.82^{\mathrm{abc}}$ & $6.61^{\mathrm{ab}}$ & $6.90^{b c}$ & 0.073 & 0.070 & 0.98 & 0.05 & 0.28 & 0.11 & 0.51 & 0.37 & 0.04 \\
\hline D56 & $7.03^{\mathrm{a}}$ & $7.33^{\mathrm{a}}$ & $6.77^{\mathrm{a}}$ & $6.72^{\mathrm{a}}$ & $7.28^{\mathrm{a}}$ & $7.03^{\mathrm{a}}$ & $6.72^{\mathrm{a}}$ & $7.28^{\mathrm{a}}$ & 0.092 & 0.121 & 0.43 & 0.09 & 0.42 & 0.41 & 0.93 & 0.49 & 0.09 \\
\hline D84 & $7.05^{\mathrm{ab}}$ & $7.40^{\mathrm{b}}$ & $7.17^{\mathrm{ab}}$ & $6.77^{\mathrm{a}}$ & $6.87^{\mathrm{ab}}$ & $7.28^{\mathrm{ab}}$ & $6.87^{\mathrm{ab}}$ & $7.27^{\mathrm{ab}}$ & 0.098 & 0.104 & 0.87 & 0.37 & 0.20 & 0.40 & 0.15 & 0.20 & 0.22 \\
\hline D35 & $20.56^{b}$ & $22.01^{b}$ & $20.92^{\mathrm{ab}}$ & $21.31^{\mathrm{ab}}$ & $22.37^{a b}$ & $21.86^{a b}$ & $20.71^{\mathrm{ab}}$ & $20.27^{a}$ & 0.634 & 0.632 & 0.16 & 0.05 & 0.77 & 0.28 & 0.60 & 0.44 & 0.94 \\
\hline D56 & $18.53^{a}$ & $22.87^{a}$ & $21.73^{\mathrm{a}}$ & $21.87^{\mathrm{a}}$ & $22.45^{a}$ & $21.20^{\mathrm{a}}$ & $22.63^{a}$ & $22.45^{a}$ & 1.299 & 1.039 & 0.67 & 0.66 & 0.45 & 0.84 & 0.28 & 0.55 & 0.43 \\
\hline D84 & $20.73^{a}$ & $21.15^{\mathrm{a}}$ & $21.07^{a}$ & $20.56^{a}$ & $20.68^{a}$ & $19.55^{\mathrm{a}}$ & $20.18^{a}$ & $20.35^{a}$ & 0.641 & 0.632 & 0.41 & 0.99 & 0.71 & 0.85 & 0.69 & 0.98 & 0.59 \\
\hline \multicolumn{18}{|c|}{$\begin{array}{l}\text { Thrombocytes } \\
\left(10^{9} / \mathrm{L}\right) \text { : }\end{array}$} \\
\hline D1 & $367.5^{\mathrm{a}}$ & $384.8^{\mathrm{a}}$ & $374.8^{\mathrm{a}}$ & $465.0^{\mathrm{a}}$ & $399.7^{a}$ & $368.5^{a}$ & $362.0^{a}$ & $365.2^{\mathrm{a}}$ & 29.5 & 25.1 & 0.59 & 0.75 & 0.58 & 0.37 & 0.35 & 0.46 & 0.79 \\
\hline D35 & $351.9^{\mathrm{ab}}$ & $311.8^{\mathrm{a}}$ & $348.2^{\mathrm{ab}}$ & $434.9^{b}$ & $274.5^{a}$ & $347.1^{\mathrm{ab}}$ & $318.8^{a}$ & $295.8^{a}$ & 18.7 & 15.9 & 0.12 & 0.22 & 0.29 & 0.17 & 0.97 & 0.73 & 0.02 \\
\hline D56 & $360.7^{b}$ & $270.0^{a b}$ & $357.5^{b}$ & $346.2^{b}$ & $193.3^{a}$ & $335.4^{\mathrm{ab}}$ & $303.5^{\mathrm{ab}}$ & $288.5^{\mathrm{ab}}$ & 17.0 & 26.3 & 0.09 & 0.37 & 0.87 & 0.95 & 0.13 & 0.61 & 0.12 \\
\hline D84 & $264.2^{\mathrm{ab}}$ & $304.8^{\mathrm{abc}}$ & $359.1^{b c}$ & $399.2^{c}$ & $219.3^{a}$ & $286.1^{\mathrm{ab}}$ & $301.3^{a b}$ & $248.3^{a}$ & 20.4 & 23.1 & 0.02 & 0.02 & 0.32 & 0.13 & 0.48 & 0.21 & 0.21 \\
\hline \multicolumn{18}{|c|}{ Monocytes $\left(10^{9} / \mathrm{L}\right)$ : } \\
\hline D1 & LSC: & 0.35 & & & HSC: & 0.62 & & & & & & & & & & & \\
\hline D35 & $0.63^{a}$ & $1.46^{\mathrm{ac}}$ & $1.21^{\mathrm{abc}}$ & $0.75^{a b c}$ & $0.52^{\mathrm{ab}}$ & $1.52^{\mathrm{bc}}$ & $0.54 a^{b}$ & $0.62^{a b c}$ & 0.147 & 0.110 & 0.45 & 0.38 & 0.07 & 0.17 & 0.34 & 0.06 & 0.42 \\
\hline D56 & $0.40^{\mathrm{ab}}$ & $0.70^{\mathrm{ab}}$ & $0.43^{\mathrm{ab}}$ & $0.33^{\mathrm{ab}}$ & $0.60^{\mathrm{ab}}$ & $0.63^{\mathrm{ab}}$ & $0.19^{a}$ & $0.83^{b}$ & 0.038 & 0.066 & 0.27 & 0.23 & 0.13 & 0.95 & 0.19 & 0.48 & 0.21 \\
\hline D84 & $0.77^{b}$ & $0.48^{\mathrm{ab}}$ & $0.82^{\mathrm{b}}$ & $0.41^{\mathrm{a}}$ & $0.70^{\mathrm{b}}$ & $0.58^{\mathrm{ab}}$ & $0.49^{\mathrm{ab}}$ & $0.72^{\mathrm{b}}$ & 0.054 & 0.061 & 0.50 & 0.63 & 0.08 & 0.95 & 0.03 & 0.46 & 0.27 \\
\hline \multicolumn{18}{|c|}{$\begin{array}{l}\text { Lymphocytes } \\
\left(10^{9} / \mathrm{L}\right) \text { : }\end{array}$} \\
\hline D1 & LSC: & 8.22 & & & HSC: & 14.14 & & & & & & & & & & & \\
\hline D35 & $10.77^{a b c}$ & $12.67^{b c}$ & $7.52^{\mathrm{ab}}$ & $9.68^{\mathrm{ab}}$ & $15.04^{c}$ & $7.26^{a}$ & $11.92^{\mathrm{abc}}$ & $10.94^{\mathrm{abc}}$ & 0.806 & 0.616 & 0.38 & 0.25 & 0.31 & 0.19 & 0.07 & 0.18 & 0.20 \\
\hline D56 & $12.07^{\mathrm{a}}$ & $14.11^{\mathrm{a}}$ & $11.94^{\mathrm{a}}$ & $9.78^{\mathrm{a}}$ & $11.19^{\mathrm{a}}$ & $12.33^{\mathrm{a}}$ & $11.12^{\mathrm{a}}$ & $11.99^{\mathrm{a}}$ & 0.774 & 0.789 & 0.79 & 0.30 & 0.68 & 0.38 & 0.64 & 0.34 & 0.40 \\
\hline D84 & $11.11^{\mathrm{a}}$ & $13.37^{\mathrm{ab}}$ & $15.67^{b}$ & $12.99^{\mathrm{ab}}$ & $11.87^{\mathrm{ab}}$ & $13.97^{\mathrm{ab}}$ & $13.20^{\mathrm{ab}}$ & $12.32^{\mathrm{ab}}$ & 1.026 & 0.581 & 0.78 & 0.26 & 0.81 & 0.19 & 0.62 & 0.03 & 0.56 \\
\hline
\end{tabular}

50 | Wageningen Livestock Research Report 1248 
Basophil

granulocytes

$\left(10^{9} / \mathrm{L}\right)$ :

\begin{tabular}{|c|c|c|c|c|c|c|c|c|c|c|c|c|c|c|c|c|c|}
\hline D1 & LSC: & 0.27 & & & HSC: & 0.36 & & & & & & & & & & & \\
\hline D35 & $0.17^{\mathrm{a}}$ & $0.52^{\mathrm{ab}}$ & $0.63^{\mathrm{ab}}$ & $0.47^{\mathrm{ab}}$ & $0.20^{\mathrm{ab}}$ & $0.89^{\mathrm{b}}$ & $0.34^{\mathrm{ab}}$ & $0.38^{\mathrm{ab}}$ & 0.112 & 0.080 & 0.98 & 0.93 & 0.18 & 0.23 & 0.36 & 0.12 & 0.77 \\
\hline D56 & $0.42^{\mathrm{ab}}$ & $0.47^{\mathrm{ab}}$ & $0.35^{\mathrm{ab}}$ & $0.33^{\mathrm{ab}}$ & $0.33^{\mathrm{ab}}$ & $0.33^{\mathrm{ab}}$ & $0.17^{\mathrm{a}}$ & $0.50^{\mathrm{b}}$ & 0.069 & 0.044 & 0.56 & 0.45 & 0.18 & 0.39 & 0.22 & 0.32 & 0.14 \\
\hline D84 & $0.33^{\mathrm{a}}$ & $0.30^{\mathrm{a}}$ & $0.35^{\mathrm{a}}$ & $0.29^{\mathrm{a}}$ & $0.53^{a}$ & $0.36^{a}$ & $0.46^{\mathrm{a}}$ & $0.52^{\mathrm{a}}$ & 0.045 & 0.046 & 0.08 & 0.69 & 0.48 & 0.77 & 0.96 & 0.44 & 0.33 \\
\hline
\end{tabular}

D84

$0.35^{\mathrm{a}} \quad 0.29^{\mathrm{a}}$

0.08

$0.69 \quad 0.48$

0.77

0.96

granulocytes

$\left(10^{9} / L\right)$ :

\begin{tabular}{|c|c|c|c|c|c|c|c|c|c|c|c|c|c|c|c|c|c|}
\hline D1 & LSC: & 0.26 & & & HSC: & 0.00 & & & & & & & & & & & \\
\hline D35 & $1.09^{a}$ & $1.73^{\mathrm{a}}$ & $0.58^{\mathrm{a}}$ & $0.56^{a}$ & $0.38^{\mathrm{a}}$ & $0.39^{a}$ & $0.48 a$ & $0.44^{\mathrm{a}}$ & 0.204 & 0.241 & 0.12 & 0.38 & 0.71 & 0.31 & 0.68 & 0.65 & 0.70 \\
\hline D56 & $1.50^{\mathrm{ac}}$ & $1.63^{\mathrm{ac}}$ & $1.38^{\mathrm{ac}}$ & $1.73^{\mathrm{ac}}$ & $0.75^{a}$ & $0.51^{a}$ & $0.50^{\mathrm{a}}$ & $1.26^{\mathrm{b}}$ & 0.410 & 0.062 & 0.24 & 0.21 & 0.02 & 0.16 & 0.94 & 0.01 & 0.04 \\
\hline D84 & $0.34^{\mathrm{a}}$ & $0.88^{\mathrm{b}}$ & $0.53^{\mathrm{ab}}$ & $0.74^{\mathrm{ab}}$ & $0.67^{\mathrm{ab}}$ & $0.77^{\mathrm{ab}}$ & $0.83^{\mathrm{ab}}$ & $0.98^{\mathrm{b}}$ & 0.094 & 0.081 & 0.23 & 0.38 & 0.04 & 0.49 & 0.29 & 0.54 & 0.43 \\
\hline
\end{tabular}

Neutrophil

granulocytes

$\left(10^{9} / L\right)$ :

\begin{tabular}{|c|c|c|c|c|c|c|c|c|c|c|c|c|c|c|c|c|c|}
\hline D1 & LSC: & 9.69 & & & HSC: & 8.48 & & & & & & & & & & & \\
\hline D35 & $10.06^{a}$ & $11.00^{\mathrm{a}}$ & $14.30^{\mathrm{a}}$ & $10.14^{a}$ & $7.80^{\mathrm{a}}$ & $18.34^{a}$ & $9.46^{a}$ & $10.15^{\mathrm{a}}$ & 1.22 & 1.99 & 0.59 & 0.79 & 0.40 & 0.49 & 0.38 & 0.35 & 0.63 \\
\hline D56 & $8.50^{\mathrm{a}}$ & $11.70^{\mathrm{bc}}$ & $9.37^{a b c}$ & $11.54^{\mathrm{bc}}$ & $8.69^{a b c}$ & $7.02^{\mathrm{ab}}$ & $7.12^{\mathrm{ab}}$ & $13.12^{c}$ & 1.326 & 0.426 & 0.97 & 0.17 & 0.01 & 0.74 & 0.25 & 0.27 & 0.01 \\
\hline D84 & $6.43^{\mathrm{ab}}$ & $6.10^{\mathrm{ab}}$ & $4.82^{\mathrm{ab}}$ & $6.86^{\mathrm{ab}}$ & $7.90^{\mathrm{b}}$ & $4.17^{\mathrm{a}}$ & $6.79^{b}$ & $7.99^{b}$ & 1.059 & 0.555 & 0.71 & 0.21 & 0.34 & 0.09 & 0.04 & 0.02 & 0.08 \\
\hline
\end{tabular}

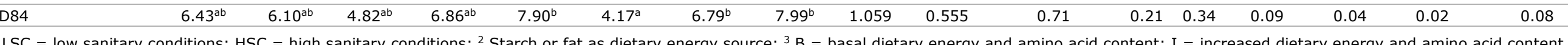

$\mathrm{SEM}=$ pooled SEM. Means are presented as least squares means; ${ }^{5} \mathrm{SC}=$ sanitary conditions; $\mathrm{ES}=$ dietary energy source; $\mathrm{EA}=$ energy and amino content. 


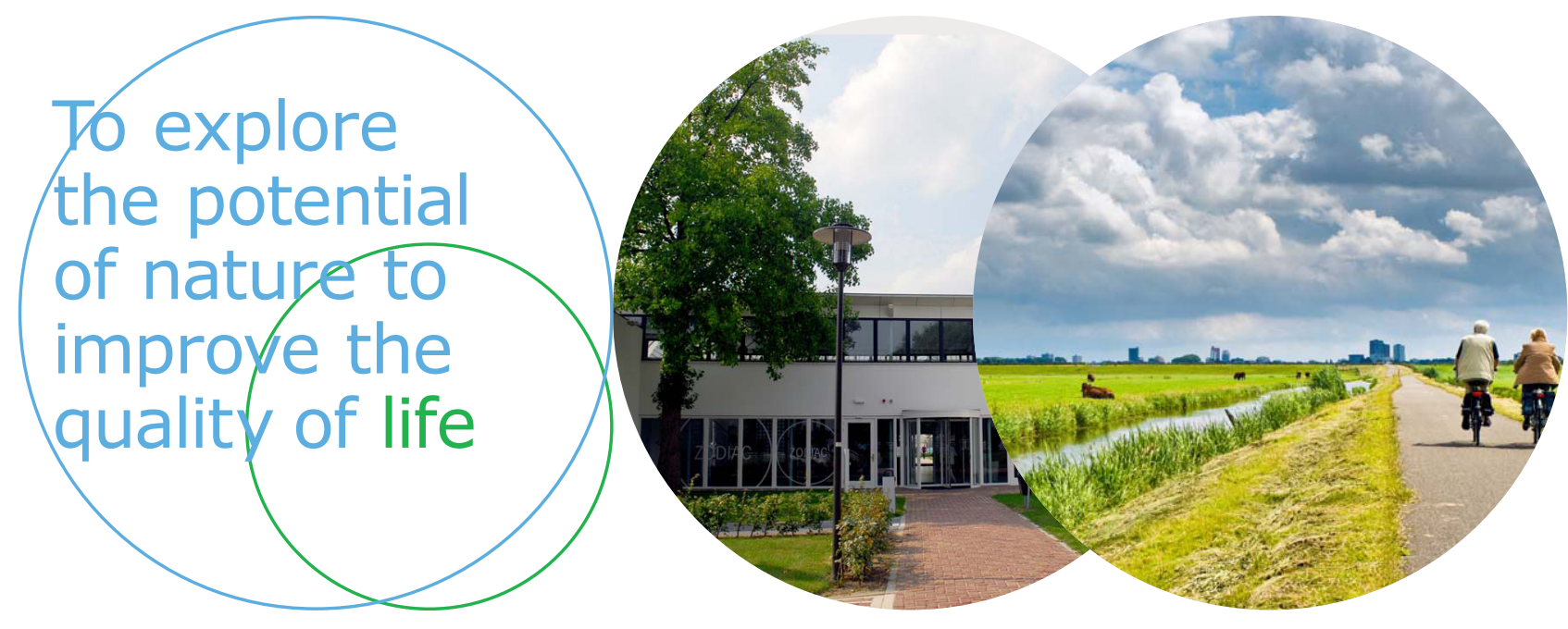

Wageningen Livestock Research P.O. Box 338

6700 AH Wageningen

The Netherlands

$\mathrm{T}+31(0) 317483953$

E info.livestockresearch@wur.nl

www.wur.nl/livestock-research

Wageningen Livestock Research creates science based solutions for a sustainable and profitable livestock sector. Together with our clients, we integrate scientific knowledge and practical experience to develop livestock concepts for future generations.

Wageningen Livestock Research is part of Wageningen University \& Research. Together we work on the mission: 'To explore the potential of nature to improve the quality of life'. A staff of 6,500 and 10,000 students from over 100 countries are working worldwide in the domain of healthy food and living environment for governments and the business community-at-large. The strength of Wageningen University \& Research lies in its ability to join the forces of specialised research institutes and the university. It also lies in the combined efforts of the various fields of natural and social sciences. This union of expertise leads to scientific breakthroughs that can quickly be put into practice and be incorporated into education. This is the Wageningen Approach. 